\title{
Little by little : perinatal asphyxia and the developing spinal cord
}

Citation for published version (APA):

de Louw, A. J. A. (2002). Little by little : perinatal asphyxia and the developing spinal cord. [Doctoral Thesis, Maastricht University]. Datawyse / Universitaire Pers Maastricht.

https://doi.org/10.26481/dis.20020920al

Document status and date:

Published: 01/01/2002

DOI:

10.26481/dis.20020920al

Document Version:

Publisher's PDF, also known as Version of record

\section{Please check the document version of this publication:}

- A submitted manuscript is the version of the article upon submission and before peer-review. There can be important differences between the submitted version and the official published version of record.

People interested in the research are advised to contact the author for the final version of the publication, or visit the DOI to the publisher's website.

- The final author version and the galley proof are versions of the publication after peer review.

- The final published version features the final layout of the paper including the volume, issue and page numbers.

Link to publication

\footnotetext{
General rights rights.

- You may freely distribute the URL identifying the publication in the public portal. please follow below link for the End User Agreement:

www.umlib.nl/taverne-license

Take down policy

If you believe that this document breaches copyright please contact us at:

repository@maastrichtuniversity.nl

providing details and we will investigate your claim.
}

Copyright and moral rights for the publications made accessible in the public portal are retained by the authors and/or other copyright owners and it is a condition of accessing publications that users recognise and abide by the legal requirements associated with these

- Users may download and print one copy of any publication from the public portal for the purpose of private study or research.

- You may not further distribute the material or use it for any profit-making activity or commercial gain

If the publication is distributed under the terms of Article $25 \mathrm{fa}$ of the Dutch Copyright Act, indicated by the "Taverne" license above, 


\section{Little by Little}

perinatal asphyxia and the developing spinal cord 



\section{Little by Little \\ perinatal asphyxia and the developing spinal cord}

\section{PROEFSCHRIFT}

ter verkrijging van de graad van doctor aan de Universiteit Maastricht,

op gezag van de Rector Magnificus

Prof. dr. A.C. Nieuwenhuijzen Kruseman, volgens het besluit van het College van Decanen in het openbaar te verdedigen op wrijdag 20 september 2002 om 16.00 uur door

Antonius Jlacobus Arduinus de Louw geboren op 14 november 1968 te Schayk

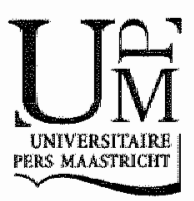




\section{Promotores}

Prof. dir. J.S.H. Vles

Prof. dr. J. Troost

Prof. dr. H.W.M. Steinbusch

Co.promator

Dr. J. de Vente

Beoordelingscommissle

Prof. dr. F.C.S. Ramaekers (voorzitter)

Prol. dr. C.E. Blanco

Prof. dr. O.F. Brouwer (Rijksuniversiteit Groningen)

Prof. dr. J.G.R. De Mey

Prof. dr. D. van Nieuwenhuizen (Universiteit Utrecht) 
scent of funis belore hond, Se, without mechanien injury to lend and neck-I am justified in roferring the spastice rygidity which follows asplyxia at birth to lesion of spinil corl, and not to lesion of brain or medulta oblongata, it is obrious, from the grenter frequency of this evidence of lesion

Uit: Little, 1861. 
Layout and cover illustration

Annebeth Nies, a'bidesign

The studies in this thesis were financially supported by:

Dr. W.M. Phelps stichting voor spastici, profileringsfonds azM, and Ipsen BV.

The publication of this thesis was fimancially supported by: Medtronic BV, Cotop BV and GlaxoWellcome

Little by Little: perinatal asphyxia and the developing spinall cord.

A.J.A. de Loum

Thesis University Maastiricht

ISBN 9052783551

Q2002. AJA. de Louw, Masstricht, The Netherlands

All righs are reserwed. Whether the whale or part of the malerial is concerred. No part of this publication may be reproduced, stored in a retreval system, or transmitled in any form or by any means, electronc mecharical photocopyng. reducing or otherwise, without writen permisston from the copyright owner 


\section{Contents}

1. Introduction

2 Localization and age-related changes of nitric oxide and ANP mediated cyclic GMP synthesis in the rat cervical spinal cord: an immunocytochemical study.

3 Developmental apoptosis in the spinal cord white matter in neonatal rats.

4 Apoptosis in the spinal cord during postnatal development; the effect of perinatal asphyxia on programmed cell cleath.

5 Baclofen inhibits ANP.mediated cyclic GMP synthesis in the rat cervical spinal cord.

6 The effects of Baclofen on ANP and SNP stimulated CGMP.IR in the rat cervical spinal cord after perinatal asphyxia.

7 The identification of c.Fos immunoreactive cells in the rat spinal cord after a radiofrequency lesion adjacent to the cervicall dorsal root ganglion.

8. Percutaneous radiofrequency lesion of the dorsal root ganglion in the treatment of spasticity in children with cerebral palsy.

9 Radiofrequency lesion of the dorsai root ganglion as a treatment for spasticity in children with cerebral palsy.

10 General discussion

1) Summary

Samenvatting

Dankwoord

Publications

Curriculum Vitae 


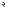



and the duration and severify of the asphyxia [61]. Omy between 8 and 20 percent of the cases of cerebral palsy are related to perinatal asphyxia [50. 56]. Other pathophysiological mechanisms involved in cerebral palsy are genetic/metabolic disorders, intrauterine infection and prematurity $[29,51]$

The CNS damage due to perinatal asphyxia can lead to mental retardation, epilepsy and motor abnormalities such as spasticity [23]. While mental retardation and epilepsy are obvious clinical signs of brain dysfunction, the locomotor abnormalities of cerebral palsy may not be solely derived from cerebral dysfunction but could also partially be caused by dysunction of the spinal cord neural network.

Studies on the effect of perinatal asphyxia in human neonates are rare. In a study by Sladky and Rorke, necropsies were performed on 2.1 asphyxiated human neonates. In this study, six of nine infants with pathological features of spinal cord infarction were premature and lesions were found to be more severe at lumbosacral levels [62]. In a later study in was found that ischemic injury to anterior horn cells within the spinal cord gray matter is relatively common among hypotonichyporeflexic neonates following severe perinatal asphyxia [7]. Furthermore, in this study, the motor abnormalities after perinatal asphyxia were partially attributed to spinal cord injury.

In the first detailed description of cerebral paisy by Little in 1861 the origin of the spastic features of cerebral palsy were attributed to lesions of the spinal cord. In later years this localization was viewed upon as inaccurate. The spastic rigidity accompanying cerebral palsy was thought to be brain derived, and has. been so to date. Nevertheless, some authors altribute the features of spasticity to abnomalities of intermeuronal activity in the spiral cord $[4,5,20]$.

Some clinical findings in neonates after perinatal asphyxia and in children with cerebral palsy point to the spinal cord as part of the origin of the spastic features of cerebral palsy as suggested by Little: a) the observation of paroxysmal (epileptic) features in neanates after pernatal asphyxia without abnomal brain function on EEG monitoring; b) the findings of both extensor and flexor spasms in 
the lower extremities of children with cerebral palsy. While extensor spasms are generally contributed to the loss of supraspinal contral after brain damage, flexor spasms are mainly observed after spinal cond injury [67].

While abundant studies have been done conceming the effects of asphyxia on the developing brain, there are virtually no studies on the effects of perimatal asphyxia on the spinal cord. Little by little we started to investigate the effects of perinatal asphyxia on the developing spinal cord in order to better understand the pathophysiological mechanisms of spasticity in children with cerebral palsy. Understanding the mechanisms of spasticity will lead to more knowledgeable (and perhaps more sensible) treatment options for a devastating condition.

\section{Normal locomotion}

The coordination of normal locomotion requires an intact CNS. Three levels of control can be distinguished: the first level consisting of the cerebral cortex. limbic system and basal ganglia. A second level controlled by the cerebellum and the brainstem and a lower level in which the spinal cord has a central role [4?]. The most basic pattern of alternating flexion and extension during mammalian locomotion is controlled by spinal central pattern generators (CPGs). These CPG's are under supraspinal control by the cerebral cortex, basall ganglia, cerebellum and brainstem through specific pathways known as the corticospinal (pyramidal) and parapyramidal tracts [2]. In the lumbar spinal cord afferent input from muscle spindles has been shown to regulate sensorimotor control of locomotion through an effect on CPGs by spinal interneurons [44].

The spinal segmental stretch reflex arc is one of the major pathways of afferent input on the spinal cord. Fast conducting sensory fibres (la afferents) relay excitatory impulses ariginated in muscle spindtes after muscle stretch. After excitation of the primary afferent la fibres an excitatory action on the alpha. motoneuron of the agonistic muscle is established. The la afferents also connect with inhibitory interneurons that project directly to the antagonist motoneuron. 
known as reciprocal inhibition. In the stretch reflex most excitatory activity is mediated via oligosynaptic and polysynaptic pathways [6]].

Besides by corticospinal and afferent input from muscle spindles, spinal interneuron activity is regulated by other inhibitory and excitatory supraspinal descending systems known as the parapyramidal tracts. The key parapyramidal tracts are: the dorsal reticulospinal tract (DRT), the medial reticulospinal tract (MRT) and the vestibulospinal tract (VRT). The MRT and the VRT are the two main excitatory pathways while the DRT is a inhibitory pathway. Lesions in either one of the above mentioned systemis will have an effect on nomal locomotion.

\section{Spastioity}

Spasticity is defined as a sensorimotor disorder with a velocity dependent increase in tonic stretch reflexes and exaggerated tendon reflexes as a result of hyperexcitability of the stretch reflex [30]. Spasticity can be a very disabling feature: limited locomotor abilities, contractures (lasting stiffness of muscles, tendons, ligaments and joints), pain and limitations for self-care and care givers, amount to considerable healthcare costs.

Spasticity is looked upon as a positive component of the upper motor neuron (UMN) syndrome [59]. The UMN is defined by all long descending tracts that control or influence movement and muscle tone $[2,59]$. The UMN syndrome is divided in positive and negative phenomena. The negative phenomena are characterised by a reduction in motor activity and the positive phenomena are characterized by excessive motor activity. In contrast to the general opinion, spasticity is not due to a pyramidal tract syndrome. Isolated lesions of the pyramidal tract are not associated with the combination of weakness, spasticity and hyperreflexia as seen in the upper motor neuron (UMN) syndrome [2].

The exact pathophysiological mechanisms of spasticity in cerebral palsy remain unclear. Nevertheless, it is generally accepted that the balance between excitation and inhibition is disturbed in favour of the excitatory forces. The la afferent stretch reflex arc is the mast basic neural circuit within the 
pathophysiology of spasticity [27]. In spasticity, this reflex circuit is impaired in favour of the excitatory action by an enhanced processing of afferent information within the spinal cord $[43,58]$.

Spinal interneurons are thought to play a role in the pathophysiological mechanisms of spasticity [24]. The role of interneurons in the stretch reflex arc is thought to be even larger than the direct comnections between sensory neurons and motor neurons [6]]. It is likely that interference with normal development of spinal (inter-) neurons will have a profound effect on the development of locomotor abnormalities such as spasticity.

\section{Treatment options for spasticity}

The management of spasticity is focussed on the improwement and/or prevention of complications like contractures. Furthemore, an emphasis an functionall improvement and/or facilitating rehabilitation after treatment should be made. The management of spasticity with the aid of physical therapy in order to improve functionality and awoid painful contractures has been the only treatment option for years. Besides physical therapy. roughly three treatment options are available nowadays; oral pharmacotherapeutic, chemical denervation and surgery [21].

Drugs mostly used for oral administration are: Baclofen, Diazepam, Dantrolene and Tizanidine. All these drugs, besides Dantrolene, enhance intribition by inhibiting excitatory neurotransmitters or augmenting inhibitory neurotransmitters at the spinal cord level, in order to reduce spasticity. An important side effect of oral drug is sedation due to an effect on brain neurotransmitters. These side effects are a limiting factor in the use of oral pharmacotherapy.

The second therapeutical option is chemical denervation. Before the introduction of Botulinum toxin type A (BTX.A), local injections with Phenol or alcohol were performed. Nowadays, intramuscullar injections with BTX.A made the use of Phenol as a local denerwation agent almost obsolete. The beneficial effect of 
BTX.A on function and nuscle tone has been extensively proven in randomized double blinded clinical trails [9. 22]. The major drawback of BTX is the recurrence of spasticity, the mean duration of the effect is approximately 3 months. Moreover, adverse events of repeated BTX therapy have been reported [46].

Besides orthopaedic interventions for the relief of contractures, the surgical management of spasticity is mainly focussed on selective dorsal rhizotomies (SDR) and intrathecal baclofen pumps. In all neurosurgical interventions, reduction of spasticity is established through interruption of the stretch reflex in order to decrease excitation [63]. After the first description of the use of dorsal rhizotomies in the treatment of spasticity by Foerster, several authors have modified the technique to the SDR used nowadays [12, 13]. SDR has several disadvantages. The invasive techniques used in the SDR are complicated and time consuming procedures only to be performed by highly specialized neurosurgeons. Moreover, considerable cooperation of the patient is required in order to successfully complete the post operative rehabilitation program during one year.

An alternative for the SDR is the percutaneous radiofrequency lesion adjacent to the dorsal root ganglion (RF.DRG). Accumulated clinical experience with RF.DRG has shown that it is possible to allewate pain without clinical signs of nerve damage [65]. Furthermore, RF.DRG is a simple and safe treatment with little side effects [57]. In this thesis, the morphological effects of RF.DRG on the rat spinal cord and the clinical effect of RF DRG on spasticity in children with cerebral palsy are investigated.

\section{Morphology: spinal development and cell death}

The occurrence of cell death in the CNS during normal development and under pathological circumstances has been well established during the past decades. Two types of cell death are known: programmed cell death, or apoptosis, and necrosis. At first, necrosis and apoptosis were wiewed upon as totally different mechanisms of cell death. Nowadays, the two mechanisms are not thought to be so strictly divided [32]. 
Apoptosis will lead to cell death characterized by: fragmentation of DNA into nucleosomal fragments, shrinkage of the cell, the formation of apoptotic bodies and phagocytosis of cell debris without features of inflammation [41]. Fragmentation of the nucleolus is a hallmark of apoptosis which can be observed using a routine histochemical stain like the hematoxylin and eosin (HE) stain. However, apoptosis is more easily detected using the TUNEL (TdT.mediated dUTP biotin nick end labelling) stain [19].

The concept of apoptosis was first thought of in 1972 by Kerr et al [28]. The exact mechanisms that trigger apoptosis are still poorly understood. However, the current opinion is that the major trigger for apoptosis are a series of events that activate caspases. Caspases are present in living cells in an inactivated isoform. For the activation of caspases two pathways have been described. Firstly, through so called "death receptors" like the Fas receptor and the tumor necrosis factor (TNF) receptor [3]. Occupation of these receptors leads to activation of intracellular caspase-8. This will lead to further activation of other caspases such as caspase-3, caspase-6 and caspase-7. After activation of caspase-3 a "point of no return" is reached, the cell will surely die. The second pathway leading to caspase activation and thus to apoptosis is through cytocrome-c from mitochondria. Cytochrome-c is exclusively located in the intermembrane space of mitochondria. During apoptosis, the outermembrane of mitochondria becomes permeable for cytochrome.c. The regulation of cytochrome.c is dependent on anti-apoptotic (Bci2 and $\mathrm{Bcl} \cdot \mathrm{x}_{\mathbf{1}}$ ) and pro apoptotic ( Bax, Bim, Bad and Bak) proteins [1, 52].

During nomal development of the brain programmed cell death has been described for both neural and glial cells and an estimated half of the originat cell population is eliminated in this way [54]. Developmental apoptosis of motor neurons in the spinal cord is grossly completed in the embryonal stage, hardly any motor neuron death is observed during postnatal development $\left[\begin{array}{ll}53 & 66\end{array}\right]$. Nevertheless, a wave of apoptotic cell death is described in the spinal cord during normal postnatal development [31. 39]. In these studies, apoptotic cells were 
identified as interneurons based on their anatomical location within the spinal cord and their immunocytochemical profile.

Besides programmed cell death during development, apoptosis in the spinal cord has been demonstrated in several pathological conditions like ischemia, infection, radiation or trauma $[25,36,40]$.

Apoptosis after (oxidative) cell injury has been related to the NO-CGMP pathway through actiwation of the NMDA receptor. Unregulated NO production can cause cell death (both apoptosis and necrosis) through, among others, oxidative stress [49]. NO.mediated apoptosis of cardiomyocytes has been found to be CGMP dependent [60]. The selectiwe and delayed neuromal death in the spinal cord after ischemia has been related to NO [68]. Furthermore, an increase of cGMP has been described in the rat striatum after severe perinatal asphyxia [37]

\section{Biochemistry: the NO-cGMP signal transduction system}

The discovery af the biological function of NO in the cardiovascular system by Furchot: and Zawadzki and the reported role of NO in the brain by Garthwaite et al. has raised considerable interes\# of neuroscientist for the molecule in the past decade [16. 18]. Several different mechanisms of action of NO within the CNS are known. Firstly, NO is a neurotransmitter with totally different properties than other known neurotransmitters. As a neurotransmitter, NO acts as an intercellular messenger molecule after activation of the NMDA receptor by glutamate (Figure 1). Activation of the NMDA receptor results in a $\mathrm{Ca}^{* *}$ influx in the cell. Intracelluarly, NO synthase (NOS) catalyses the conversion of L-arginine and oxygen to $\mathrm{L}$-citrulline and $\mathrm{NO}$ (a $\mathrm{Ca}^{*} / \mathrm{Calmodulin}$ and $\mathrm{NADPH}$ dependent process). After diffusion across the cell membrane and into surrounding cells, NO activates soluble guanylyl cyclase (SGC) which in turn synthesizes the secand messenger cyclic guanosine 3', 5' monophosphate (cGMP) [42]. Secondly, NO is known to be a hightly reactive free raclical with a strong cytotoxic action through the formation of peroxinitrite $\left(\mathrm{O}_{2} .+\mathrm{NO} \rightarrow \mathrm{ONOO}\right)$ [26] 
From a functional point of view No has been implicated in the regulation of excitation, long term potentation, long term depression and in memory processes [55]. In the CNS, CGMP is synthesized by guanylyl cyclases. This class of enzymes can be differentiated into two main groups, i.e. conventionally called the membrane-bound or particulate guanyly cyclase (pGC) and the cytosolic or soluble guanylyl cyclase (SGC). White activation of SGC is mainly NO-mediated. pGC is activated by natriuretic peptides [10]. Once cGMP is formed, it is rapidly hydrolyzed to the biologically inactive non cyclic form 5'. GMP by the familly of cyclic nucleatide phosphodiesterases (PDE's) [11]. All members of the PDE family. 11 different isoforms have been described thus far "differ in their tissue distribution, affinity for CGMP or CAMP and regulatory mechanisms [15].

Although the exact function of CGMP in the CNS is largely unknown, cGMP is thought to have several effects in the (developing) CNS. In the spinal cord, cyclic nucleotides like cGMP contribute ta spinal hyperalgesia [17]. Recent sidies provide evidence for a contribution of the NO-CGMP pathway in the development and maintenance of central sensitization of spinothalamic tract neurons by reducing the effectiweness of spinal inhibition $[33,34]$. Furthermore, cyclic nucleotides are thought to be involved in the guidance of neural growth cones during development [6].

Immunocytochemistry studies revealed that, in response to NMDA. CGMP accumulated in a population of small cells and neuropil in laminae II and 111 of the dorsal horn [48]. The localization and function of cGMP in the spinal cord in rats after perinatal asphyxia is presently unknown. 
Figure 1. The NO-CGMP pathway

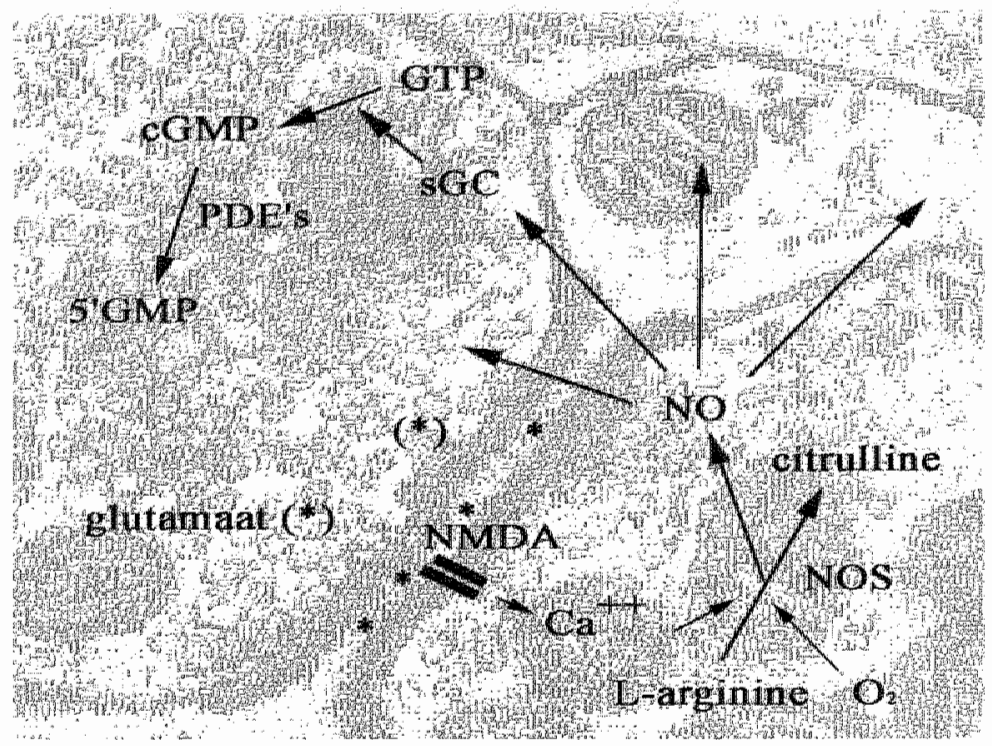

Schenatic representation of the NO.CGMP pathway superimposed on a drawne of the symaptical cleft. The explanation of the figure is given in the text.

\section{Perinatal asphyxia in the rat}

Several models for cerebral asphyxia have been described in the literature. Most of these models are arterial occlusion models in combination with an hypoxic environment, most probably more representative for local ischemia and not for the asphyxia as we have used in our perinatal asphyxia model [14. 25]. We used a model for perinatal asphyxia described by Loidl et al. which is a more representative model for the clinical situation of perinatal asphyxia [38].

In short, time pregnant Wistar rats were used (Figure 2). The rats were decapitated and hysterectomized after their first pup was allowed to be delivered vaginally (control, CVD). Both the uterus horns were placed in a water bath at $37^{\circ} \mathrm{C}$ for 20 minutes (severe perinatal asphyxia, SPA). After 20 minutes the uterus horns 
Since approximately 150 years doctors and scientists thave studied the patient with impairments in locomotion which originated in childhood, initially known as Little's disease and later termed cerebral palsy. The first detailed description of cerebral palsy was done by Little in 1861 in a paper presented for the London Obstetrical Society [35]. The clinical features observed by Little were attributed to difficult birth. Nowadays the term cerebral palsy is used for a group of conditions mainly characterized by motor disabilities resulting from a permanent and non progressive injury of the developing central nerwous system (CNS) [45]. The injury of the CNS can take place during several stages of development namely: pre-peri- or post- natal.

The care for neonates is constantly changing. Due to the improwing care for increasingly younger and sicker neonates, an increasingly higher survival rate is achieved. Two of the long term consequences of this changing care are an increase in the incidence and prevalence of cerebral palsy $[8,64]$.

Perinatal asphyxia, a condition which may lead to the clinical picture of cerebral palsy, is a common cause of mortality and morbidity in childhood with a prevalence of 1.5 to 2.5 per 1000 live term births [29]. In perinatal asphyxia a combination of ischemia (no bloodilow), hypercapmia and hypoxia (low oxygenation of the blood) can cause tissue damage in all organ systems. The severity of CNS damage after asphyxia is dependent on the developmental stage of the newborn. 
were opened, the pups removed, resuscitated and allowed to recover in an incubator at $37^{\circ} \mathrm{C}$. The pups were placed with a surrogate mother; The advantages and disadwantages of this model are discussed in the general discussion.

Figure 2. Rat model for perinatal asphyxia

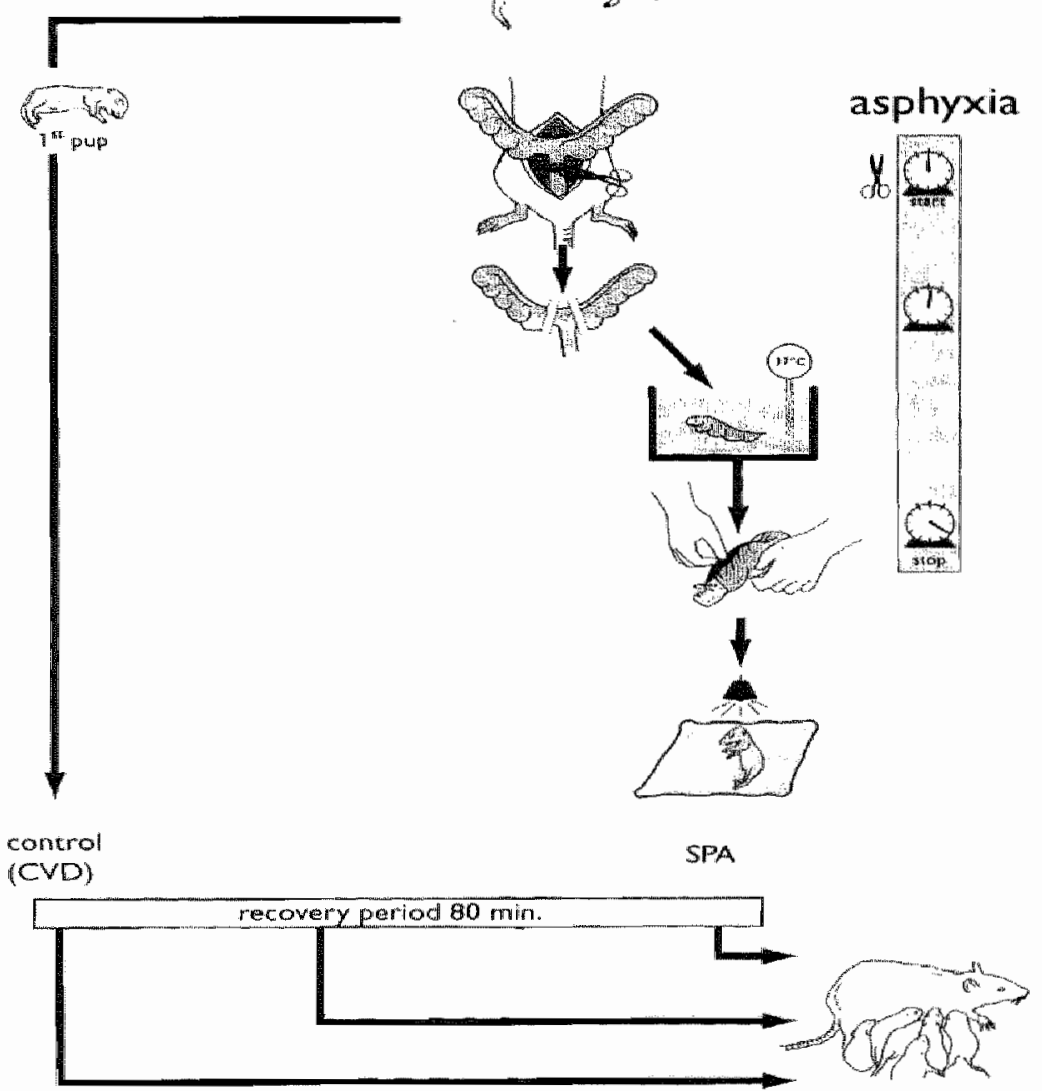

The used rat model for permatal asphyxat. Adapted from Loid at al[3]. 


\section{Thesis outhe}

Far the outline of this thesis we choose to make a clinically oriented arrangement of the different chapters, starting with the studies describing normat development of the rat neonatal spinal cord, both biochemical and morphological, followed by the studies describing the pathological condition (perinatal asphyxia) and the studies on the (pharmaco-) therapeutical interventions. The intial emphasis on the animal model changes to a more clinical emphasis in the last chapters.

In chapter 2 the localization of NO and ANP mediated CGMP synthesis in the developing rat spinal cord are investigated. Furthermore, the developmental pattern of apoptosis in the spinal cord white matter is described in chapter 3.

The effects of perinatal asphyxia on developmental apoptosis in the spinal cord of neonatal rats is described in chapter 4.

In chapters 5 and 6 the effects of the spasmolytic drug Bacloten on the CGMP symthesis in the spinal cord are studied, both during normal development and after perinatal asphyxia. The effects of the radiofrequency lesion of the dorsal root ganglion on the rat spinal cord are studied in chapter 7.

In chapters 8 and 9 the clinical implications of RF-DRG as a treatment option for spasticity in children with cerebral palsy are reviewed and investigated. Finally, in the general discussion, the results of the different stuclies and the future aims are discussed 


\section{References}

1 Adams J.M and Cony S. The Bel.2 protein family. arbiters of cel surviwa. Science. 281 (1998) 1322.1326 .

2. Alexander G.E. and Delong M.R. Central mechanisms of initiation and contral of movement. In A.K. Asbury. G. M. Mckhann and W. I. MoDonald (Eds.) Diseases of the nerwous swstem clinicai neurobiology. Vol. I, W.B. Saunders company, Philactephia. 1991. pp. 285.308.

3 Asmkenazi A, and Dixit V.M. Death receptors: signaling and modulation. Science. 281 (1998) $1305 \cdot 1308$.

4 Barolat Romana G. and Davis R. Neurophysiological mechanisms in abnomal reflex activities in cerebral palsy and spinal spasticity. J Neurol Neurosurg Psychiatry. 43 (1980) 333.342

Burke D. and Ashby P. Are spinal presymaptic inhibitory mechanisms suppressed in spasticity? J Neurol Sci. 15(1972) 321.326

Caroni P. Driving the growth cone. Science. 281 (1998) 1465.1466.

Clancy R.R. Sladky J.T. and Rorke L.B. Hypoxic ischemic spinal cord injury following perinatal asphyxia. Ann Neurol. 25 (1989) 185.189.

Colver A.F., Gibson M. Hay E.N., Jarwis S.N.., Mackie P.C. and Fichmond S. Increasing rates of cerebrail palsy across the severity spectrum in north east England 1964.1993. The North of England Collaborative Cerebral Pallsy Survey. Arch Dis Chitd Fetal Neonatal Ed. 83 (2000) F7.F12.

Corry H., Cosgrove A. Walsh E. Meclean D. and Graham H. Botuthum toxin A in the hemiptegic upper limb: a double binded trial. Dev Med Chitd Neurol, 39 (1997) 185. 193.

10 Denninger J.W. and Marletta M.A. Guanylate cyclase and the NO/CGMP signating pathway. Biochim Brophys Acta, 1412 (1999) 334350.

11 Dousa T.P. Cyclic 3.5nucleotide phosphodiesterase soenzymes in cell biology and pathophysiology of the hidney. Kidney Int. 55 (1999) 29.62

12 Fasano V.A. Broggi G., Zeme S. Lo Russo G. and Sguazzi A. Longterm results of posterior functional hizotomy. Acta Neurochir Suppl Wien. 30 (1980) 435.439.

13 Foerster 0. On the indications and results of the excision of posterior spinal roots in men. Surg Gynecol obstet. 16 (1913) 463474 
14. Follis F., Scremin O.U., Blisard K.S. Scremin A.M. Pett S.B. Scott W.J., Kessler R.M. and wernly J.A. Selective vulnerability of white matter during spinal cord ischema. J Cereb Blowd Flow Metab. 13 (1993) $170-178$. Francis S.H., Turko IV. and Corbin J.D. Cyclic nucleotide phosphodiesterases: relating structure and function. Prag Nucl Acid Res Mol Biol. 65 (2001) 1 52. Furchott R.F. and Zawadzki J.V. The obligatory role of endathelial cells in the relaxation of arterial smooth muscle by acetylcholine. Nature. 288 (1980) 373.376 . Garry M.G., Abraham E., Hargreaves K.M. and Aanonsen L.M. Intrathecal injection of cell-permeable analogs of cyclic $3^{\prime} 5^{\circ}$. guanosine monophosphate produces hyperalgesia in mice. Eur J Phamacol. 260 (1994) 129.131.

Garthwaite J., Charles S.L. and Chess-Williams R. Endothelium derived relaxing factor release an activation of NMDA receptors suggests a role as intercellular messenger in the bram. Nature. 336 (198:3) 385388 .

Gavriet $Y$. Sherman $Y$. and Ben-Sassan S.A., Identification of programmed cell death in situ via specific labeling of nuclear DNA fragmentation. J Cell Biol. 119 (1992) 493.501

Geltan S. Altered spinal motoneurons in dogs with experimental hind lamb rigidity. J Neurophysiot. $29(1966) 583.611$.

21 Goldstein E.M. Spasticity management: an overview. 1. Child. Neurol. 16 (2001) 16. 32

Graham H.K., A.oki K.R.. Autti.Ramö I., Boyd R.N., Delgado M.R., Gaebler Spira D.J., Gormley M.E. Guyer B.M., Heinen F., Holton A.F. Mathews D. Molenaers G., Motta F., Garcia Ruiz P.J. and Wissel J. Recommendations for the use of botulinum toxin type A in the management of cerebral palsy. Gait and Posture. 11 (2000) 67.79. Hack M. and Fanaroff A.A. Outcomes of children of extremely low bithweight and gestationat age in the 1990s. Semin Neonatol. $5(2000) 89-106$. Harrison A., Spastic cerebral palsy: Possible spinal interneural contributions. Dev Med Child Neurol. 30 (1989) $769 \cdot 780$. Hayashi T. Salkurai M. Abe K. Sadahiro M. Tabayashi K. and Itoyama Y. Apoptosis of motor neurons with induction of caspases in the spinal cord after ischemia. Strake. $29(1998) 1007 \cdot 1012$.

Hughes M.N. Relationships between mitric oxide, nitroxyl ion, nitrosonium cation and peroxynitrite. Biochim Biophys Acta. 14.11 (1999) 263272. 
Katz R.T. and Rymer W.Z. Spastic hypertonia: mechanisms and meastrement. Arch Phys Med Rehabil. 70 (1989) 14.4.155.

Kerr J.F., Wyllie A.H. and Currie A.R. Apoptosis: a basic biological phenomenon with wide ranging implications in tissue kinetics. Br J Cancer. 26 (1972) 239257. Kuban K.C. and Leviton A. Cerebral palsy. N Engl J Med. 330 (1994) 188.195. Lance J.W. The control of muscle tone, reflexes, and movement: Robert Wartenberg Lecture. Neurology. $30(1980) 1303 \cdot 1313$

31 Lawson S.J., Davies H.J., Bennett J.P. and Lowre M.B. Evidence that spinal interneurons undergo programmed cell death postnatally in the rat. Eur $j$ Neurosci. $9(1997) 794.799$

Leist $M$. and Jattela $M$. Four deaths and a funeral: from caspases to alternative mechanisms. Nat Rev Mol Cell Bial. 2. (2001) 589.598.

33 Lin Q. Palecek J. Palechova V., Peng Y.B., Wu J. Cui M. and Willis W.D. Nitric oxide mediates the central sensitization of primate spinothalamic tract neurons. J Neurophysiol. $81(1999) 1075-1085$

34 Lin Q. Wu J., Peng Y.B., Cui M. and Willis W.D. Inhibition of primate spinothalamic tract neurons by spinal glycine and GABA is modulated by gatanosine $3^{\prime}, 5^{\prime}-c y c l i c$ monophosphate. J Neurophysiol. 81. (1999) 1095.1103.

35 Little W.J. On the influence of abnomal parturation, difficult labors, premature birth, and asphyxia neonatorum, on the mental and physical condition of the child. especially in relation to deformities. Trans Obstet Soc. 3 (1861) $293 \cdot 344$.

36 Liu X.Z., Xu X.M., Hu R., Du C., Zhang S.X., McDonald J.W., Dong H.X., Wu Y.J., Fan G.S., Jacquin M.F., Hsu C.Y. and Choi D.W. Neuronal and glial apoptosis after traumatic spinal cond injury. J Neurosch. 17 (1997) 5395.5406.

Loidl C.F. de Vente J., Markerink van ittersam M., van Dijk C.H.J., Vies J.S.H., Steinbusch H.W.M. and Blanca C. Severe perinatal asphyxia induces increase of stratal cGMP levets. Eur J Ped Neurol. (1997) Alo0.

Loid C.F., Gavilanes A.W., Van Dijk E.H., Vreuls W., Biokland A. Ves J.S.H., Steinbusch H.W.M. and Btanco C.E. Effects of hypothermia and gender on survizal and behavior after perinatal asphyxia in rats. Physiol Behav. 68 (2000) 263.269. Lowrie M. B. and Lawson S.J., Cell death of spinal intemeurones. Prog Neurobiot. 61 (2000) 5.43 .555$. 
Mackey M.E., Wu Y. Hu R. Dekaro J.A, Jacquin M.F., Kanellopoulos G.K. Hisu C.Y. and Kouchoukos M.T. Cell death suggestive of apoptosis after spinal cord ischemia in rabbits Stroke. 28 (1997) 2012.2017 .

4) Martelli A.M. Zweyer M. Ochs R.L., Tazzari P.I. Tabellimi G., Narducci P. arid Bortul F. Nuclear apoptotic changes: an overview. J Cell Biochem. 82 (2001) 634646 .

42. Mayer B. Biochemistry and molecular pharmacology of nitric axide synthase. in $\mathrm{S}$. Whcent (Ed.) Nitric oxide in the nevous system. Academic press limited. London. $1995.00,21.42$

43 Mayer N.H. Clinicophystologic concepts of spasticity and motor dysfunction in adults wh th an upper motoneuron lesion. Muscle Nerve Suppl. 6 (1997) S1-13. MaCrea D.A. Spinal circuitry of sensormotor control of locomotion. I Physiology $533(2001) 41.50$.

45 Miller G. Cerebral palsies: an overvew In G. Miller and Q.D. Clark (Eds.). The cerebral palsies. Butherworth. Hememanm. Boston, 1998, pp. 1.36.

46 Mohamed K.A., Moore A.P. and Rosenbtoom L. Adverse events following repeated injections with botulinum toxin A in children with spasticity. Dev Med Child Neurol $43(2001) 791.792$.

47 Mori S. Matstyama K. Miyashita E. Nakajma K. and Asanome M. Basic neurophysiology of primate locomotion. Folia Primatol. 66 (1996) 192.203.

48 Morris R., Southam E, Gittins S.R., de Vente J, and Garthwaite J. The NO.cGMP pathway in neonatal rat dorsal horn. Eur J Neurosci. 6 (1994) 876.879.

49 Murphy M.P. Winic oxide and cell death. Biochim Biophys Acta. 1411 (1999) 401. 414.

50 Neison K.B. and Ellenberg J.H. Antecedents of cerebral palsy. Multwariate analysis of risk. N Engh J Med. 315 (1986) 81.86.

51 Netso K.B. and Willoughby R.E. Infaction, infammation and the risk of cerabral palsy. Curr Opin Mevol. $13(2000) 133.139$

52 Nijhawan D. Honarpour $N$. and Wang $X$. Apoptosis in neural development and disease. Annu Rew Neurosci. 23 (2000) 73.87.

53 Dppenhem R.W. The absence of significont postnatal motoneuron death in the brachial and lumbar spinall cord of the rat. J Comp Neurol. 246 (1986) 281-286.

54 Oppentheim R. Cell death during development of the nerwous system. Annu Rev Neurosci. 1.4. (1991) 453.501 . 
Prast H. and Philippu A. Nitric oxide as modulator of netronal function. Prog Neurabial. 64 (2001) 51.68

Pschirrer E.R. and Yeomans E.R. Does asphyxia cause cerebral palsy? Semin Perinatol. 24 (2000) 215.220.

57 Segnarbieux $F$, and Frenbeau $P$. The different (open surgical, percutaneous themal and intrathecal chemical) rhizotomies for the treatment of spasticity. In M. Sindou. R. Abboti and K. Y. (Eds.) Neurosurgery for spasticity: a muttidisciplinary approach. Springer Verlag. New York. 1991, pp. 133-139.

58 Sheean G. Pathophysiology of spasticity. In G. Sheean (Ed.) Spasticity rehabilitation. Churchill Communications Europe Ltd. London. 1998, pp. 17.38.

59 Sheean Gi.L. Clinical features of pasticity and the upper motor meuron syndrome. In G.L. Sheean (Ed.) Spasticity rehabijitation. Churchil Communications Europe L.td. London. 1998, pp.7.15.

60 Shimojo T. Hiroe M., Ishiyama S., Ito H. Nishikawa T. and Marumo F. Nitric axide induces apoptotic death of cardiomyocytes via a cyclic.GMP. dependent pathway. Exp Cell Res. 247 (1999) 38.47.

6) Simon N.P. Long term neurodewelopmental outcome of asphyxiated newborns. Clin Perinatol. 26 (1999) 767.78

62 Sladky J.T. and Rorke L.B. Perinatal liypoxic/ischemic spinal cord injury. Pediatr Pathol. 6(1986) 87-101.

63 Smyth M.D. and Peacock W.J. The surgical treatment of spasticity. Muscle nerve. 23 (2000) $153 \cdot 162$.

64. Stanley F.J. Surviwal and cerebral palsy in low bithweight infants: implications for perinatal care. Paediatr Perinat Epideniol. 6(1992) 298310.

65. varn kieef M. Radiofrequency lesions of the dorsal root gangtion in the treatment of spinal paim. Thesis. Maestricht Uniwersity. Maastricht. 1996.

66 Yanamoto $Y$. and Henderso. C.E. Pattems of programmed cell death in populations of developing spinal motoneurons in chicken, mouse, and rat. Dev Biol. 2I 4. (1999) 60.71 . 

Zhou Y., Zhao Y.N, Yang E.B., Ling EA., Wang Y., Hassouna M.M. and Mack $P$. Induction of neuronat and inducible nitric pxide synthase in the motoneurons of spinal cord following transient abdominal aarta occlusion in rats. J Surg Res. 87 $(1999) 185 \cdot 193$. 




\section{Abstract}

An immunocytochemical technique was used to study the localization and developmental aspects of GMP (CGMP).synthesizing structures in the cervical spinal cord of 2 weeks and 3 months old Lewis rats in respons to the nitric oxide (NO) donor sodium nitroprusside (SNP) and / or atrial natriuretic peptide (ANP). By using cell-specific markers, the cell structures inwolved were investigated. To visualize cGMP a combined technique of low and high-power magnification, using a confocal laser scanning microscope was used. NOS mediated cGMP synthesis was observed in the cervical spinal cord in laminae I, 11 and 111 in 14 days old rats. which activity was mainly absent at the age of 3 months. The involvement of NO in the NMDA.mediated increase in CGMP immunostaining (CGMP.IS) was demonstrated by the absence of CGMP.IS in slices incubated in the presence of NMDA together with the NOS inhibitor $N^{6}$.mittro-L.arginine methyl ester (L.NAME). This NO-mediated effect of NMDA on CGMP.IS was completely absent in the 3 . month-ald rats. ANP-mediated CGMP synthesis resulted in an increase in cGMP in laminae I and II which was generally similar at both ages. Astrocytes in both white and gray matter were found to be CGMP.IS in the basal, NO and ANP.stimulated conditions. Using confocal laser microscopy, NO-mediated CGMP synthesis was observed in large chalinergic terminals nearby motor netmons in the ventral hom. An extensive colocalization between NO-stimulated cGMP synthesis and parvalbumin-positive (GABAergic) neurons and fibers was observed in all laminae. In the ANP.stimulated condition a colocalization with parvalbumin strucures was found in laminae II and III. No NO or ANP.mediated CGMP synthesis was found in fibers immunopositive for the presynaptic glutamate transporter, serotonin, or tyrosine hydroxylase. 


\section{Introduction}

In the central nerwous system (CNS) the second messenger cyclic GMP (CGMP) is synthesized by guanylyl cyclases. This class of enzymes can be differentiated into two main groups, i.e. conventionally called the membrane. bound or particulate guanylyl cyclase (PGNC) and the cytosolic or soluble guanylyl cyclase (SGNC) [36, 37, 43,63]. pGNC's are large transmembrane molecules which have a receptor domain at the outside and the catalytic site at the inside of the cell. pGNC is activated through interaction of peptide hormones with the receptor domain. In the rat CNS, activation of PGNC has only been demonstrated for matriuretic peptides (ANP's). SGNC, in the form which can be activated by NO, is composed of two different subunits associated with a heme group $[20,24,36,37$. 43]. In recent years, evidence has accumulated that $N O$ is an important endogenous activator of SGNC in the CNS $[5,17,18,24,44,52]$ The distributions of neuronat NOS (nNOS) and MO mediated CGMP synthesis, as visualized using immunocytochemistry, were shown to be overlapping throughout the CNS [5, 52]. Although it has been demonstrated that CGMP synthesis may occur in a few NOS. containing structures such a colocalization proved to be an exception $[5,6]$.

The cGMP. signalling pathways in the rat brain changes significantly during postnatal development, and both, sources and targets of No seem to be irvolved $[8,34,55]$. PGNC and sGNC activities are high after birth and decline until adult levels of enzyme activity are reached at post-natal age of 21 days. Not only the enzyme activities change, but also the cellular structures containing the active enzymes change with age [34].

The distribution of nNoS in the spinal cord of the rat has been described in datail $[3,35,54,56,61,66]$. In contrast. little is known about the regulation and especially the localization of CGMP synthesis in the spinal cord. Morris et al. showed that the NO.CGMP pathway in the neonatal rat spinal cord is lacated primarily in the superficiall layers of the clorsal hom (lamina I and U1) [35]. There is evidence that CGMP in the dorsal hom facilitates hyperalgesia, although this has 
been questioned recently $[16.26]$. However, at present it is not known which cell. types are involved in the CGMP response. In addition, although ANP receptors have been described in the spinal cord, there are no data on ANP mediated CGMP synthesis in this part of the nervous system [42,58,68].

The aim of this study was to describe the localization of CGM synthesis in the spinal cord in response to the NO-donor sodium nitroprusside (SNP) and/or ANP. We performed a detailed study on the localization and developmental aspects of the cGMP synthesizing structures in the spinal cord of the 2 weeks and 3 months old rat. In addition, we attempted to characterize these structures in terms of neurotransmitters imvolved, or cell-specific marker molecules.

\section{Materials and Methods}

\section{Tissue preparation}

Lewis rats aged 2 weeks and 3 months were used. Rats were bred and housed at the University facility for experimental animals. All experiments were approved by the committee on animal welfare according to Dutch governmental regulations.

At each age, at least six rats were examined. After decapitation, the cervical spinal cord was taken out and cut into $400 \mu m$ slices using a Mcllwain tissue chopper [8]. Individual slices were immediately placed in aerated Krebs. Ringer bicarbonate buffer, kept at $25^{\circ} \mathrm{C}$. Subsequently the temperature was raised till $35^{\circ} \mathrm{C}$ and the slices were incubated in the same buffer for 30 minutes at $37^{\circ} \mathrm{C}$ under an atmosplere of $95 \% \quad \mathrm{O}_{2}$ and $5 \% \quad \mathrm{CO}_{2}$ and in the presence of $1 \mathrm{~mm}$ isobutylmethylxanthine (IBMX) to inhibit phosphodiesterase activity.

In each experiment the slices were further incubated for another 10 minutes with either $100 \mathrm{nM}$ ANP or $0.1 \mathrm{mM}$ of the NO donor sodium nitroprusside to activate $\mathrm{PGNC}$ and $S \mathrm{SNC}$ respectively. NMDA $(0.1 \mathrm{mM})$ was present for 2 imin. 
To block NOS activity, some slices were incubated with $100 \mathrm{mM} \mathrm{N}^{6}$-nitro-L-arginine methyl ester (L.NAME) from the start of the incubation.

The incubations were terminated by adding ice.cold fuxative solution (final concentration $4 \%$ paraformaldehyde, $10 \%$ sucrose, $\mathrm{pH} 7.4$ ). Fixation was continued for 2 hrs, followed by a 30 min wash in ice-cold 0.1 M phosphate $(\mathrm{pH} 7.4)$ containing $10 \%$ sucrose. Subsequently, cryostat sections (10um) were cut and thawed on to chrome-alum/gelatin-coated slides and processed for immunochemistry.

\section{Immunocytochemistry}

All antibodies dilutions were made in Tris.buffered saline (TBS; pH 7.6) containing $0.3 \%(\mathrm{~W} / \mathrm{v})$ Triton X-100 (TBS-T). Sections were incubated overnight at $4^{\circ} \mathrm{C}$ with the primary antibodies in the cilutions indicated below. Primary antibodies were visualized with the secondary antibodies as indicated.

CGMP-immunoreactivity was visualized using sheep anti-cGMP antiserum (1:4000) in combination with a fluorescen isothiocyanate (FITC) conjugated donkey anti-sheep antiserum at a 1:150 dilution, or a rabbit anti-cGMP antiserum (1:300) in combination with a $\mathrm{CY}$-3 conjugated donkey anti-rabbit antiserum (1800). To investigate nNOS immunoreactivity a sheep anti-nNOS antiserum (a gift of Plers Emson, Babraham Institute, Cambridge, UK) (1:750) was used in combination with a FlTC-conjugated donkey anti-sheep antiserum (1:150) [21]. A mouse monoclonal antibody against GFAP was used (1:30) visualized with a CY.3 conjugated donkey anti-mouse antiserum (1:300), The acetylcholine transporter molecular (VAchT) was wisualized using a rabbit antibody raised by the late Dr. Ichikawa [23]. The neuronal glutamate transporter molecule (EAAT1) was demonstrated using a rabbit antibody (1:300) (a gift by J. Rothstein, NHH, USA) [15]. Parvalbumin was visualized with a rabbit antiserum (1:1000) provided by P.C. Emson (Babraham Institute, Cambridge, UK). The mouse monoclonal antibody against tyrosine hydroxylase (1:30) was a gift from Prof. A.C. Cuello (McGill University, Montreal, Canada). 


\section{Photography}

Sections were examined with an Olympus Ax70 microscopy equipped with a narrowband MNIBA.type FITC filter, or a MNG filter for CY fluorescence (Chroma Technology). These filters made it possible to photograph FITC or CY.3 ffurescence in the complete absence of cross over fluorescence. As demonstrated previously, this fillter combination is adequate to visualize two markers in the same section [5].

\section{Confocal Microscopy}

Confocal laser scanning microscopy was performed using a Leica TCS NT (Leica Microsystems, Germany). The Argon.Krypton laser was used for excitation at $488 \mathrm{~nm}$ (FITC) and 568 (CY-3). The fluorescence emission was separated with a 580 dichroic beam splitter. Thereafter, FITC fluorescence was selected by a $530(/ 30) \cdot \mathrm{nm}$ band pass filter, and CY 3 fluorescence was selected by a $590 . \mathrm{mm}$. long pass filter. Cross over fluorescence was negligible. Each optical section $(0.5 \mu m)$ was averaged twice and a series of 8 opticat sections (FITC and CY3 fluoresence separately) was made from one tissue section. A representative optical section from the series was selected for photography. FITC fluorescence and CY. 3 fluorescen are depicted either separately or combined using the integrated software of the Leica TCS NT.

\section{Materials}

Atriopeptin III was from Sigma; sodium nitroprusside and L. NAME were from Fluka; GFAP antiserum was from Inmogenetics; FITC-conjugated donkey anti. sheep antiserum was from Alexia; CY-3 conjugated donkey anti-rabbit and donkey anti-mouse antisera were from Jackson: NMDA was from RBI. 


\section{Results}

CGMP-immunocytochemistry on sections from spinal cord slices incubated in vitro in the absence of a nonspecific phosphodiesterase inhibitar like IBMX yielded no results, similar to the situation described for most areas of the brain and peripheral rervous system [8, 47,67]. Incubation of the rat spinal cord slices at PN14 in the presence of $1 \mathrm{mM} \mathbb{M} M \mathrm{X}$ resulted in intense cGMP immunostaining (CGMP.IS) in the superficial layers of the dorsal hom. This finding indicates the presence of high phosphodiesterase activity. Therefore, all incubations were performed in the presence of $1 \mathrm{mM}$ IBMX. Reference in the text to basal cGMP levels refers to cGMP levels observed after incubation of the slices in the presence of $1 \mathrm{mM}$ IBMX only.

In Table 1 we present a summary of the experiments. In this table, we indicate that, although the majority of the responses of the slices to the pharmacological treatments was consistent, there was some inter-experimental variation. Thus, basal cGMP.IS in the spinal cord slices at the age of 3 months, was generally absent (even in the presence of $1 \mathrm{mM} \backslash \mathrm{BM})$. Nevertheless, in 2 experiments a very sight basal CGMP.IS was observed. In addition there was an inter-experimental variation in the extent of CGMP.IS in the slice after stimultation of the respective cyclases, which was most prominent with ANP (compare Figs. I and 3$)$. 


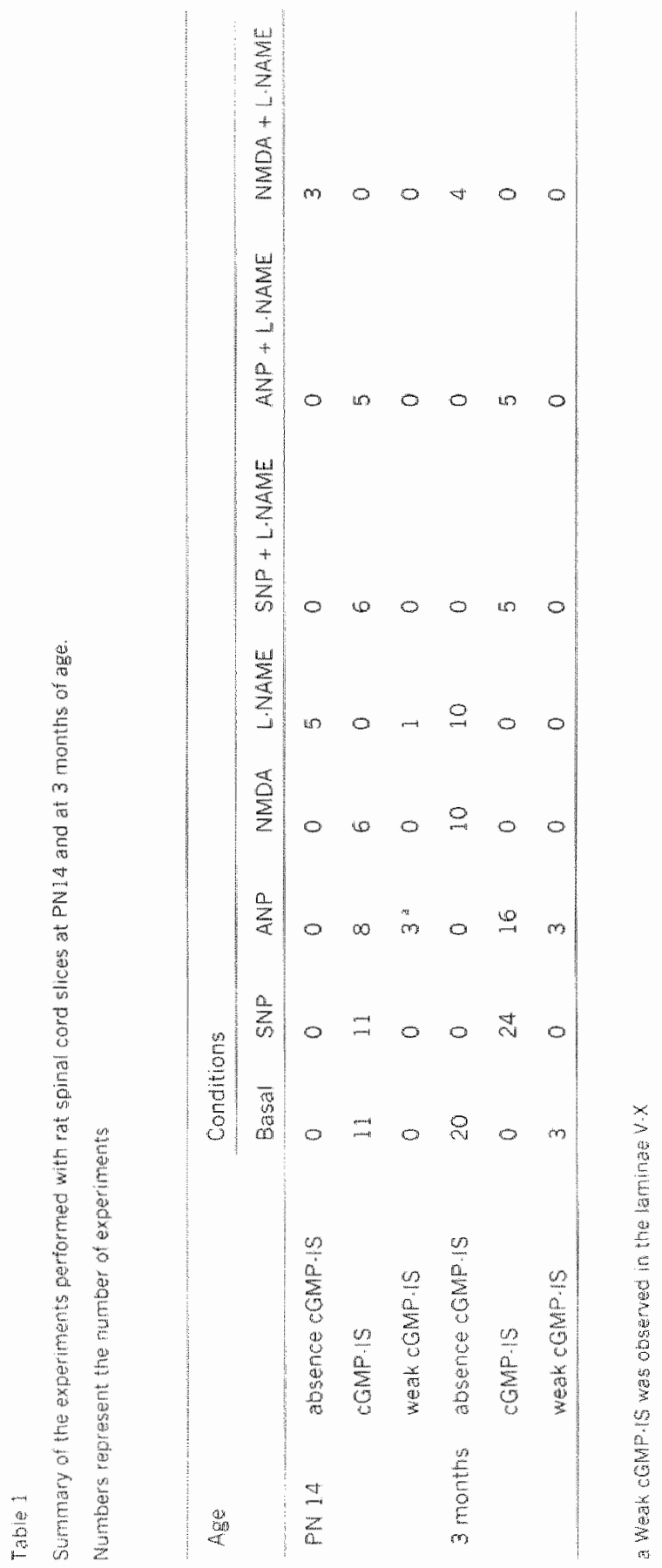

37 
CGMP synthesis in the cervical spinal cord at PN14

At 2 weeks atter birth, in the absence of stimulators of either pGNG or sGNC added to the slices (basal conditions). CQMP.IS was observed in laminal. II and 111 of the dorsal horn and in some ramifying, isolated cells which might be obserwed in each layer $(F \mathrm{G}$. la). Incubation of the slices in the presence of $0.1 \mathrm{mM}$ L.NAME abolished this basal CGMP.IS (Fig. I b), indicating that active NOS was involved in this cGMP symthesis. Treatment of the slices with $0.1 \mathrm{MM}$ SNP for 10 min resulted in the accumulation of NO induced CGMP in cells and fibers in the white and grey matter (Fig. 1C). This effect of SNP on CGMP.IS was not sensitive to 1. NAME (Fig. 1d). Incubation of the slices in the presence of $0.1 \mathrm{mM}$ NMDA increased cGMP.IS in lamina 1 and $\|$ (Fig. 1e). The involvement of NO in the MMDA.mediated increase in CGMP.IS was demonstrated by the absence of CGMP. IS in slices incubated in the presence of NMDA together with $0.1 \mathrm{MM}$ L.NAME (Fig. 11). Stimulation of PGNC with $100 \mathrm{nM}$ ANP resulted in an increase in CGMP in lamina | and 11 , the areas where also basal cGMP synthesis is ongoing (Fig. Ig). Therefore, the effect of ANP was revealed convincingly in the presence of $0.1 \mathrm{mM}$ L.NAME (Fig. 1h). The effect of ANP was consistently strong in the lamina I and II and a variable effect was noted in white matter areas.

At 2 weeks after birth NOS-immunostaining was observed in structures which were mainly located in laminae I. If and $x$ (particularly in the dorsal commissure), the lateral cervical nucleus and in neuronal cell bodies diffusely present in grey and white matter. In general the nNos immunostaining was in agreement with previous published daten (see Section 4). We found a good complementary overlap beween the NO-mediated CGNP. IS and nNOS throughout the slice, with an occasional colocalization between NO mediated cGMP and nNOS (Fig. $2 \mathrm{a}$ and $\mathrm{b}$, arrowheads). In all layers of the cervical spinal cord we found accumulation of CGMP in astrocytes which were chanacterized by GFAP.IS. However, as shown in Fig. $2 c$. $4 \%$ not all GFAP positive structures were CGMP. poshtive as well. 

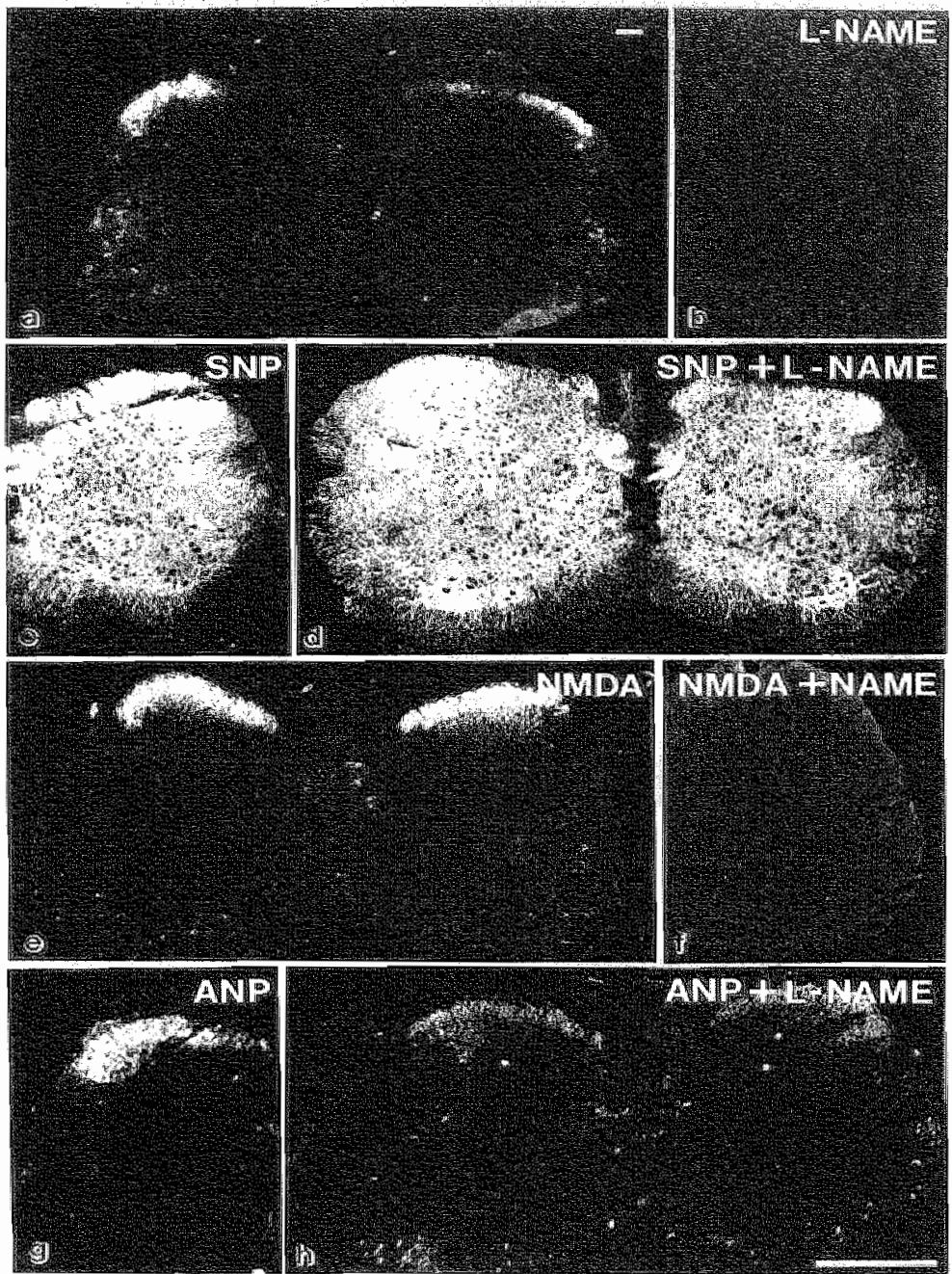

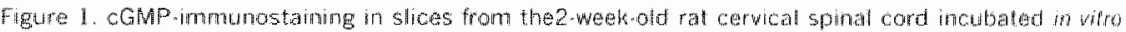
under the following conditions: (a) basat situation; (b) in the presence of O.1 MMA L.AME: (c) in the

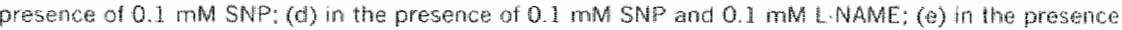

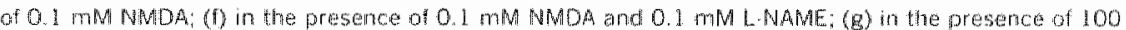

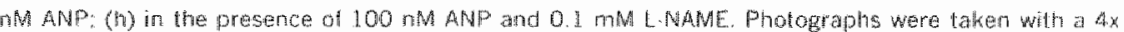
obiective using extended expasure times up 105 minutes (g and h). Bar is 100 um tor all plctures. 

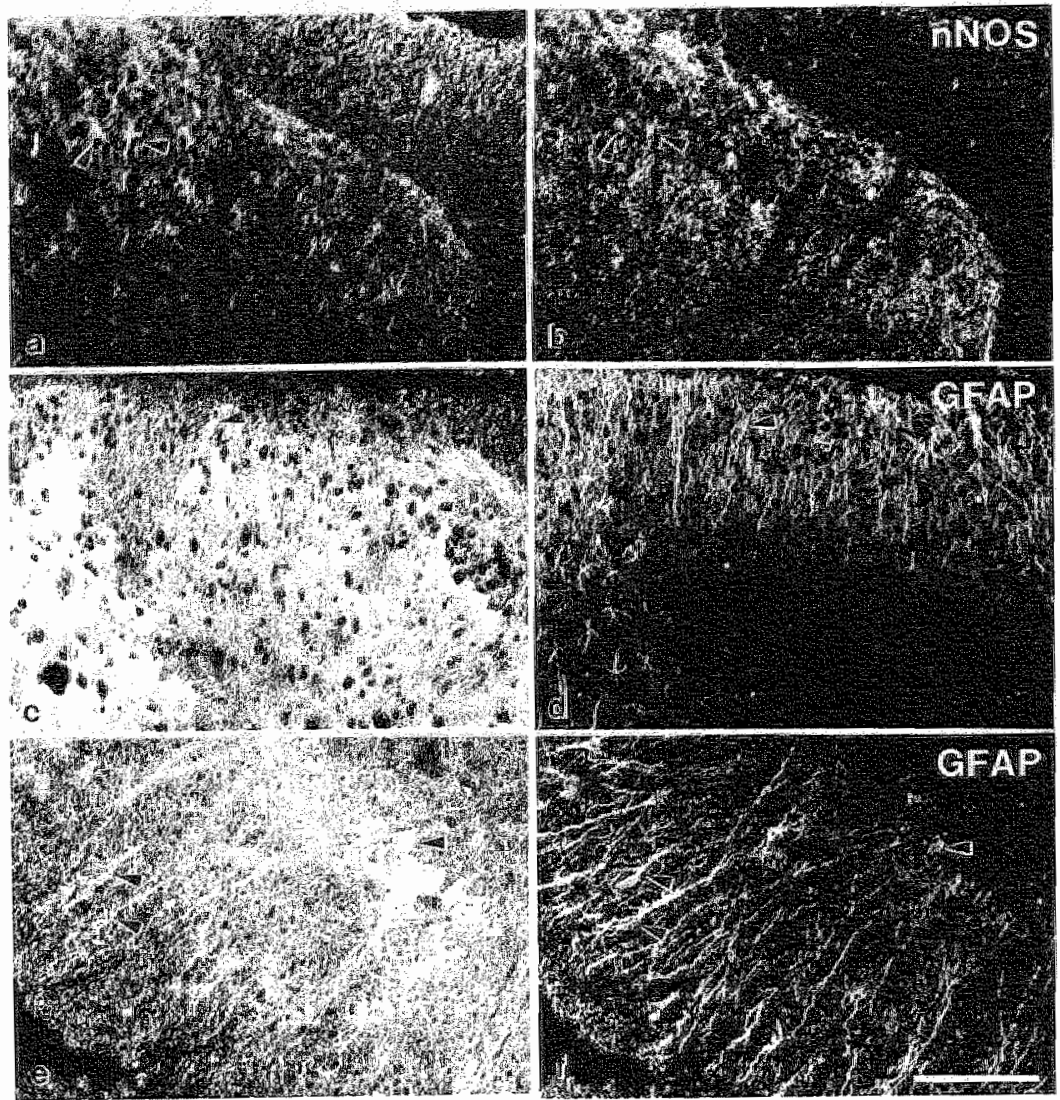

Figure 2. Rat corvical spinat cord at the age of 2 weeks. Double imnunostaining of oGMP with nos ta

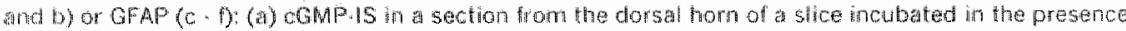

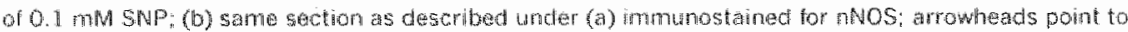
colocalization of CGMP and HNOS. In (C) and (Q) CGMP. BS bs shown wh the dorsal (c) and venthat (e) part of a sloe inchosted in the presence of 0.1 mM SMP. The same section was atso mmunostaned for GFAP (d and 1). Arowheds point to a colocilization betwean cGinp and GFAP. For cGMP.IS in (a) we

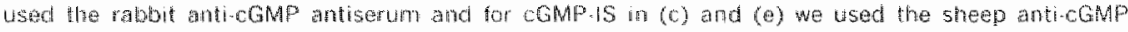
antigerum. Attrough both antisera imminostan exacty the same structures (verined usmg doublo

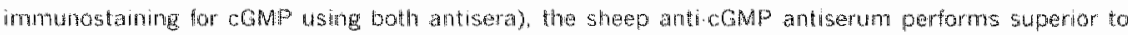

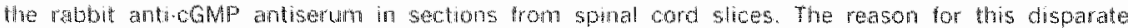
pertormance of the amisera is not known. (see also Figs 3d, f. and hy bar 50 pm for all pictures. 

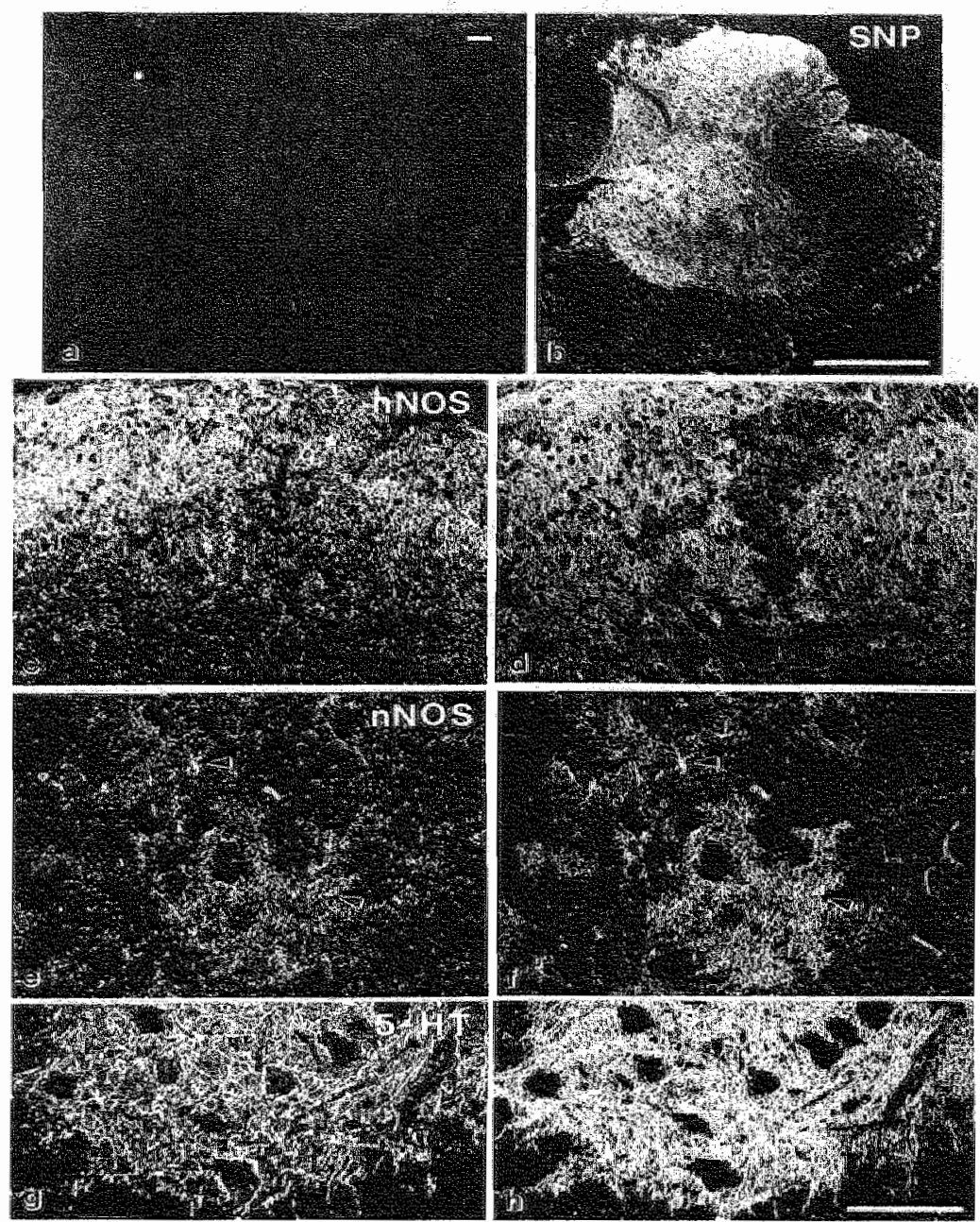

Figute 3. Charemerization of eGMP IS (a, b, d, f, and h) in sections from rat spinal cond at the age of 3 months, (ai) basal conditions; (b, $d, f$, and fa) in the presence of $0.1 \mathrm{mM}$ Stup; (c) and (d) doutbe ifrmmostaining of the same section for nNOS and CGMP (dorsal horrot (e and f) doulate inmmostaning of the same section for nNos and coMP (ventral horn) (g and h) double immunostaining for serotomin (SHT) ard GGMP in the ventral horr. Arrowheads in (c) through ( $f$ ) point to colocalization of nNOS and CGMP. See the note in the legends of frify. 2 on the perforntamce of rabit anti.cGMP antiserum and the sheep anticGMP antserum. the otllyer pictures 
cGMP synthesis in the cervical spinall cord at 3 months

At the age of 3 months, using low power magnification, no cGMP-IS could be obserwed in the cervical spinal cord slices incubated under the basal conditions (Fig. 3a). Nevertheless, at high magnification, using a confocal laser scanning microscope, we were able to demonstrate CGMP.IS in some experiments (Fig. 7d) (see also the summary of the results in Table 1). Similarly as found at PN14, NO. responsive GNC activity in the 3 months old spinal cord (incubation in the presence of $0.2 \mathrm{mM}$ SNP) was found in neuronal fibers and cells in all lamina (Fig. 3b). Discrete and dispersed activity was found in cell somata and fibers of the grey matter and in fibers extending into the white matter. The NO-mediated effect of NMDA on CGMP.IS was completely abolished in the 3 months old spinal cord slice. On the other hand, activation of $\mathrm{PGNC}$ at this age proved to be generally similar as at PN14, as ANP. mediated CGMP synthesis was found in isolated astrocytes (see below) in both grey and white matter, and also in fibers in lamina 1 and II of the dorsal hom which showed a clear punctate staining pattern (Fig. 4a and d). No effect of L.NAME on the ANP-responsiveness was observed at this age. 

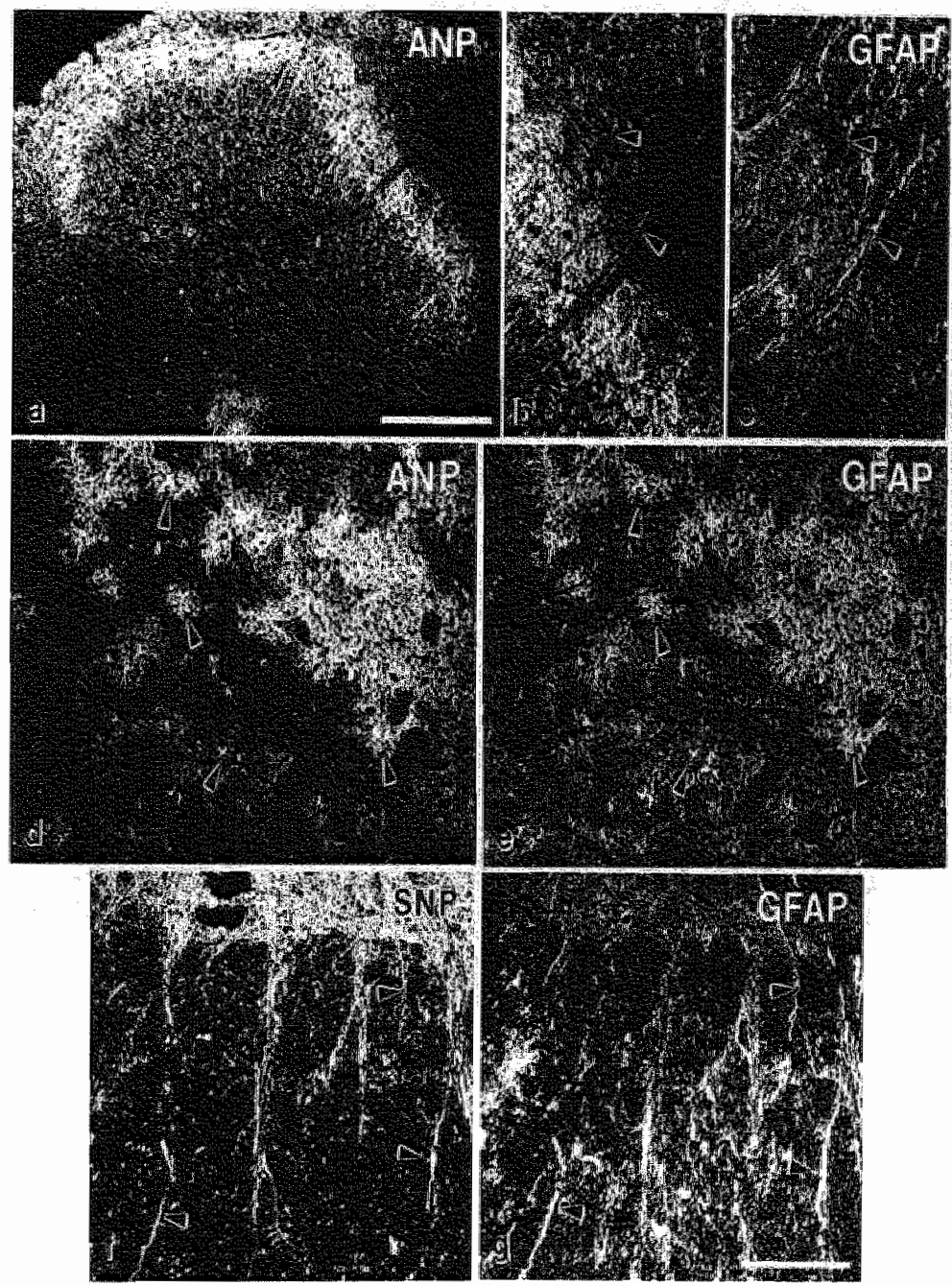

Figure 4. Dauble immunostaning of CGMP ard GFAP in sections from slices of the 3 months oid rat spinal cord. Slices were incubated in the presence of $100 \mathrm{mH}$ ANP (a, b, and d) or 0.1 mM SNP (A). GFAP immunostammg in $(c)$. (e) and $(g)$ has ben done on the same sections as shown in (b), (e), and (g) nespectivety. (b) is a two times endargement of the upper right hand part of (a). Ar rawhads point to sites of colocalization between CGMP and GFAP. Bar is $50 \mu \mathrm{m}$ for (a) and 25 pm for all other pictures. 

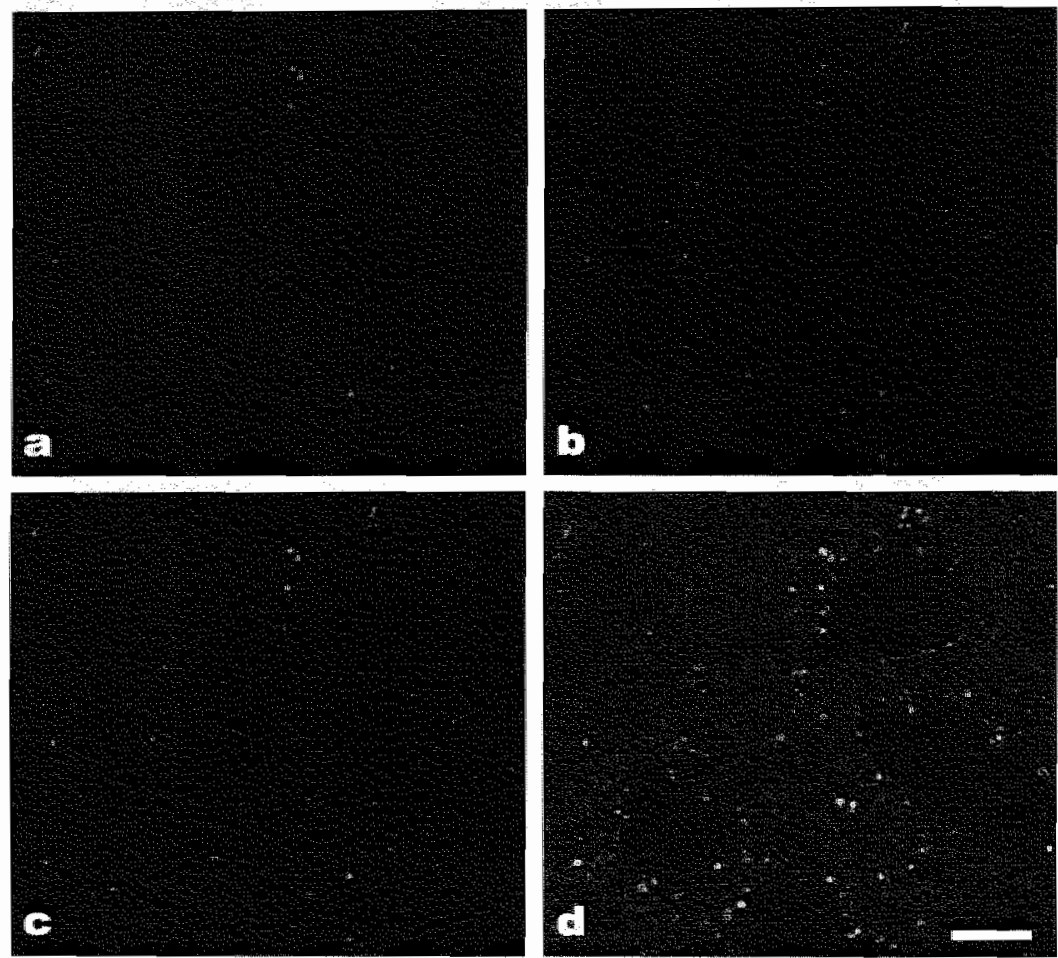

Fagure 5. Confocal laser scan microscopy of a section from a slice, hocubated in the presence of $0.12 \mathrm{mM}$

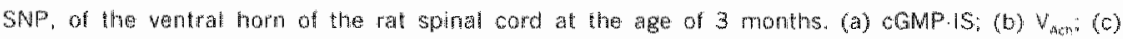
combingttiort of (a) and (b): summation of eight singhe color sections (eight scans for fach colory each laken at a different depth in the section. Yeltow color shows the colocalization between the two markers. Bar is 20 um tor all pictures. 
Double immunostaining of CGMP.IR structures

rNOS-immunostaining in the spinal cord at the age of 3 months was fownd in varicose fibers throughout all layers and in several cell groups. Many small mNOS-mmunopositive cells were observed in the lamina 11 and $\| I I$ (Fig. 3c). The same pattern as was observed at the age of 2 weeks, however. less intense. Similarly, a good complementary overlap was found between NO.mediated CGMP and nNOS-immunostaining, and an infrequent colocalization of SGNC activity and nNOS was observed in neuronal cells or fibers (Fig. $3 \mathrm{C}-\mathrm{f}$ ).

In all layers of the 3 months old spinal cord some, but certainly not all, astrocytes (GFAP.positive cells) were found to be cGMP.IR in the basal, NO. or ANP.stimulated condition (Fig. 4).

There was no accumulation of CGMP.IR, after stimulation with either NO or ANP, observed in serotonergic (Fig. $3 \mathrm{~g}$ and h) or dopaminergic (not shown) fibers. Similarly, no NO or ANP stimulated CGMP production was found in fibers which were immunopositive for the presynaptic glutamate transporter (EAAC1) (not shown). Using confocal laser microscopy, we were able to demonstrate No. mediated CGMP synthesis in large cholinergic terminals situated on or near the motor neurons in the ventral horns (Fig. 5). In addition, we found a colocalization between ANP.stimulated cGMP synthesis and parvalbumin in cells and fibers of the lamina $\mid 1$ and $|1|$ (Fig. 6a - c). We found extensive colocalization between parvalbumin and cGMP in all lamina of the spinal cord (Fig. 6d. f dorsal horn, and Fig 7 a - c ventral horn). Even in spinal cord slices incubated under basal conditions an occasional colocalization between parvalbumin and CGMP. IS could be demonstrated (Fig. 70 ). 
a

b
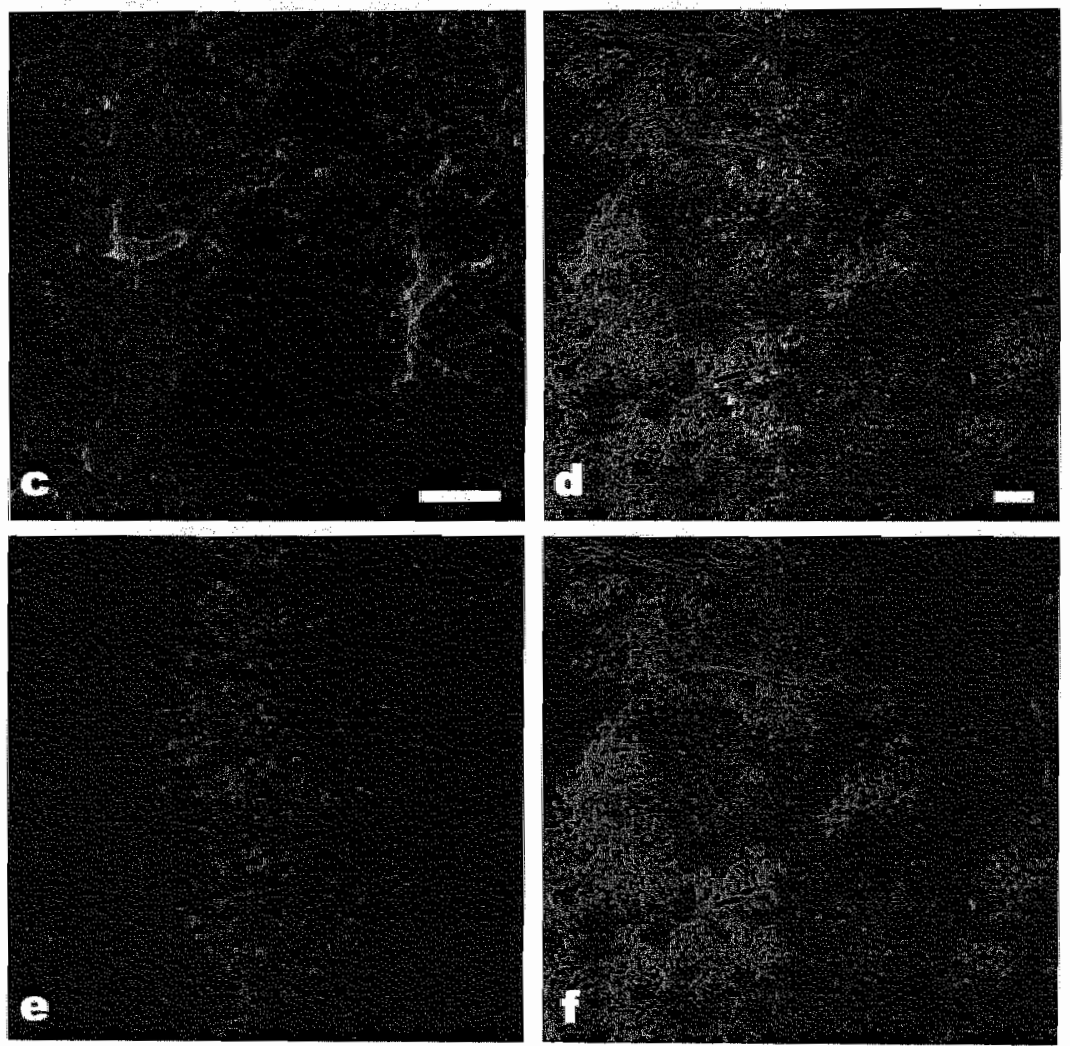

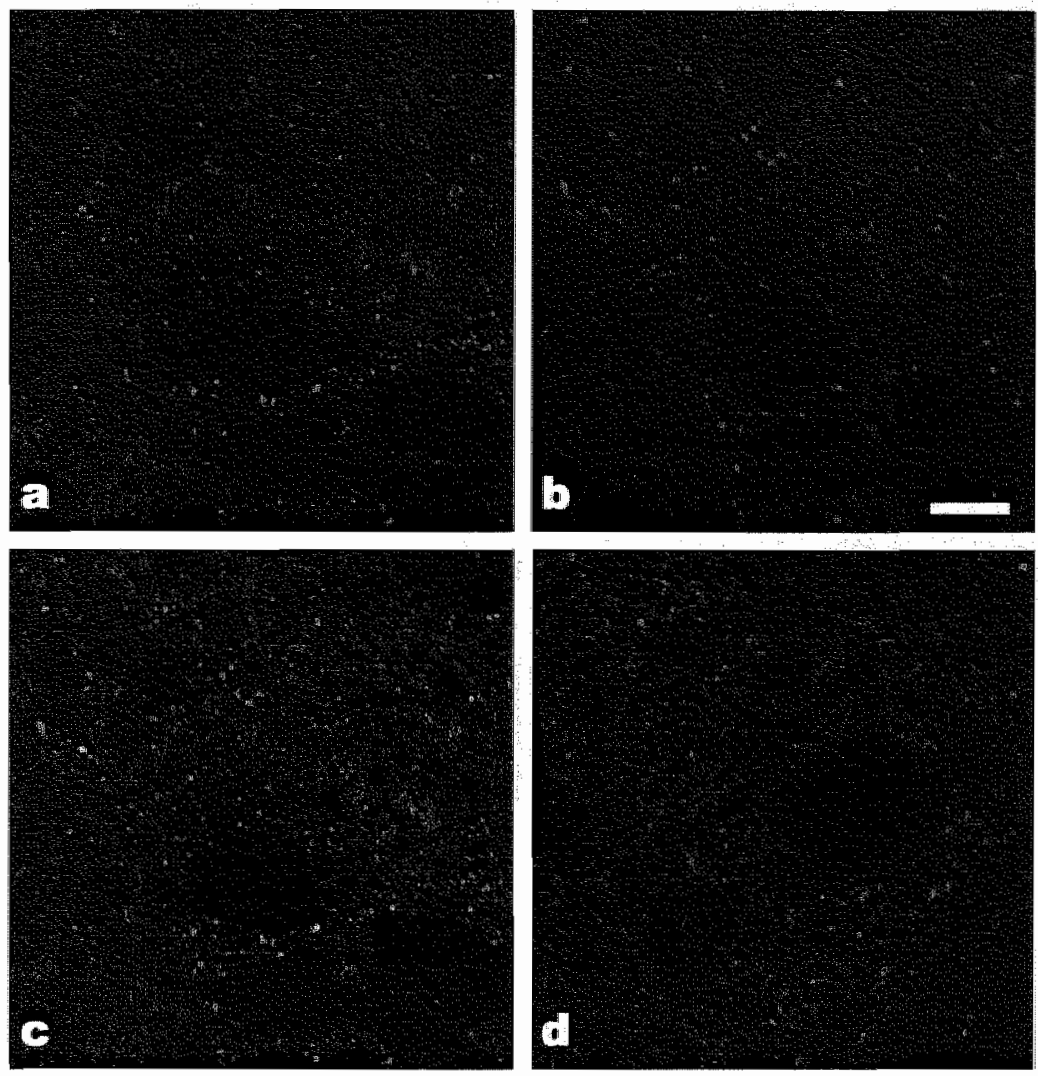

Figure 7. Confocal laser scan microscopy from the ventral fhom in sections of shices of the sptnat cord of

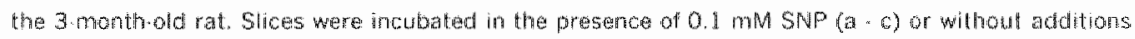
(basal) (d) (a) cGMP; (b) parvabumin; (c) combinathon of (a) and (b) dy combination of comp (ereen) and parvalbumin (red). Colocalization between parvalbumn and cGMp shows yellow. Bar is 10 fum for alll pittures.

- Figure 6. Contocal laser scan microscopy from the dorsal hor in sections of alices of the spinat cord of the 3month old rat. Slices were inchbated in the presence of 100 nM ANP (a - c) or O I mM SHP (d 9) (a) Parvalbumin; (b) cGMP; (c) combination of (a) and (b). (d) combination of (e) and (f): (a) parvabumin: (T) cGMP. Collocalization of parvabumin and cGMP is shown in yellow. Bar is 10 unth for $(a)$ (c) and 20 un for (d) - (b). 


\section{Discussion}

The expression of the various molecular entities of the CGMP signal transduction cascade shows a strong developmental profile in the CNS of different species $[8,13,34,55.57]$. As there is little information avallable on the cGMP response in the spinal cord of the rat, we studied the developmental aspects of this pathway, in combination with a characterization of the cellular structures responsive to NO and/or ANP. From our results we may conclude that, similar to the brain, WOS and SGC have an extensive distribution in the rat spinal cord and that both enzymes are distributed in overlapping structures. Again similar to the rat brain, colocalization between NOS and SGC appears to be an exception. NO. mediated cGMP synthesis was found in parvalbumin positive (GABAergic) neurons and in isolated cholinergic synaptic terminal in the ventral horn. We could not demonstrate the presence of NO-mediated CGMP symthesis in other neurotransmitter systems. In contrast to the situation in the rat brain, the properties to activate SGC (by NO) and PGC (by ANP), appeared to be fully deweloped at PN14. In contrast, the glutamatergic activation of NOS by NMDA was still in a developmental phase at this age.

We compared the effects of a number of NO donor compounds from which NO is released through different mechanisms on CGMP.IR in spinal cord slices of the 3.4-day old rat (Fig. 3) [11, 14]. As demonstrated, the effects of SNP, S. mitrosopenicillamine (SNAP) and S.nitrogiutathione (SNOG) on cGMP accumulation in the spinat cord slices was qualitatively similar. SNP has been reported to antagonize the NMDA receptor [12]. However, this antagonism was just significant at $0.1 \mathrm{MM}$ SNP only under magnesium free conditions. This indicates that. considering our experimental conditions, the antagonism of the NMDA receptor by SNP is not relevant for our results. In addition, our condition of $0.1 \mathrm{MM}$ SNP for 10 min results in an NO concentration of $50 \mathrm{nM}$ or lower, a concentration which is considered to be in the physiological range $[46,50,51]$. Also, considering the corts, we took SNP as the NO donor compound for this study. 


\section{Mos in the adult spinal cord}

The localization of NOS is studied routinely using two different approaches: i.e. immunocytochemistry uising antibodies against NOS or NADPH-diaphorase histochemistry [2.22.60]. The pattern of distribution of NOS positive neurons in the spinal cord was qualitatively similar across four species, i.e. the rat, mouse, cat and squirrel monkey [10, 12]. Several studies of the adult rat spinal cord showed that distinct groups of neurons express NOS: groups of meurons around the central canal, in preganglionic sympathetic neurons in the intermediolateral horm, throughout the deeper laminae of the dorsal horn and in the ventral horn $[9,35,40$, 53. 55. 62]. Our findings using inNOS immunocytochemistry are in agreement with these previous studies.

Compared to the continuous NADPH diaphorase/NOS expression th the above described groups of neurons, somatic motor neurons in the rat spinal cord may show a more transient or biphasic diaphorase activity, which may be species dependent [4]. Wetts et al observed a transient expression of NOS in motor neurons, which is in accordance with the observation made by Bruning et al in mouse spinal cord $[3,64]$. In adult rats, no NOS in motor neurons could be found, while in aged rats, with increasing age the number of NADPH.d positive motor neurons increased $[9,28,40,54]$. Wu et all, found an upregulation of NADPH.d in motor neurons before they died after spinal root awulsion [66]. Motor neuron death could be prevented by nitroarginine, a nonspecific inhibitor of NOS, and it was suggested that induction of NOS expression may be involved in the neuronal death after traumatic injury [66]. In addition the maturation of motor neurons could be blocked by NOS antagonists [27]. We did not find NNOS expression in motor newrons at both ages studied. Therefore, it is clear that the expression of NOS in the spinal cord is complex and depends on age. cell type, topography and state of maturation. 
Developmental aspects of NOS expression

The pattern of expression of nNOS in the rat spinall cond at different ages was shown to be different for the various groups of nNOS containing spinal neurons, not only in a horizontal plane but also in a rostral to caudal direction [3. 31. 61. 64]. Thus, cells around the central canial expressed NADPH.diaphorase already very early during development, whereas cells in laminae I and II express this enzyme activity relatively late during dewelopment. Similarly, it has been reported recently that the rat embryonic motor neurons contain eNOS and in adition, it was suggested that at this stange of development, motor neurons were capable of NO-mediated cGMP synthesis [12]. We never observed nNOS-IS, nor NADPH.diaphorase staining or CGMP.IS in motor neurons at the age of 2 weeks or 3 months. This difference in maturation probably reflects the changing capabilities of the developing animal. Our results show that at 14 days after birth, the location and sensitivity of SGNC, as the target for NO, is already similar to the adult situation.

This contrasts with the developmental pattern in the activation of NOS by NMDA receptors which is evident at PN 14 and absent in the adult spinal cord slices. This latter finding is in agreement with the results of Liuzzi et al who described an adult pattern of NOS localization as late as the end of the third postnatal week [31].

CGMP synthesis in the spinal cord: particulate guanylyl cyclase

Little information is available about the localization of both ANP. and NO. mediated CGMP synthesis. In the meonatal rat, the ANP.stimulated CGMP synthesis could only be demonstrated in the presence of L.NAME (Fig. 1). In the adult rat we found ANP.responsive structures in laminae 1.11 with a clear punctate non-somatic staining and, in addition, in cell somata (Fig. 6). Information about the localization of ANP receplors and ANP containing structures in the spinal cord are scarce. Immunoreactive ANPS were found in porcine and rat spinal cord, respectively [58.68]. Nevertheless, ANP binding sites were not observed in the rat, 
guinea pig, cat and human [33, 38]. However, Saper et al demonstrated immunostaining for brain ANP of sensory afferent fibers innerwating lamina I and Ila, the regions where we localized the ANP-responsive, cGMP-producing cells [42]. In addition Simonnet et al reported the presence of ANP receptors at non meuronal cells, i.e. astrocytes and epitheloid cells, of the mouse spinal cord [49]. In accordance with these observations and in agreement with our results obtained in the rat brain, we were able to localize. ANP.stimulated cGMP synthesis in astrocytes [?]. Presently the function of the ANP-mediated cGMP synthesis in the spinal cord is unknown.
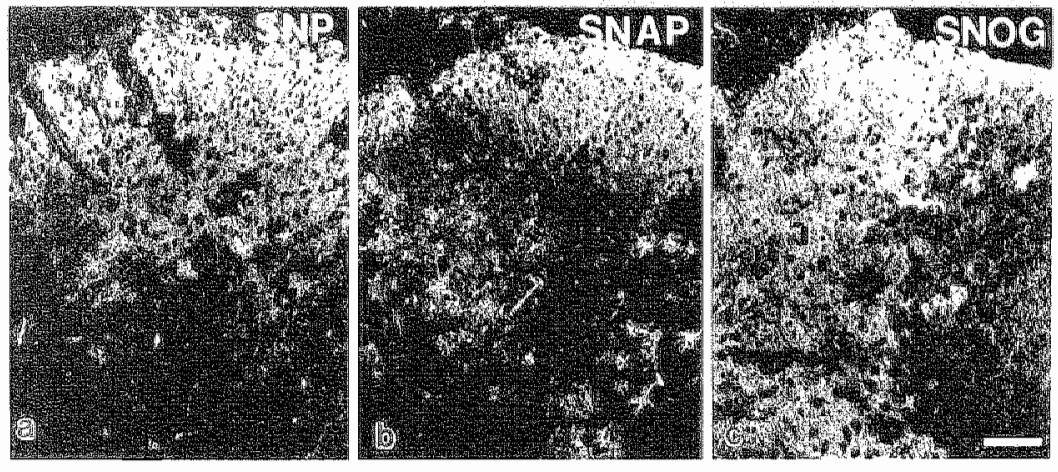

Figure 8. CGMP immunostaing in slices from the 2week-otd rat cervical spirial cond incubated in witro for 10 min with three differemt NO donor compounds: (a) in the presence of 0.1 mM SNP: (b) in the

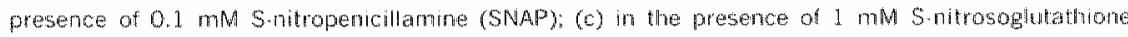

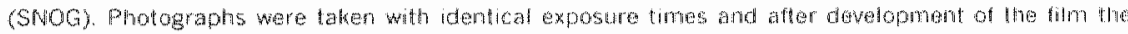
exposure timyes were kept constant. Bar is 25 um for abl pret lures. 
cGMP synthesis in the spinal cord: SGMC

Morris et al described the NO mediated CGMP response in immature spinal cord, and our results confirm these initial observations [35]. Using IBMX as a PDE inhibitor, we found that in the neonatal spinal cord slices there is a certain amount of age related ongoing No symthesis. This 'spontaneous' endogenous No synthesis is absent in the adult spinal cord slices. As already discussed above, we found an age related decline of NMDA.stimulated and NO-mediated cGMP response in the spinal cord. On the other hand, our results did not show qualitatiwe changes in the eftects of SNP on CGMP synthesis during maturation. A close correspondence in location was observed between the NO mediated CGMP response and the nNoS in the spinal cord. This correspondence is generally complementary, with accasional colocalization between CGMP-IR and NOS. These findings are in agreement with previous findings in the rat brain $[5,52]$.

\section{Double immunolabeling of CGMP: colocalization studies}

Our double immunolabeling studies showed that NO-mediated cGMP synthesis in the rat spinal cord is found primarily in parvalbumin containing cells and fibers. About $60-70 \%$ of the parvalbumin-immunoreactive neurons in lamina I and II were described as being GABAergic neurons whereas in the layers III and IV this percentage of colocalization was considerably lower [1]. Newertheless, as GABA is found in all gray matter layers, the parvalbumin immunopositive fibers. observed in layers V.VIII could arise from interneurons situated in layers VII and VIll or belong to dendritic trees of cells in layers 111 and IV [32]. These findings raise some questions about structure and function of the NO. CGMP signal transduction pathway in the spinal cord. First, the complementary nature of the location of NO-synthesis and the NO effect (cGMP synthesis) as discussed above, supports the concept of an intercellular messenger role for NO [17]. In this concept NO is often thought to act as a retrograde messenger and to enhance excitatory neurotransmission $[17,18,29,65]$. Secondly, it has been reported that there is some degree of colocalization of NOS and GABA in the lamina $\|$ islet cells and the 
laminae $\| 1.11$ border cells [30. 59]. On the basis of the absence of colocalization between CGMP.IR and NOS and the presence of colocalization between CGMP.IR and parvalbumin, we conclude that CGMP synthesis does not take place in the GABA.ergic neurons which also contain NOS. Thirdly, CGMP.IS was found in large boutons which where positive for the acetylcholine transporter molecule (Fig. 5). These boutons were found in the ventral horn and adjacent to the large motor neurons. The significance of this observation is presently unclear. Apart from the motor neurons, cholinergic neurons are found in lamima III and these celis have been reported to possess also NOS [54]. According to our observations these cells do not contain SGC as an NO target. This disparity in NO-responsiveness of the cholinergic somata and fibers has also been observed in the rat brain (De Vente et al. submitted). Our finding of NO-mediated cGMP accumulation in parvalbuminpositive fibers and some chalinergic fibers does not encourage interpretation of the effect of NO as a retrograde messenger molecule inducing longlasting changes in excitatory synaptic transmission. It is not clear what the effect of a raise in cGMP level in the GABAergic terminal will have on GABAergic neurotransmission. As there is good evidence that NO and CGMP are involved in nociceptive signalling. it might also be that NO decreases GABAergic neurotransmission along a cGMP. dependent pathway $[16,26,41,48]$. Therefore, our data support the concept, as has been reported for the rat brain, that NO may mediate both excitatory and/or inthibitory functions depending on the site of activation of NOS in specific neural networks [19, 39, 45]. Our results are in agreement with a recent concept that during development NMOA-receptor mediated activation of NOS in the wentral hom may be involved in the arborization of motor neuron dendrites [25]. In addition, our findings show that it is not possible to generalize one concept of NO. action in the spinal cord. Depending on the layer of the spinal cord, Figs 8 and 9 summarize tentatively the NO-CGMP pathways in the dorsal horn and the ventral horn respectively. 


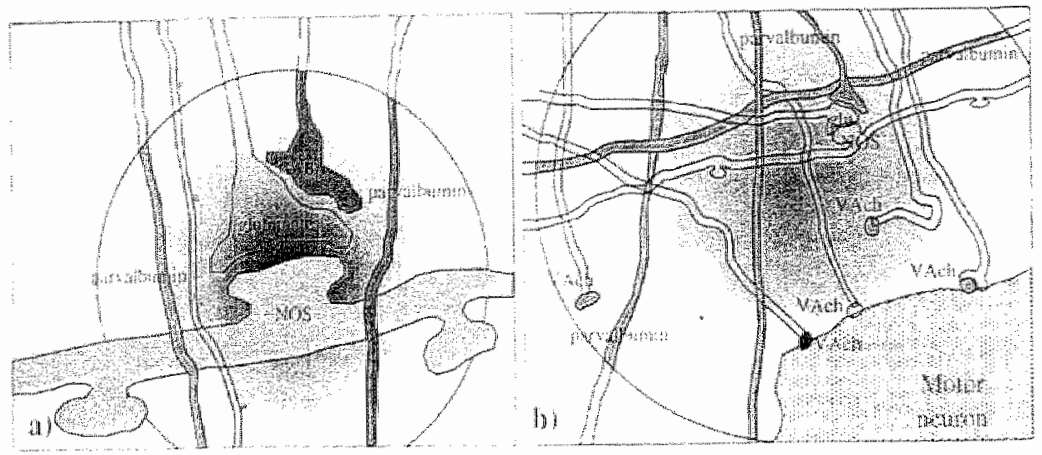

Figale 9. Schematic representation of the organzation of sources and targets of ho in the dorsal forn (a) and ventral horn (b) of the cemical spinal cord slice. NOS is activation by ghtitamate and No diffuses of the range indicated by the sphere (hte diameters of the spheres in (a) and (b) bear no retation to the

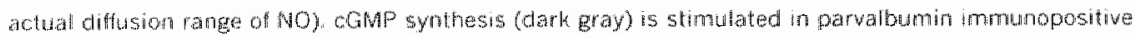
structures in the dorsal horn (ai) and in the venthat hom (b). Large synaptic terrmats which are immunostaining fat cGMP and $V_{\text {s.n }}$ are found ir the ventral hom (dark grey). Similar synaptic ferminats

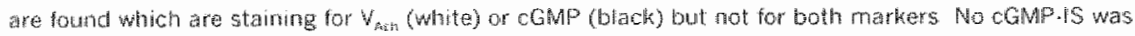
observed in glutamatergic fibers. The asterisk (*) in (a) indicates a passing fiber not responding to No: this might be a glutanatergic. Serotonergic, or dopaminergic fiber, Contrary to the in wivo stuation in our study. CCMP sythesis is stimulated only in that segment of the parvalbumin fibers. which is situated whin the diflusion distance of no.

\section{Conclusions}

In conclusion, our data show the presence of an abundant NO. CGMP signaling system in all tayers of the spinat cord. The NOmediated CGMP synthesis lakes place in parvalbumin (GABAergic) neurons and in the ventral horn in axon terminals probably connecting to the motor neurons. In addition cGMP synthesis Can be found in a subpopulation of glal cells either through activation of pGNC and/or sGNC. Using cGMP.1S as a read out for NO effector structures, no evidence was found for a role for NO as a retrograde messenger in glutamatergic presynaptic terminals in the aduit cervical spinal cord. 


\section{References}

1

Antal M. Polgar E., Chalmers J., Minson J.B., Llewellyn Smith L., Heizmann C.W. and Somogyi P. Different populations of parvalbumin. and calbindim.D28kimmunoreactive neurons contain GABA and accumulate 3H.D aspartate in the dorsal hom of the rat spinal cord. J Comp Neurol. 314 (1991) 114.124.

Bredt D.S., Glatt C.E., Hwang P.M., Fotuhi M., Dawson T.M. and Snyder S.H. Nitric oxide synthase protem and mRNA are discretely tocalized in neuronal populations of the mammalian CNS together with NADPH diaphorase. Neuron. 7 (1991) 615.624.

Bruning $\mathrm{G}$. and Mayer $\mathrm{B}$. Prenatal development of nitric oxide synthase in the mouse spinal cond. Neurosci Lett. 202 (1996) $189 \cdot 192$.

Clowry G.J. and McHanwell S. Expression of nitric oxide synthase by motor nearones in the spinal cord of the mutant mouse wobbler. Neurosci Lett. $215(1996) 177-180$. De Vente J. Hopkins D.A. Markerink Van Ittersum M., Emson P.C., Schmidt H.H. and Stembusch H.W. Distribution of mitric oxide synthase and nitric oxide receptive. cyclic GMP.producing structures in the rat brain. Neuroscience. 87 (1998) 207.241. de Vente J., Hopkins D.A., Markerink van Ittersum M. and Steinbusch H.W. Nitric oxidemediated CGMP production in the islands of Calleja in the rat. Brain Res. 789 $(1998) 175-178$.

De Vente J., Manshanden C.G., Sikking R.A., Ramaekers F.C. and Steinbusch H.W.M. A functional parameter to study heterogeneity of glial cells in rat brain slices: cyclic guanosine monophosphate production in atrial natriuretic factor (ANF) responsive cells. Glia. $3(1990) 43.54$.

8 de Vente J. and Steinbusch H.W.M. On the stimulation of soluble and particulate guanylate cyclase in the rat brain and the involvement of nitric axide as studied by cGMP immunocytochemistry. Acta Histochem. 92 (1992) 13.38.

Dun N.J., Dun S.L., Forstemam U. and Tseng L.F. Nitric oxide synthase immunoreactivity in rat spinal cord. Neurosct Lett. 147 (1992) 217.220

Dun N.J., Dun S.L., Wu S.Y., Forsterman U., Schmidt H.H. and Tseng L.F. Nitric oxide synthase immunoreactivity in the rat, mouse, cat and squirrel monkey spinal cord. Neuroscience. 54 (1993) 845.57. 
East S.J. Bachelor A.M. and Garhwate 3. Selective blockade of N.thethylD. aspartate receptor hunction by the nitric oxide donor nitroprusside. Eur I phanacol. 209(1991) 19.121.

12 Estensz A.G. Spear M. Thompson J.A. Cormel T.L., Radi R. Barbeito L. and Beckman J.S. Whric oxide dependemt production of CQMP supports the survival of rat Embryonic motor neurons cutured with brainderived newrotrophic factor. I Melroset. $18(1998) 37083714$

13 Ewer J.and Truman J Wh Increases in cyclic 3, 5'guanosne monophosphate (cGMP) occur at ecoysis in an evolutionarity consened crustacean cardioactive peptide. immunoreactue insect neuronal network. J Comp Aeturol. 370 (1996) 330.341 .

14 Feelisch $M$. The whe of nitric oxide donors in phanmacological studies. Naunya Schmiedeberg Arch Pharmacol. 358 (1998) 113122

I5 Furita A. Rothstein J.D. and Marti, L. J. Glutamate lramsooter protein sublypes are expressed differentialy during rat CMS dewelopment. J Newrosci. 17 (1997) 8363 . 8375

16 Garry M.G. Richardson J.D. and Hargreaves K.M. Camageenan induced inflammation alters the content of I.CGMP and I.cAvP in the dorsal horn of the spmal cord. Brain Fes $646(1994) 135139$

17 Garthwaite 1. Glutamate, nitric oxicle and cell cell signaling in the nerwous system. Trends Neurose: 14 (1991) 60.67

18 Garthwate J, and Boulton C.L. Nitic oxide signaling in the central nerwous system Amon Rev Physial. $57(1995) 683 \cdot 706$.

19 Getting S.J., Segieth J., Ahmad S., Biggs C.S. and Whiton P.S. Biphasic modulation of GABA ralease by nitric oxide in the hippocampus of freely mowing rats in vivo. Brain Res. 717(1996) 196.199.

20 Harteneck C. Koesing D. Soling A. Schutz G, and Dohne E. Expression of soluble guanylyl cyctase. Catalytic activity requirs two enzyme subunits. FEBS Lett. 272 $(1990) 22 ! \cdot 223$

21. Herbison A.E. Simoman S.X. Norris.P.J. and Emson P.C. Relationship of neuronal mithic oxde symbase mmmonoactivity to GRH neurons in the ovariectomzed and intact female rat. J Neuroendomingl. $8(1996) 73.82$.

2 Hope B.T. Michel G.J. Krigge K.M. and Vincent S. R. Neuronal NACPH diaphorase is a nitic oxide symthase. Proc Nat Acad 50 . 88 (1991) 2811.2814. 
Ichikawa T. Ajiki K., Matsunura J. and Misawa H. Localization of two cholinergic markers, choline acetyltransterase and wesicular acetycholine transporter in the central nervous system of the rat: in situ hybridization histochemistry and immunohistochemistry. J Chem Neuroanat. $13(1997) 2339$ Ignarro L.d. Regulation of cytosolic guanylyl cyclase by porptyrns and metalloporphyrins. Adv Pharmacol. 26 (1994) 35.65. inglis F.M., Furia F., Zuckerman K.E. Stritmatter S.M. and Kalb R.G. The role of nitric oxide and NMDA receptors in the cevelopment of motor neuron dendrites. I Newrosci. 18 (1998) 1049310501 .

Inoue T., Mashimo T., Shibata M.. Shibuta S. and Yoshiya I. Rapid development of mincic oxide induced hyperalgesia depends on an alternate to the cGMP-mediated pathway in the rat neuropathic pairn modiet. Brain Res. 792 (1998) 263270

27 Kalb R.G. and Agostini 3. Malecular evidence for mitric oxide mediated motor neuron development. Neuroscience. 57 (1993) 1.8.

Kanda K. Expression of neuronal nitric oxide synthase in spinal moloneurons in aged rats. Neurosci Lett. $219(1996) 41.44$.

Kurithara $T$, and Yoshioka $K$. The excitatory and infibitory modulation of primary afferent fibre-evoked responses of wentral roots in the neonatal rat spinal cord exerted by nitric oxide. Br J Pharmacot. 118 (1996) 1743.1753.

Laing I., Todd A.J., Heizmann C.W. and Schmidt H.H. Subpopulations of GABAergic neurons in laminae I.III of rat spinal dorsal hom detinedi by coexistence with classical transmutters, peptides, nitric oxide synthase or parvalbumin. Neuroscience. 61 (1994) 123.132.

Liuzzi. F.J. Wu. W. Scoville. S.A. and Schinco. F.P. Development of nitric oxide Synthase expression in the superficial dorsal hom of the rat spinal cond. Exp Neurol. 121 (1993) 275.278 . Malcangio M. and Bowery N.G. GABA and its receptors in the spinal cord. Trends Phamacol Sci. 17(1996) 457.462.

Mantyh C.R., Kruger L., Brecha N.C. and Martyh P.W. Localization of specific binding sites for atrial natriuretic factor in the centrall nervous system of rat. Gunea pig. cat and human. Erain Res. 412 (1987) 329.342. 
Markerinthan Hersum M. Steinbusch H.W.M. and De Wente J. Region-specific developmental pattems of atrial natriuretic factor and nitric oxide activated guanyly cyclases in the postnatal trontal rat bran Neuroscience. 78 (1997) 571.587 . Moris R., Southam E. Gittins S.R., de Vente J. and Garthwaite J. The NOCGMP pathwaly in meonatat rat dorsal horn. Eur I Neurosci. 6 (1994) 876.879. Murad F. Regulation of cytosolic guanyly cyclase by nitric oxide: the No-cyclic GMP signal transduction system. Adv Pharmacol. 26 (1994) 19.33. Murad F., Mteal C.K., Arnoid W.P. Katsuki S. and Kimura H. Guarylate cyclase: activation by azide, nitro compounds, nitric oxide, and hydroxys radical and inhibition by hemoglobin and myoglobin. Adv Cyclic Nucleotide Res. 9 (1978) 145. 158.

38 Quirian R., Dalpe M. De Lean A., Gutkowska J. Cantin M. and Genest J., Atrial natriuretic factor (ANF) binding sites in brain and related structures. Peptides. 5 (1984) 1167.1172 .

39 Robello M., Amico C., Bucossi G. Cupello A., Rapalino M.V. and Thellung S. Nitric oxide and GABAA receptor function in the rat cerebral cortex and cerebeliar granule cells. Neuroscience. 74 (1996) 99.105.

40 Saito S., Kidd G.J., Trapp B.D., Dawson T.M., Bredi D.S., Wilson D.A., Traystman R.J., Snycer S.H. and Hanley D.F. Rat spinal cord neurons contain nitric oxide synthase. Neuroscience. 59 (1994) 4.7.456.

41 Salter M., Stribos P.J., Neale S., Duffy C., Follentant R.L. and Gartimwaite J. The nitric oxide cyclic GMP pathway is required for nociceptive signalling at specific loci within the somatosensory pathway. Newroscience. 73 (1996) 649.655.

42 Saper C.B., Hurley K.M., Moga M.M., Holmes H.R., Adams S.A. Leahy K.M. and Nedleman P. Brain matruretic peptides: differential localization of a new family of neuropeptides. Neurosci Lett. 96 (1989) $29 \cdot 34$.

43 Schmdt H.H. NO. CO and. OH. Endogenous soluble guanylyl cyclase activating factors. FEBS Lett. $307(1992) 102107$.

44. Schnridt H.H., Gagne G.D., Nakane M., Pollock I.S. Miller M.F. and Murad F. Mapping of neurat nitric oxide symthase in the rat suggests frequent collocalization with NACPH diaphorase but not with soluble guarylyl cyctase, and novel paraneural functions for mitrinergic signal transduction. J Histochem Cytochem. 40 (1992) $1439 \cdot 1456$ 
Semba J., Sakai M. Miyoshi R. and Kito S. NG-monomethyl-Largmine, an inhibitor of nitric oxide symthase, increases extracelluar GABA in the striatum of the freely moving rat. Neuroreport. 6 (1995) 1426-1428.

46 Shibuki $K$. and Okada D. Endogenous nitric oxide release required for long tem synaptic depression in the cerebellum. Nature. 349 (1991) 326.328 .

47 Shuttleworth C.W. Xue C., Ward S.M., de Vente J. and Sanders K.M. Immunohistochemical localization of $3^{\prime \prime}, 5^{\prime}$ cyclic guanosine monophosphate in the canine proximal colon: responses to nitric oxide and electrical stimulation of enteric inhibitory neurons. Neuroscience. 56 (1993) 513.522.

48 Siegan J.B., Hama $A . T$, and Sagen d. Alterations in rat spinal cord cGMP by peripheral nerve injury and adrenal madullary transplantation. Neurosci Let. 21.5 (1996) 49-52.

49 Simonnet G. Allard M., Legendre P., Gabrion J. and Vincent J.D. Characteristics and specific localization of receptors for atrial natriuretic peptides at monneuronal cells in cultured mouse spinal cord cells. Neuroscience. 29 (1989) 189-199.

50 Sorg D., Horn T.F., Yu N., Gruol D.L. and Bloom F.E. Inhibition of astrocyte glutamate uptake by reactive oxygen species: role of antioxidant enzymes. Mal Med. $3(1997) 431.440$.

51 Southam E. and Garthwaite J. Comparative effects of some mitric oxide donors on cyclic GMP levels in rat cerebellar slices. Neurosci Lett. 130 (1991) 107.111.

52 Southam E. and Garthwaite J. The nitric oxide cyclic GMP signaling pathway in rat brain. Neuropharmacalogy. 32 (1993) 1267.1277.

53 Soyguder Z., Schmidt H.H. and Morris R., Postnatal development of nitric oxide synthase type 1 expression in the lumbar spinal cord of the rat: a comparison with the induction of $c$ fos in response to peripheral application of mustard on. Neurosici Lett. $180(1994) 188 \cdot 192$

54 Spike R.C., Todd A.J. and Johnston H.M. Coexistence of PADPH diaphorase with GABA, glycine and acetylcholine in rat spinal cord. J Comp Neurol. 335 (1993) 320 333.

55 Tanaka J., Markerink van Ittersum M., Steinbusch H.W.M. and De Vente J. Nitric axide-mediated cGMP synthesis in ofigodendrocytes in the deweloping rat bran. Glia. $19(1997) 286.297$. 

region (lamina $x$ ) of rat upper thoracic spinal cord. I Neurocytat. 24 (1995) 735 743.

57 Truman J.W. De Vente J. and Ball E.E. Nitric oxide-sensive guanylate cyclase activily is associated with the maturational phase of netronal development in insects. Development. $122(1996) 3949 \cdot 3958$.

58 Ueda S. Minamino N. Sudon T. Kangawa K. and Matsuo H. Regionai distribution of immunoreactive bran natriuretic peptice in porcine brain and spinal cord. Biochem Biophys Res Commur. 155 (1988) 733739.

59 Vattschanaff I.G. Weinberg R.J. Rustioni A and Schmidt H. Hit. Nitric oxide synthase and GABA colocalize in lamina II of rat spinal cond. Meurosci Lett. 148 (1992) 6. 10.

60 Vincent S.tx and Kimura H. Histochemical mapping of nitric oxide synthase in the rat brain. Neuroscience. $46(1992)>755.784$

61 Vizzard M.A., Erdman S.L. Forstemann U. and de Groat W.C. Ontogeny of nitric axide synthase in the lumbosacral spinal cord of the neonatal rat. Brain Res Dev Erain Res. 81 (1994) 201217.

62 Vizzard M.A. and Erickson K. Locatization of NADPH diaphorase in the thoracolumbar and sacrococcygeal spinai cond of the dog. J Auton Nerv Syst. 64 (1997) $128 \cdot 142$

63 Wedel B.J. and Garbers D.L. New insights on the functions of the guanylyl cyclase receptors. FEBS Lett. $410(1997) 29.33$.

64 Wetts R. Pheips P.E. and Waughn J.E. Transient ard continucus expression of NADPH diaphorase in different neuronal populations of developing rat spinal cord. Dev Dym. $202(1995) 215228$.

65 Wu S.Y. Dun S.L. Forstermann U. and Dun N.J. Nitric oxide and excitatory postsynaptic currents in mmature rat sympathetic preganglionic neurons in vitro. Neurascience. 79 (1997) $237 \cdot 245$

66. Wh W and Li L Inhbition of nitric oxide synthase reduces motoneuron death due to spinal root avusion. Neurosci Lett. $153(1993) 121-124$.

67 Young H.M. McConalogie $K$. Funess J.B. and De Vente N. Nitric oxide targets in the guineapig intestine identified by induction of cyclic GMP inmunoreactivity. Newroseience. 55 (1993) $583-596$. 
68 Zamir N., Skofitsch G. Eshay R.L. and Jacobowitz D.M. Distribution of immunoreactive atrial natruretic peptides in the central nenous system of the rat. Brain Res. 365 (1986) $105-111$. 





\section{Abstract}

We investigated developmental apoptosis in the white matter of the neonatal rat cervical spinal cord at postnatal day 2, 5, and 8. Apoptotic cells were labeled using TUNEL and caspase-3 immunostaining. Apoptotic cells were diffusely distributed throughout the white matter of the spinal cord. The total amount of apoptotic cells in the cervical spinal cord white matter was related to postnatal age, with the lowest at P2 (mean 7.9, SD 5.6) and the highest at P8 (mean 109, SD 21.4). Using double immunostaining for $\mathrm{ED} \cdot 1$ and 04 , apoptotic cells were identified as microglia and oligodendrocytes. 
Ceal death during normal development has been described in nearly all neuronal cell types in the central newous system (CNS) and peripheral nervous system (PNS) as well as in the cerebral gray and white matter [8.11]. In contrast to a large number of studies in brain tissue, only few studies described ceil death in the spinal cord. The main focus of these studies was cell death through apoptosis or necrosis of motoneurons after trauma, infection or ischemia of the spinal cord [6.12]. For developmental cell death, a wave of apoptosis in the gray matter of the embryonic and postnatal spinal cord of the rat has been reported [4. 13]. A distribution of apoptotic cells was found from a ventral to a dorsal extension, with a high total number of cells in the ventral horn at embryonic day 16 and high counts in the dorsal horn postnatally. No developmental apoptosis has been described in the white matter of the spinal cord of normal rats $[4,7]$.

The present study demonstrates apoptosis in the white matter of the developing spinal cord of normal postnatal rats. This abservation was made coincidentally in a project studying the effects of perinatal asphyxia on the developing spinal cord in rats.

Wistar rats were used to investigate developmental apoptosis in the spinal cord. The rats were anaesthetized and sacrificed by transcardial perfusion fixation with $4 \%$ paraformaldehyde at postnatal day 2 (P2), 5 (P5) and 8 (P8). For the labeling of apoptotic cells we used a madified TdT.mediated dUTP-biotin nick end. labeling (TUNEL) technique in which we used methacarn (methanal : chloroform : acetic acid $=66.33 \mathrm{l})$ in stead of proteinase $K[2]$. TUNEL positive cells were counted in 6 successive cervical spinal cord sections per rat at level C3.CA.

TUNEL - positive cells were detected in the spinal cord white matter (figure 1). These cells were distributed diffusely throughout the whole white matter (both cervical and lumbar), with no obvious preference for a subscribed region. The total amount of apoptotic cells in the cervical spinal cord white matter differed with age, being the iowest at P2 (mean 7.9, SD 5.6), median at P5 (mean 76.2, SD 41.3) and the highest at P8 (mean 109, SD 21.4). 
To confirm apoptosis, we investigated co-localization between TUNEL and activated caspase-3 (BD Blosciences. Europe), and detected conlocalization of TUNEL and caspase.3 (figure 2a, 2b) in nearly all TUNEL stained cells. With concern to gray matter apoptosis our findings are in agreement with the findings of Lawson et al. However, in contrast to Lawson et al, we also observed apoptosis in the white matter [4].

To identify the type of cells which were TUNEL positive, different (immuno.) cytochemical markers were used. Negative controls were performed by omitting the primary antibody. No co-localization was seen using neuron specific enolase (NSE) as a marker for neurons, or glial fibrillary acidic protein (GFAP) as a marker for astrocytes. The observations of the lack of co-localization between TUNEL and GFAP are in accordance with the findings of Lawson et al. [4]. Similarly, using vimentin, a marker for immature astrocytes, no collocalization with TUNEL was observed.

Colocalization was observed between TUNEL and EDI (figure $2 \mathrm{~g}, 2 \mathrm{~h}, 2 \mathrm{i}$ ), a specific marker for reactive microglia or macrophages, in both the white and gray matter of the cervical and lumbar spinal cord. Approximately 5\% of ED1 positive cells were also TUNEL positive, while $18 \%$ of TUNEL positive cells could be identified as microglia or macrophages.

TUNEL positive cells could also be identified as immature oligodendrocytes in both the white and gray matter, using the specific marker 04 (Chemicon international, Temacula) (figure $2 \mathrm{c}, 2 \mathrm{~d}, 2 \mathrm{e}, 2 \mathrm{f}$ ) [9]. With the use of methacarm (methanol) in the TUNEL technique, 04 immunoreactivity coujid still be observed. Co.localization with 04 could be detected in $32 \%$ of TUNEL positive cells. This most probably is an underestimation due to the influence of methanal on 04 immunoreactivity.

To our knowledge no studies hawe reported developmental apoptosis in the spinal cord white matter. One study describing myelination patterns in the anterior funiculus of the lumbar spinal cord of newborn rats reported electron dense material in immature oligodendrocytes [14]. Howewer, these features were 
attributed to phagocytosis and not to apoptotic cell death. More recently, apoptosis in the spinal cord white matter has been described in genetically altered mice or myelin-deficient rats $[3,12]$. These models are not fully representing the normal developmental process in the spinal cord. In addition, apcptotic features in oligodendrocyles in the white matter have been described after trauma, ischemia or radiation $[1,6,10]$. In these studies cell death was induced in adult rats, again a process not representative for nomal developmental apoptosis.
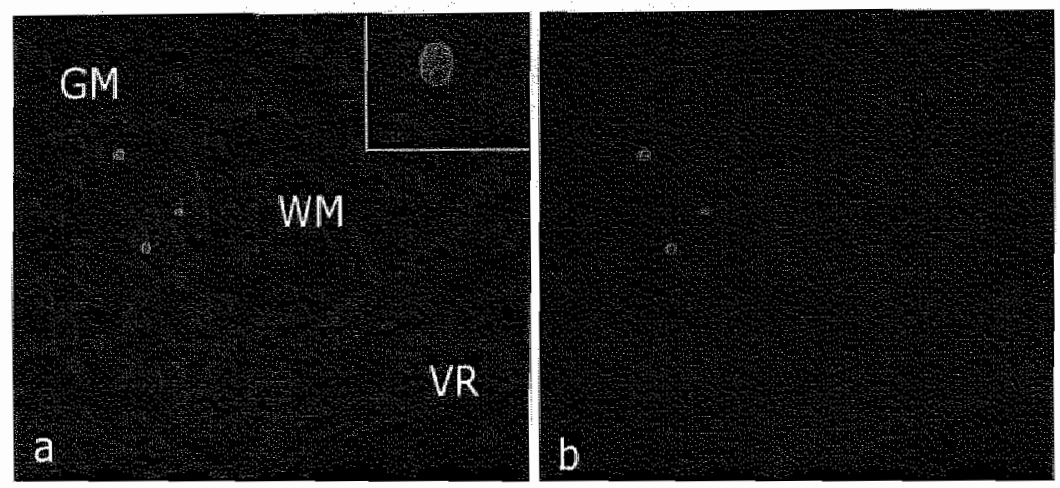

Figure 1.

(a) Localization of TUNEL positwe (red) cells in lithe cervical spinall cord white matter at post inatal day 5 of a normal rat (blue; Hoechst. Sigmay. These inages were taken using an olympus Ax70 microscope

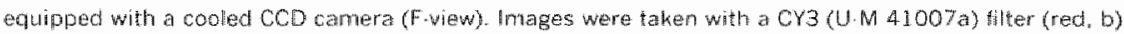
Ior TUNEL processed sections and with a DR (U M 6 looo) fitter for the Hoechst staining. Using the Hmage Amalysis Systen (SISH. gray scated mages were drecthy converted into artificial colors. This representatue low power michophotograph dearly macates TUNEL positive cells within the white matter. Due to the low magnification. the typical combination of red and blue only appears very

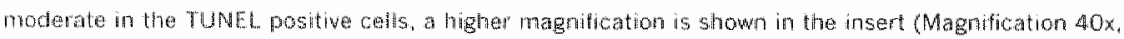

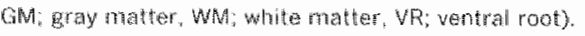



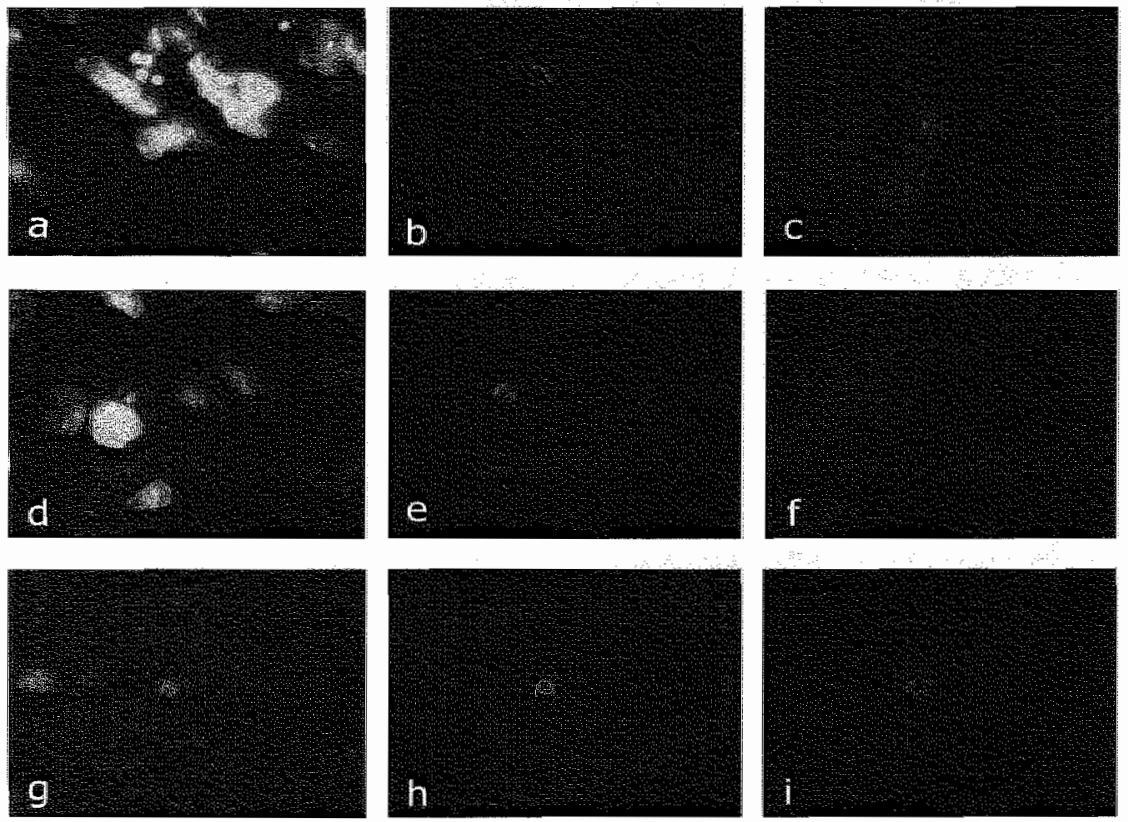

Figure 2 ,

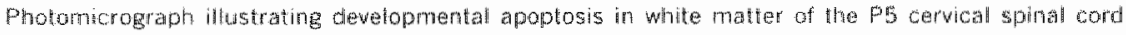
(roagnifution 100x for all images). The cells shown in (a), (di) and (g) all show the ofharacteristic nuslear fragmentation observed during apoptosis (Hoerthst, Sigma, blua). (a) TUNEL positive coll double labeled for the apoptotic marker caspese 3 (red, b).

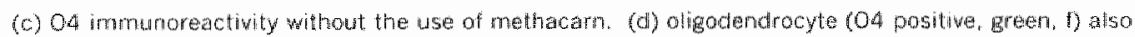
staming positively for TUNEL (red e), (g) an EDI positive microglia/matrophage (green, D) dowble labeling for TUNEL (red, h). The images were taken using an Olymplis AX70 rmicroscope equipped wilth Sony color cro power HAO 
Not all the TUNEL positive cells could be identified in our study. The remaining cels most probably are astrocytes, although no co-localization between TUNEL and GFAP, or vimentin was detected. Identifying fillamentary proteins during development of neural tissue camnot always be done because of difference of developmental profile of the various markers. This may be the case in this study with both vimentin and GFAP.

Future studies will focus upon the functional relationship between (inter-) neurat and oligodendrocyte apoptosis, as our findings imply a role for apoptosis in the spinal cord white matter in the development of normal locomotor behavior and possibly of locomotor abnormalities (e.g. spasticity) after perinatal asphyxia [3]. 


\section{References}

1 Farn R. and Mollet T. Fapid ischemic cell death in mmature atigodendrocytes: a fatal glutamate release feedback toop. INeurosci. 20 (2000) 34-42.

2 Gavrieli Y. Sherman Y. and Ben-Sasson S.A. Identitication of programmed cell death in situ via specific labeling of nuclear DNA fragmentation. I Cell Biol, 119 (1992) 493.501.

Harrison A. Spastic cerebral palsy: Possible spinall interneural contributions. Dev Med Child Neurol. $30(1989) 769.780$.

Lawson S.J., Davies H.J., Bennett J.P, and Lowrie M.B. Evidence that spinal

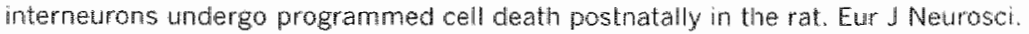
$9(1997) 794.799$.

Lipsitz D., Goetz B.D. and Duncan I.D. Apoptotic glal cell death and kinetics in the spinal cord of the myelin deficient rat. I Neurosei Res. 51 (1998) 497.507.

Liu X.Z., Xu X.M. Hu R., Du C., Zhang S.X., MeDonald J.W. Dong H.X.,Wu Y.J., Fan G.S., Jacquin M.F. Hsu C.Y. and Choi D.W. Neuronal and glial apoplosis after traumatic spinal cord injury. I Neurosci. 17 (1997) 5395.5406.

Lowrie M.E. and Lawson S.J. Cell death of spinal interneurones. Prog Neurobiol. 61 (2000) 543.555

Oppenhem R.W. Celf death during development of the nervous system. Annu Rev Neurasci. $14(1991) 453.501$.

9 Sakurai M. Hayashi T. Abe K., Sadahiro M. and Tabayashi K. Deiayed and sellective motor newron death after transient spinal cond ischemia: a rola of apoptosis? J Thorac Cardiovase Surg. $115(1998)$ 1310-1315.

10 Sasaki R. Matsumoto A. Itoh K. Kawabe T. Ota K. Vamada K.. Maruta T., Soejima T. and Sugimura $K$. Target cells of apoptosis in the adult murine dentate gyrus and 04 immunoreactivity atter bonzing radiation. Neurosci Lett. $279(2000) 57.60$.

11 Spreafica R., Frassoni C., Arcelli P., Selvaggio M. and De Biasi S. In situ labeling of apoptotic cell death in the cerebral comex and thalamus of rats during dewelopment. JComp Neurol 363 (1995) 281.295.

12 Vela I.M. Dalmau I. Gonzalez B. and Castellan B. The miorogliat reaction in spinal cords of fimpy mice is related ta apoptotic oligodendrocytes. Brain Res. 712 (1996) 134. 142. 
13 Yamamoto Y. and Henderson C.E. Patterns of programmed cell death in populations of developing spinal motoneurons in chicken, mouse, and rat. Dev Biol. 21.4 (1999) 60.71 .

14. Voshioka T. Inomata K. Sugioka $K$ and Nakamura $K$. Ultrastructural study on myelination in rat spinal cord during the early postnatal stage. Brain Dev. 2 (1980) 337.343. 



\section{Abstract}

The aim of our study was to investigate the effect of perinatal asphyxia on developmental apoptosis in the cervical and lumbar spinal cord in the neonatal rat. Perinatal asphyxia was induced by keeping pups at term in utero after hysterectomy in a water bath at $37^{\circ} \mathrm{C}$ for $20 \mathrm{~min}$, followed by resuscitation. Effects of this treatment on developmental apoptosis were studied at postnatal day 2.5 and 8 using TUNEL and caspase-3 staining. TUNEL positive cells were identified using double immunostaining.

On postnatal day 2 an increase of $215 \%$ in TUNEL positive cells was detected $(P=0.005)$ in laminae IV.VII of the lumbar spinal cord of rats which underwent perinatal asphyxia compared to controls. An increase of $55 \%$ compared to controls $(\mathrm{P}=0.03)$ was seen in laminae $\|\cdot\| \|$ of the lumbar spinal cord at postnatal day 8. TUNEL positive cells could be partly identified as microglia cells (EDI positive) and olligodendrocytes (04 positive).

The effect of perinatal asphyxila on programmed cell death in the neonatal rat spinall cord was mainly obserwed in the intermediate zone and dorsal horn of the lumbar spimal cord.

It is concluded that perinatal asphyxia has a pronounced effect on the survival of cells in a specific region of the spinal cord and thus may have a profound effect on the development of motor networks. 


\section{Introduction}

Perinatal asphyxia leading to cerebral palsy is the most common cause of mortality and morbidity in chitdhood, with a prevalence of 1.5 to 2.5 per 1000 live births [18]. Although cerebral palsy is not due to birth injury alone, between 8 and 20 percent of children with cerebral palsy suffered some degree of asphyxia during birth [28, 30].

In the first description of cerebral palsy by Little in 1861, the assumption was made that chronic spasticity after asphyxia is referred to lesions in the spinal card [21]. In a more recent study, histological evidence of hypoxic-ischemic imjury of the spinal cord gray matter was present after neuropatholgical examination of asphyxiated neonates [3].

Perinatal asphyxia can lead to mental retardation, epilepsy and motor abnormalities such as spasticity [13]. Seizures and mental retardation are obvious clinical signs of an impaired cerebral function. However, the locomotor abnormalities of cerebral paisy may not be solely derived from cerebral dysfunction but could also partly be caused by dysfunction of the spinal cord neurall network. Spasticity, a velocity dependent increase in tonic stretch reflexes, is a common locomotor abnormality after perinatal asphyxia [19].

The pathophysiological mechanisms in spasticity are not completely understood. Yet, in spastic cerebral palsy, evidence for hyperexcitability of spinal alpha motor neurons due to abnormal supraspinal inhibition or abnomal segmental control of spinal motor neuron output exists [9.15, 34]. An emphasis on spinal inter-neuron damage has been made by Harrison as a possible cause of local spinal disorganisation and spasticity [15].

In recent studies by Lawson and Lowrie developmental programmed celi death of spinal interneurons in the rat has been described [20, 24]. A wave of apoptosis in the grey matter of the lumber spinal cord in late embryonic and early postnatal rats was observed. By means of immunocytochemilcal labelling for heuronal markers and the anatomical distribution of apoptotic cells, they 
concluded that most apoptotic cells were intermeurons and not motoneurons. astrocytes or oligodendrocytes.

Although neural networks within the spinal cord are involved in the development of normal and abnormal locomotion no studies have been done addressing the influence of perinatal asphyxia on (programmed) cell death in the spinal cord.

The am of our study was to irvestigate the effect of perinatal asphyxia on developmental apoptosis in the cervical and lumbar spinal cord in the neonatal rat.

\section{Experimental Procedures}

Inducing asphyxita

Severe perinatal asphyxia was induced as described in detail by Loidl et al., using time pregnant Wistar rats at the last day of gestation [23].

Rats were bred by Charles.Riwer company and housed at the University Maastricht facility for experimental animals. Water and food were given ad libitum. All experiments were approved by the committee on animal welfare according to Dutch governmental regulations and all efforts were made to minimize the number of rats used and their suffering.

The rats were decaptated and hysterectomized after their first pup was allowed to be delivered vaginally (control, CVD). Both the uterus horns wete placed in a water bath at $37^{\circ} \mathrm{C}$ for 20 minutes (severe perinatal asphyxia, SPA). After 20 minutes the uterus horns were opened, the pups removed, resuscitated and allowed to recover in an incubator at $37^{\circ} \mathrm{C}$. The pups were placed with a surrogate mother and sacrificed at either postnatal day 2 (PN2), 5 (PN5) or 8 (PN8). The overall mortality rate after 20 minutes of severe perinatal asphyxia was approximately 40 percent and similar to previously reported moriality rates using the above described model for inducing perinatal asphyxil [23]. 


\section{Tissue preparation}

The rat pups were anaesthesized by an intra peritoneal injection of sodium pentobarbital (Sanofi, $60 \mathrm{mg} / \mathrm{kg}$ ) and transcardially perfused with a flush of Tyrode solution ( $\mathrm{pH} 7.4,37 \mathrm{C}$ ) followed by $4 \%$ paratormaldehyde, in $0.1 \mathrm{M}$ phosphate buffer $\left(\mathrm{pH} 7.4,37^{\circ} \mathrm{C}\right)$. The total spinal cord was dissected and post-fixed in $4 \%$ paratormatdehyde in $0.1 \mathrm{M}$ phosphate buffer $(\mathrm{pH} 7.4)$ overnight. The spinal cord was cut into parts of two segments, and embedded in warm $10 \%$ gelatin in $0.1 \mathrm{M}$ phosphate buffer.

The gelatin cups were kept on ice for 1 hour, and fixed in $4 \%$ paraformaldehyde in $0.1 \mathrm{M}$ Phosphate buffer for 2 hours. The gelatin blocks containing the spinal segments were cryoprotected in $15 \%$ sucrose in Tris.buffered saline (TBS, pH 7.4) overnight at $4^{\circ} \mathrm{C}$, and frozen in liquid-nitrogen cooled 2.methylbutane.

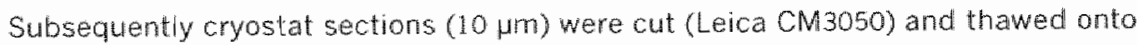
chrome-alum/gelatin coated slides, stored at $80^{\circ} \mathrm{C}$ and processed for immunocytochemistry.

\section{Inmunocytochemistry and histochemistry}

Cervical and lumbar segments of the spinal cord slices were used for the various staining techniques. Three methods were used to study the presence of apaptotic nuclei. First presence of apoptotic nuclei was studied using a chemical hematoxylin and eosin (HE) staining. Secondly, a modified terminal deoxynucleoticlyl transferase mediated biotinylated-14nduTP nick end labelling (TUNEL) technique was used and thirdly a caspase-3/TUNEL dowble staining was performed using an antibody against activated caspase-3 (BD Biosciences, Europe). TUNEL technique was performed according to Gavrieli [12].

Slides were washed in TBS $3 \times 5$ min. thereafter permeabilisation of the tissue was done with methacarn (methanol : chloroform : acetic acid $=66: 33: 1 \mathrm{v} / \mathrm{w} / \mathrm{w}$ ) during 10 min and a final wash in TBS during 10 min. Slides were incubated in a humidified box at $37^{\circ} \mathrm{C}$ for 90 min using 20 fl reaction solution per slide consisting of: $0.4 \mu$ terminal deoxynucleotidyl transferase $(0.5 \mathrm{U} / \mu \mathrm{l}) ; 2 \mu \mathrm{ll}$ cobalt chioride $(2.5$ 
mM); $4 \mu$ TdT reaction buffer; $0.8 \mu$ biotine EUTP (2 nM); $12,8 \mu$ MilliQ. Roche. Germany). To stop the incubation, slides were washed with SSC for $4 \times 5$ min and TBS for $2 \times 5$ min. Slides were incubated with streptavidine Cy3 (1:2000, Jackson ImmunoResearch Laboratoties InC) in TBS containing 0.3\% Triton X-100 (TBS.T) and thereafter washed with TBS for $2 \times 5$ min, after which slides were incubated with Hoechst (1:500, Sigma) in TBS.T. The procedure was finished by washing with TBS for 10 min and enclosure with TBS:glycerol (1:3).

\section{Double staming}

In order to characterize the TUNEL positive cells a number of double(immuno) stainings were performed. To identify astrocytes we used an antibody to monoclonal anti-glial fibrillary acidic protein (anti-GFAP) (1:1600, Sigma) and mouse anti-vimentin antiserum (undiluted) (Zymed, San Francisco, California, USA). Neurons were identified with a palyclonal antiserum against neuron specific enolase (NSE antiserum)(undilluted, Immunotech, Marseille, France) and a mouse monoclonal anti-neuronal nuclei (NeuN) antibody (1:50, Chemicon international. Temacula). For identification of activated microglia we used an anti ED 1 antibody (1:5, gift from J. Damoiseaux, University Maastricht. The Netherlands). Oligodendrocytes were detected with a monoclonall antiserum against $2 ., 3^{\prime}$-cyclic nucleotide phosphodiesteras (anti.CNPase) (1:4000, Sigma) and anti 04 antiserum (1:50, Chemicon International, Temacula). Negative controls were performed by omitting the primary antibody. After counting TUNEL posiluve cells, glass covers of the slides were remowed and the slides were washed with TBS $3 \times 5$ min. After application of the primary antibodies as describec above, slides were kept overnight at $4^{\circ} \mathrm{C}$. After repeated washes with TBS and TBS.T, the approprated secondary antibodies were added and enclosure with TBS:glycerol (1.3) was done.

Part of the apoptotic cells in the spinal cond gray matter could be inhibitory intemeurons, i.e. GABAergic cells. We tried to demonstrate apoptosis in GABAergic cells by combining TUNEL with markers for GABAergic cells using rabbit antibody to glutamic acid decarboxyase $\left(G_{A D} D_{656}\right)(1: 200$, Biotrend), sheep anti parvalbumin 
antiserum (1:1500) and arti-cabindin antiserum (1:2000, gifts of Dr. P.C. Emson).

Analysis

TUNEL positive cells were counted in 6 consecutive sections of the cervical and lumbar intumescence of each rat at PN2, PN5 and PN8. Counting was done by two investigators (AdL and HPS), blinded for the experimental groups. Inter observer wariation between the two investigators using the Pearson correlation test was 0.755 and significant at the 0.01 levell.

In counting cells in the spinall cord, a distinction was made between the number of TUNEL positive cells in the cervical gray and white matter. In the lumbar region, counting was only performed in the gray matter as the small size of the white matter at the investigated ages prevented reliable counting in this region. Counting was done separately in the dorsall horn (Rexed's laminae 1.11 ), the intermediate zone (Rexed's laminae IV-VII), the ventral hom (Rexed's lamirae VIII and $X$ ) and the area surrounding the centrat canal (Rexed's laminae $X$ ) [32]. Mearis and the standard error of mean (SEM) were calculated and statistically analysed Using a one way ANOVA. A p value < 0.05 was taken as a significant difference. Microphotographs were taken using an Olympus A.X.70 microscope. Details on the photagraphy are supplied in the legends of the figures. 


\section{Results}

For both the asphyctic and control group at each age (PN2, PN5 and PN8) at least 5 spinal cords were analysed. Light microscopic analysis of HE stained sections showed no large morphological differences (e.g. lesions) between SPA and CVD at both the cervical and lumbar level. However, many cells displayed features of apoptosis (condensation, shrinkage and fragmentation) in spinal cord sections of both asphyctic and control rats in all age groups (Figure $1 a, 1$ b and 10 ). These cells were diffusely distributed throughout the gray and white matter.

\section{Developmental apoptosis, quartification of TUNEL positive celis}

In the control group we detected developmental apoptosis in both the gray and white matter of the cervical and lumbar spinal cord. In the white matter TUNEL. positive cells were diffusely distributed with no obvious preference for a subscribed region [6]. The results of the counting of TUNEL-positive cells in the gray matter of asphyctic and control rats are summarized in Table 1. In Figure $1 d$, TUNEL-positive cells are shown in the dorsal horn at PN5.

In the cervical dorsal horn (Rexed's laminae 1.111) of control rats a statistically significant increase in apoptotic cells was observed between PN2 and PN5 from 11 $+\% 3$ to $29+\% 5(\mathrm{p}=0.016)$. Also in the lumbar dorsal horn a statistically significant increase was evident between PN2 and PN5 from $15+1-4$ to $47+1.76$ $=0.006)$ and a decrease between PN5 and PN8 to $20+/ .4 .(p=0,003)$. 


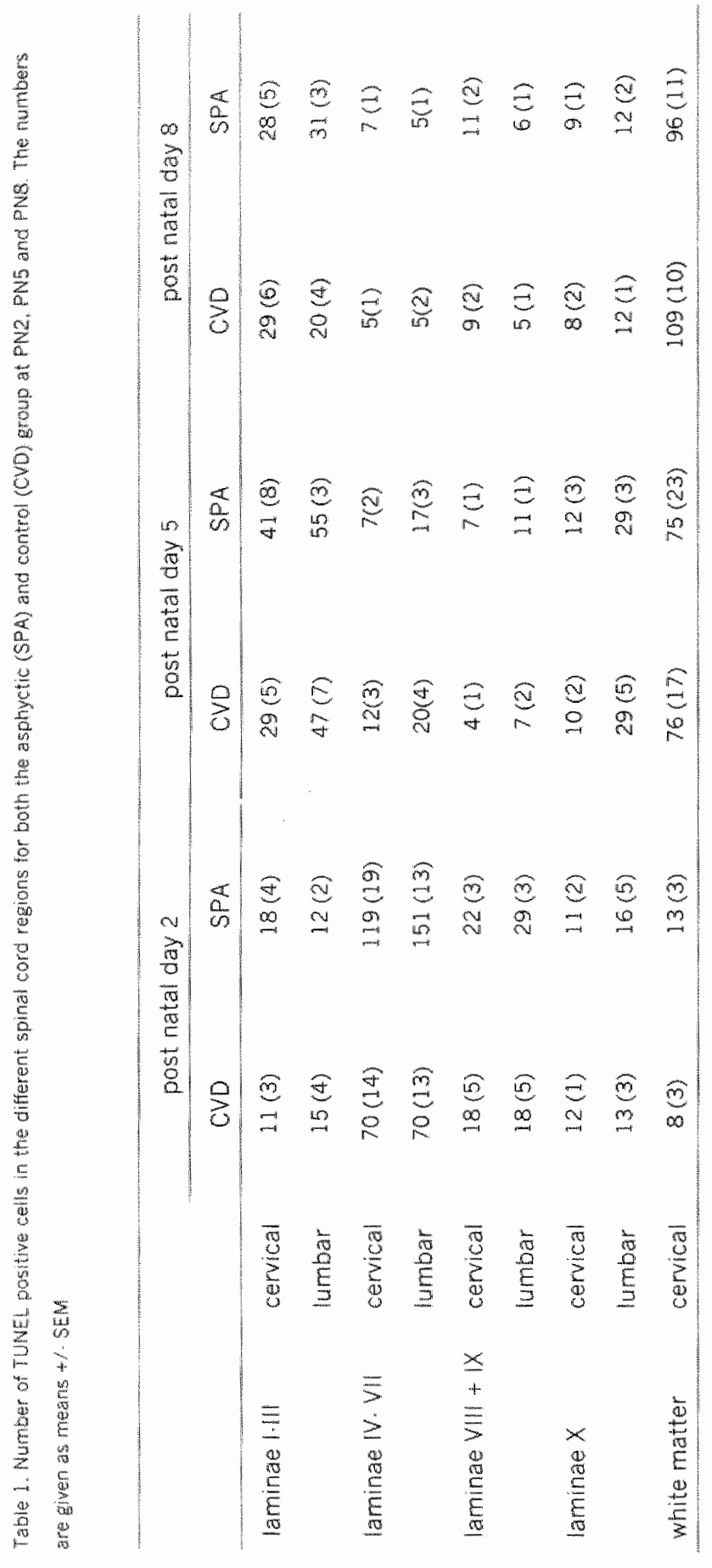



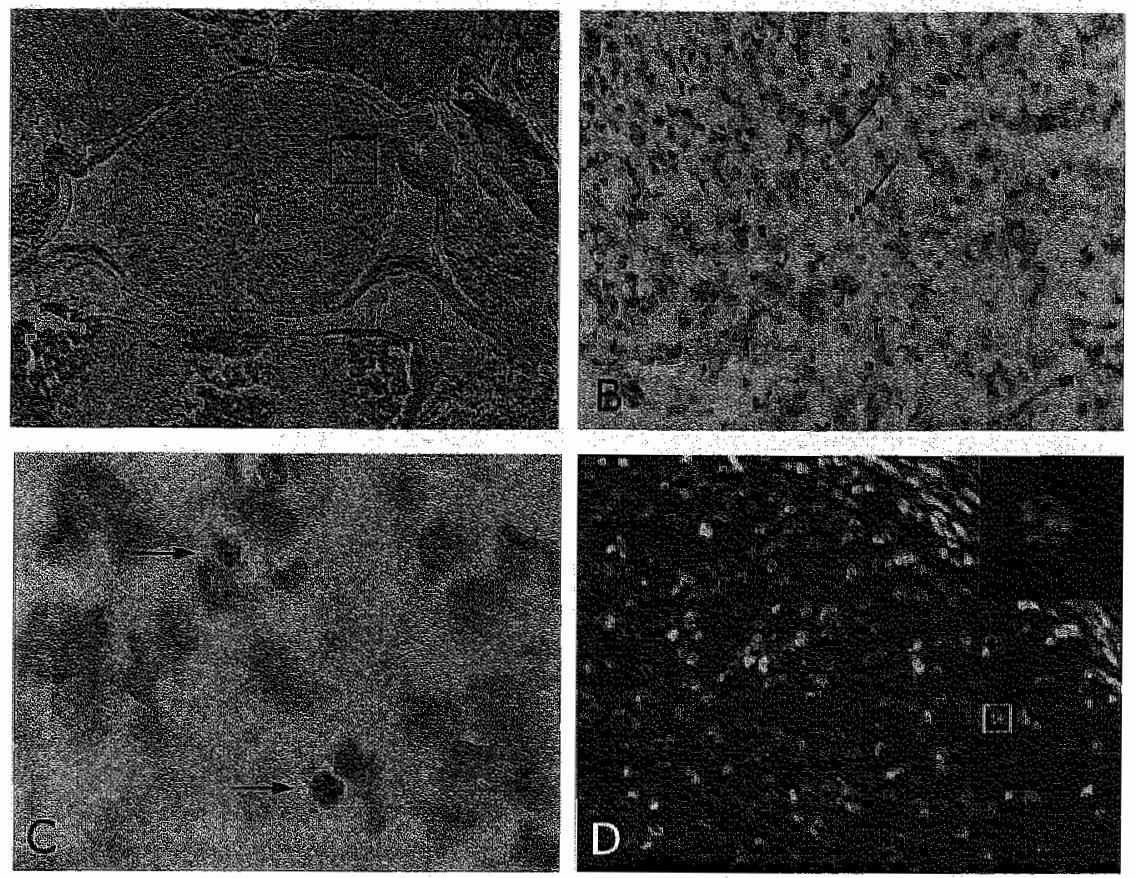

Figure 1. Apoptosis in the normal neonatal rat cerveal spinal cord at PN2. a: HE staining (4x) showing the spinal cord with the corsal loot ganglions. The pegion indicated by the square is shown enlarged in

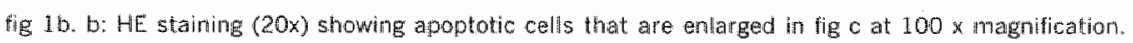
Apoptotic cells (arrows) show muclear fragmertation. d: TUNEL pasitive cells at $20 \times$ magniflcation(red). The area in the white square is shown enlarged at the top right cormer. Image a b and c were made with

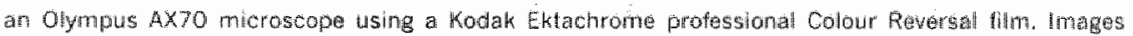

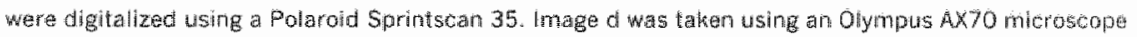
equipped with sony colour CCD power HAD camera. Except for the insert in image d, no digital manipulations were mude.

Pernatal asphyxia

Although the number of TUNEL.positive cells the gray matter areas in the cervical spinal cord of asphyctic rats was generally higher than in the corresponding regions of control rats, the differences were statistically not significant. Moreover, no significant difference in the number of apoptotic cells 
could be detected in the cervical white matter of contral and asphyctic rats.

In the lumbar spinal cord, a statistically significant increase in TUNEL-positive cells was detected from $70+1.13$ (controis) $10151+1.13(p=0.005)$ on PN2 after perinatal asphyxia (Figure 2). This increase in apoptosis by $215 \%$ was only observed in the intermediate zone (Rexed's laminae WWII). On PNB a increase from $20+1 \cdot 3$ (controls) to $31+1.4(p=0.03$ ) was seen in the dorsal horn (Rexed's laminae 1.111) of the lumbar spinal cord of asphyctic rats.
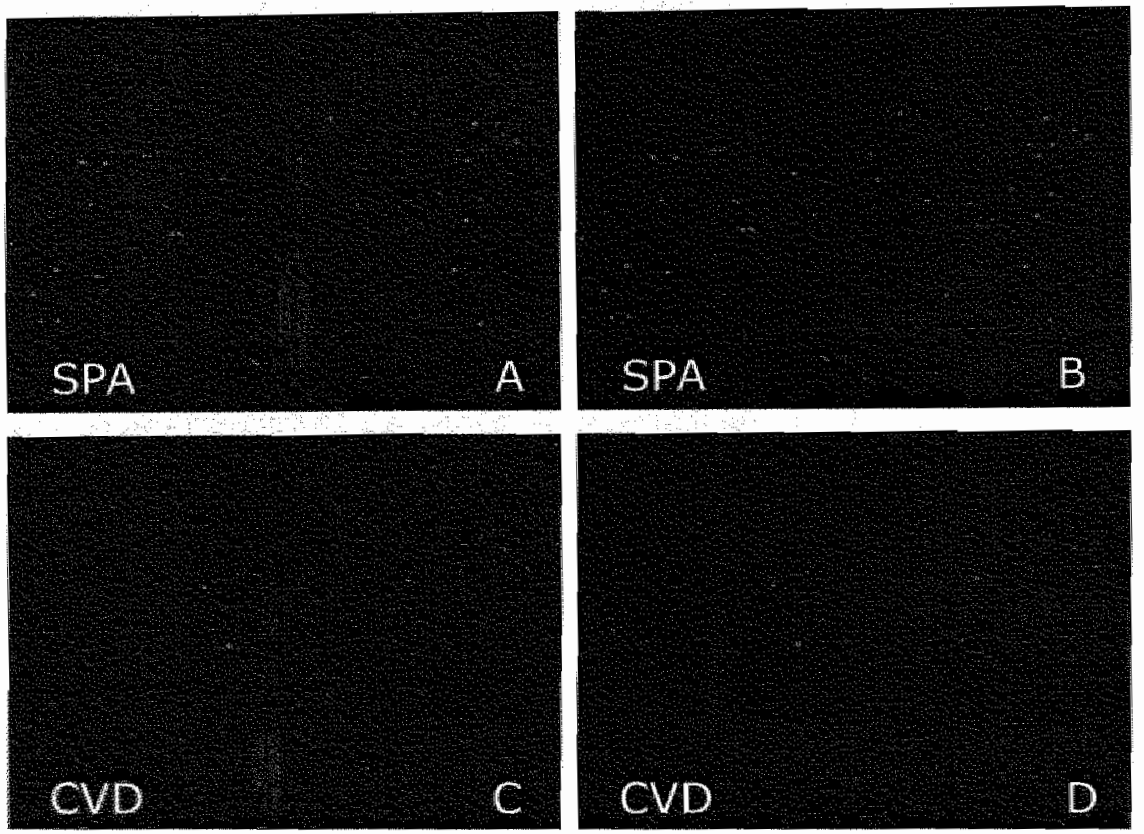

Figute 2. moreased number of TUNEL positive cels after pernatal asphyia. Localization of TUNEL

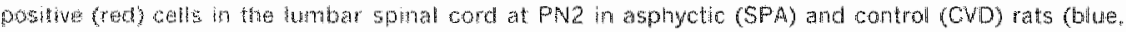

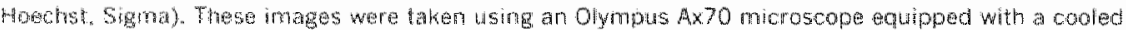

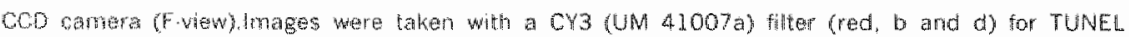
processed gatichs and with a DFR (UM 61000) fither for the Hoechs staining (a and o). Using the Image Analys System (S1S). gray scaled mages were direcily converted into artificial colors. In abl images the contrast was digitally enhanced by $50 \%$ to imporove clarity. 
Double staning

We used a double staining technique of TUNEL and activated caspase. 3 immunocytochemistry in order to confirm apoptosis in TUNEL-positive cells. In both asphyctic and contral spinal cord sections the localization of caspase-3 could be detected in nearly all TUNEL.posibive cells. Nevertheless, the intensity of the caspase-3 immunostaining differed considerably between TUNEL positwe cells (Figure 3).

No colocalization of TUNEL-staining was observed using NSE, NeuN or GFAP. Similarly, vimentin (a marker for immature astrocytes) immunostaining showed no co.1ocalization with TUNEL staining in control or asphyctic rats [4].

EDl immunostaining, a specific manker for reactive microglia or macrophages, colocalized with TUNEL-staining to some extent in both the white and gray matter of the cervical and lumbar spinal cord. Based on colocalization, cell morphology and soma size, we identified $18 \%$ of TUNEL-positive cells as microglia or, this population being approximately $5 \%$ of ED1 positive cells.

TUNEL-positive cells could also be identified as immature oligodendrocyles in both the white and gray matter, using the specific marker 04. Collocalization with 04. could be detected in $32 \%$ of TUNEL-positive celis in the contral rats. Double staining in cervical and lumbar sections of both control and asphyctic rats with anti-calbindin, anti. parvalbumin or anti-GAD did not result in localization of these markers in TUNEL-prositive cells.

\section{Discussion}

Several models for cerebral asphyxia have been described in the literature Most of these models are arterial occlusion modes in combination with an hypoxic environment. most probably more representative for local ischemia and not for the asphyxia as we have used in our perinatal asphyxia model [10, 16]. We used a model for perinatal asphyxia described by Loid et al which is a more 
representative model for the clinical stuation of perinatal asphyxia [23]. In this model we studed the influence of perinatal asphyxia on apoptosis in the developing spinat cord.
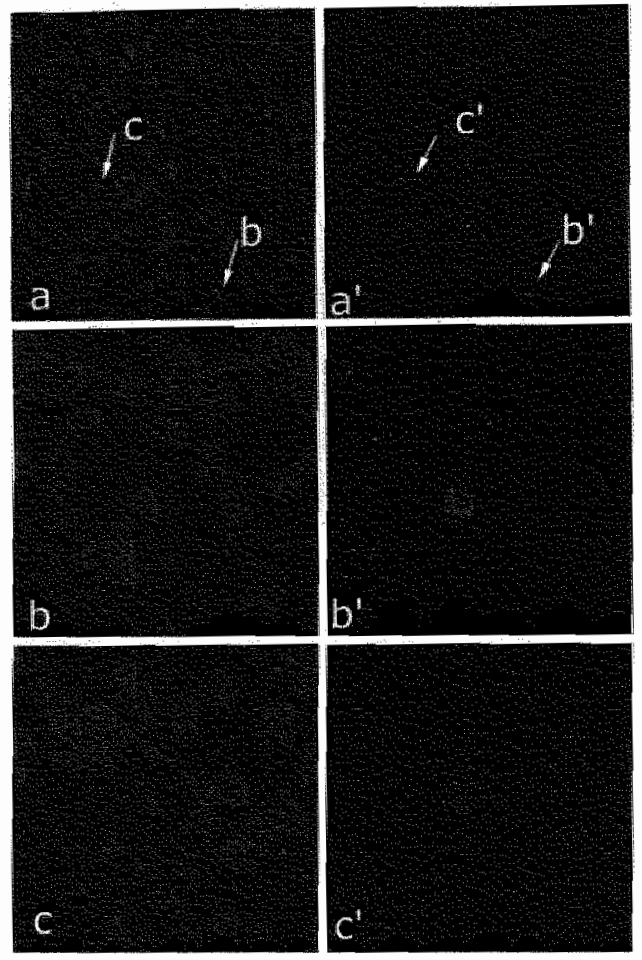

Figure 3. Co.tocatization of TUNEL and caspase. 3 LoCatization of TUNEL positwe cetis in the cervicat

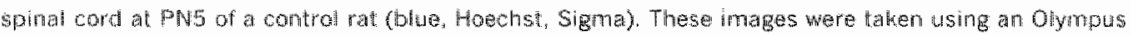
AX70 mocroscope equiped with a cooled CCO camera (F wiew). Images were taken with a CY3 (UM

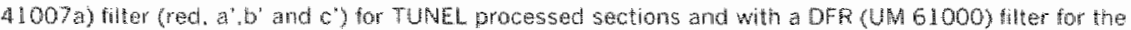
Hoechst staining (a, b and o). Using the Inage Analyis System (SIS), gray scaled inages were directly

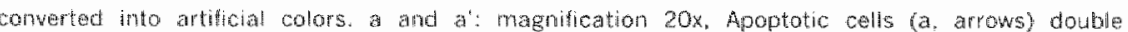
inmunostaned with caspase. 3 (a) arrows). b and comagnification $100 \mathrm{x}$. TUNEL positive cells shown in imase a. Note the difference in caspase 3 immunoneativity from evicent b') fo hardly detectable (c). For reasons of charily the contrast in all images was digitally altered. 
In our study, we showed that perinatal asphyxia increases apoptotic cell death superimposed on normal (developmental) cell death in a specific region within the gray matter of the lumbar spinal cord at a specific stage of development: i.e. at PN2 we observed an increased number of TUNEL. positive cells in the inter. mediate zone (laminae IV.VII).

The findings in our experiment on developmenta apoptosis in the spinal cord gray matter of control rats are well in accordance with the findings of Lowrle and Lawson [24]. In their study, as in ours, no evidence was found for astrocytic apoptosis using GFAP as a marker. Moreover, we could not detect double staining between TUNEL and vimemtin, a marker for immature astrocytes [4, 40].

In addition, we found no evidence for motoneuron related apoptosis, neither during nomal development nor after asphyxia. In the study of Oppenhem [29], no postnatal motoneuron death in the spinal cord of the rat was detected. Nevertheless, it has been well established in different species that motoneurons undergo apoptosis during embryonic development [39]. Other studies have demonstrated postnatal apoptosis of motoneurons after ischemia, infection or trauma $[16,22,25]$. In our study we used NSE and NeuN as neuronal markers. No double labelling between these neuronal markers and TUNEL was observed. This seems surprising compared to the study by Lawson et al. in which post natal apoptosis of neurons in the spinal cord has been described [20]. Howewer, the immunocytochemical techniques used by Lawson were different from the TUNEL technique used in our study. This difference in techniques could account for the differences in the detection of neuronal apoptosis. In addition, although NSE and NeuN are neuron specific markers, this does not imply that all neurons will be stained with these antibodies.

To our knowledge, no detailed rewiews have been published on the comparability of central nerwous system (CNS) maturation at birth between humans and rats. Nevertheless, it is assumed that CNS maturation at PN day 7.9 in the rat is comparable with the CNS development in a full term human neonate $[1,27]$. 
In our model of perinatal asphyxia the hypoxic/ischemic injury was introduced atter an derm pregnancy in the rat, corresponding with a pre-term human neonate.

The clinical effects of preterm neonatal injury in humans have been well described. Prematurity as the only cause of diplegia (spastic paraplegia of the lower extremities) was found to be likely in $41 \%$ of children with cerebral palsy $[5$. 14. 38]. In à term perinatal asphyxia, a quadriplegic cerebral palsy (spastic paralysis of all four extremities) is more likely to occur [41]. Postmortum studies on perinatal hypoxic/ischemic spinal cord injury are rare. In a study by Sladky and Rorke [35], necropsies were performed on 21 asphyxiated human neonates. In this study, six of nine infants with pathological features of spinal cord infarction were premature and lesions were found to be more severe at lumbosacral levels. Moreover, in a study by Takahashi et al[36]. the dendrites of lumbar motoneurons were found to be shorter and less elaborated in rats with a neonatal hypoxic insult than in controls. In their study, no significant difference between hypoxic and control rats was observed in cervical motoneurons. The observed clinical features of spastic diplegia in preterm human neonates corresponds with the findings of increased cell death in the lumbar spinal cord in our model.

We were able to identify a proportion of the apoptotic cells in the spinal cord as activated microglia or macrophages using the specific marker EDl. Apoptotic microglia were diffusely distributed throughout the spinal cord white and gray matter, without an obvious preference for a described region. Using the marker 04. a population of apoptotic cells could be identified as immature oligodencrocytes in the white and gray matter of both the control and the asphyxiated spinal cord $[8,11]$.

The finding of oligodendrocytic apoptosis has been described after radiation and trauma in the aduit spinal cond $[8,22,33]$. Besides our recent findings, oligodendrocytal apoptosis in the developing rat spinal cord has not been reported [6]. Disturbance of the developing myelinisation pattern in the spinal cord could have a profound effect on locomotor abilities. 
Nat all TUNEL positive cells could be characterized in our study. Part of the remaining cells might be astrocytes, although no co-localization between TUNEL and GFAP, or vimentin was detected. ldentifying filamentary proteins during development of neural tissue cannot always be done because of difference of developmental profiles of the various markers [40]. In this study this may be the case with both vimentin and GFAP.

Considering the anatomical localization of the increased number of apoptotic cells in the intermediate zone at PN2 and the dorsal horn at PNB after perinatal asphyxia, the abundant presence of interneurons in these zones and the uncertainties concerning the staining properties of marker antibodies as described above, it can be speculated that part of the apoptotic cells are interneurans $[7,17$ 31]. Spinal interneurons mediate an inhibitory effect upon motorneurons [37]. Unfortunately, all immunocytochemical markers for GABAergic neurons did not co. localize with the TUNEL staining. In a recent study evidence was found for suppression of interneuronal pathways with la afferent input after a disruption of the descending system [2]. After muscle stretch, primary afferent la fibers are excited resulting in a monosynaptic excitatory action on the agonistic muscle. The la afferents also monosynaptically conmect with inhibitory interneurons that project directly to the antagonist motoneuron. In spasticity, this connection is impaired in favour of the excitatory action [26, 34]. Considering this mechanism. our data imply that an increased cell death of lumbar spinal inhibitory interneurans could be contributing to the development of spasticity in preterm perinatal asphyxia. 


\section{References}

Benesova O. Temalowa H. Kristofikowa $Z$. Panalotova $W$ and Husek P. Neuro immumo-teratogenichty of drugs used in neonatal phammeotherapy in relation to the Gntogenic stage at the thme of their adninistration. Gen Physiol Biophys. 18 Spec Mo (1999) $21 \cdot 27$

Chen D. Theiss R.D., Ebersole K. Miller JF. Rymer W.Z. and Heckman C.J., Spinal interneurons that receive input from muscle afferents are differentialy modulated by dorsolateral descending systems. I Neurophysiol. 85 (2001) 10051008.

Clancy R.R. Stadky J.T. and Rorke L.B. Hypoxicischemic spinal cord injury following perinatal asphyxia. Ann Neurol. $25(1989) 185 \cdot 189$.

Dahf D., Rugger D.C., Bignami A., Weber K, and Osborn M. Wimentin. the 57000 molecular weight protein of fibroblast fitament, is the major cytoskelatal component in imnature glia. Eur J Cell Biol. 24 (1981) 191-196.

Dammann 0 . Allred EN. and Veeken N. Uncreased risk of spastio diobegia among very low birth weight chilloren after preterm labor on prelabor rupture of membranes. J Pediattr. 132 (1998) 531.535.

de Loww A.J.A., wan de Berg W.D.J., de Vente J., Blanco C.E., Gavilanes A.W.D., Stembusch H.F.J., Stembusch H.W.M., Troost J. and Vles J.S.H. Dewelopmental apoptosis in the spinal cord white matter in neonatal rats. Glia. 37 (2002) $89-91$

Eide A.L., Glover $\mathfrak{d}$, Kjaerulf 0 , and Kiehn 0 . Characterization of commissural interneurons ir the lumbar region of the neonatal rat spinal cord. I Comp Neurol. $403(1999) 332 \cdot 345$.

Fern $\mathrm{R}$ and Moller T. Rapid ischemic cell death in imnature ollgodendrocytes: a fatial glutamate release feedback loop. J Neurosci. 20 (2000) 34.42

Filloux F.M. Neuropathophysiology of movement disonders in cerebral palsy. I Chill Neurol. 11 Suppl $\downarrow$ (1996) $55 . \$ 12$

Follis F."Scremin O.U., Blisard K.S. Soremin A.M. Petl S.B., Sicoth W.J., Kesster R.M. and Wemly J.A. Selective vunerability of white matter during spinal cord ischemia. J Cereb Blood Flow Metab. 13 (1993) 170 178.

11 Gard A.L. Willants W.C. 2nd and Burrell M.R. Oligodendroblasts distinguished from $0.2 \mathrm{Aglial}$ pirogenitors by surface phenotype $(04+\mathrm{GalC})$ and response to cytokines using sigmal transducer LIFR beta. Dew Bioll. 167 (1995) 596.608. 
Gavrieli Y. Sherman Y, and Ben Sasson S.A. Identification of programmed cell death in situ via specific labeling of nuclear DNA fragmentation. I Cell Biol. 119 (1992) 493.501 .

Hack M. and Fanaroff A.A. Qutcomes of chidren of extremely low birthweight and gestational age in the 1990s. Semin Neonatol. $5(2000) 89.106$.

Hagberg $B$. and Hagberg $G$. The changing panorama of cerebral palsy-bilateral spastic forms in particular. Acta Paediatr Suppl. 416 (1996) 48.52.

Harrison A. Spastic cerebral palsy: Possible spinal interneural contributions. Dev Med Child Neurol. 30 (1989) 769.780.

Hayashi T., Sakurai M., Abe K., Sadahiro M., Tabayashi K. and Itoyama Y. Apoptosis of motor neurons with induction of caspases in the spinal cord after ischemia. Stroke. 29(1998) 1007-1012. Jankowska $E$, and Riddell J.S. Interneurones mediating presynaptic imhibition of group II muscle afferents in the cat spinal cord. J Physiol. 483 (1995) 461.471. Kuban K.C. and Leviton A. Cerebral palsy. N Engl J Med. 330 (1994.) 188.195. Lance J.W. The control of muscle tone, reflexes, and movement: Robert Wartenberg Lecture. Neurology. 30 (1980) 1303.1313.

Lawson S.J., Davies H.J., Bennett J.P. and Lowrie M.B. Evidence that spinal interneurons undergo programmed cell death postnataliy in the rat. Eur $J$ Neurosci. 9 (1997) 794799

Little W.J. On the influence of abnormal parturation, difficult labors, premature birth, and aspliyxia meonatorum, on the mental and physical condition of the child, especially in relation to deformities. Trans Obstet Soc. 3 (1861) 293-3.44. Liu X.Z., Xu X.M., Hu R., Du C., Zhang S.X., McDonatd J.W., Dong H.X., Wu Y.J. Fan Q.S. Jacquin M.F., Hsu C.Y. and Choi D.W. Neuronal and glial apoptosis alter traumatic spinal cord injury. J Neurosci. 17(1997) 5395.5406.

Loid! C.F., Gavitanes A.W., Van Dijk E.H., Wreuls W., Blokland A., Vles J.S.H., Steinbusch H.W.M. and Blanco C.E. Effects of hypothermia and gender on survival and behavion after perinatal asphyxia in rats. Physiol Behav. 68 (2000) 263.269. Lowrie M.B. and Lawson S.J. Cell death of spinal interneurones. Prog Neurobiol. 61 $(2000) 543.555$. Mackey M.E., Wu Y.. HuR., Dekaro J.A., Jacquin M.F. Kanellopoulos G.K. Hsu C.Y. and Kouchoukos N.T. Cell death suggestive of apoptosis after spinal cord ischemia 
in rabbits, Stroke $28(1997) 2012.2017$.

Mayer N.H. Cinicophysiologic concepts of spasticity and motor dystunction in adults whith an upper motoneuron lesion. Muscle therve Suppl. 6(1997) 51.13.

Nakaima W. Ishida A., Lange M.S., Gabrielson K.L., Wilson M.A., Martin L.J., Bue M.E. and Johnston M.Y. Apoptosis has a prolonged role in the neurodegeneration after hypoxic schemia in the newborn rat. J Neurosci. 20 (2000) 7994.8004 . Nelson K. B. and Elenberg J.H. Antecedents of cerebral palsy. Muthariate analysis of risk. W Engl J Med. $315(1986) 81.86$

Oppenhem FW. The absence of significant posthatal motoneuron death in the brachial and lumbar spinal cord of the rat. J Comp Neurol. 246 (1986) 281.286. Pschirre. ER, and Yeomans E.R. Does asphyxia cause cerebral palsy? Semin Perinatol. 24 (2000) 215220.

31 Puskar $Z$. and Antal M. Localization of lastordier premotor interneurons in the lumbar spiral cond of rats. J Comp Neurol. 389 (1997) 377.389. Rexed B., The cytoarchitectonic organizationof the spinat cord in the cat. I Comp Neural. $96(1952) 415.494$

Sasaki R., Matsumoto A., ltoh K., Kawabe T., Ota Y., Yamada K., Marufa T., Soejima T. and Sugimura $K$. Target cells of apoptosis in the adult murime dentate gyrus and O4 immunoreactivity after ionizing radiation. Neurosci Letk. 279 (2000) 57.60. Sheean G. Pathophysiology of spasticity. In G. Sheean (Ed.) Spasticity rehabilitation. Churchill Communications. Europe Ltd, London. 1998, pp. 17.38. Sladky U.T. and Rorke L.B. Perinatal hypoxic/ischemic spinal cord injury. Pediatr Pathol. 6(1986)87.101.

Takahashi S. Tanaka H. and oki J. Development of spinat motoneurons in rats atter a neonatal hypoxic insult. Pediatr Neurol. 21 (1999) 715720

37 Takakusaki K., Kohyama J. Matsuyama Kand Mori S. Medulary reticulospinal tract mediating the generalized notor intribition in cats: paralle inhibitory mechansms acting on motonetrons and on intemeuronal transmission in reflex pathways. Neuroscience, $103(2001) 511.527$.

Weeken N., Hagberg B. Hagberg G. and OHow I. Diptegic cerebral palsy in Swedisth tem and preterm children. Differences in reduced optimality, relations to neurology and pathogenetic factors. Neuropediatrics. 14 (1983) 20.28 . 
39 Yamamoto $Y$, and Henderson C.E. Patterns of programmed cell death in populations of developing spinal motoneurons in chicken, mouse, and rat. Dev Bid. 2.4 (1999) 60.71 .

40 Yoshida M. Intermediate flament proteins define different glial subpopulations J Neurosci Res. 63 (2001) 284.289.

41 Yudkin P.L., Johnson A., Clover L.M. and Murply K.W. Assessing the cantribution of birth asphyxia to cerebral palsy in term singletons. Paediatr Perinat Epidemiol. 9 (1995) 156.170 . 





\section{Abstract}

The neurotransmitter gamma aminobuteric acid (GABA) is thought to have a controlling action on spinal locomotor networks. In spasticity, spinall locomotor networks are thought to play a rolle. A well known drug in the treatment of spasticity is the $\mathrm{GABA}_{\mathrm{B}}$ agonist Baclofen. In a previous study we demonstrated atrial natriuretic peptide (ANP)-mediated cyclic GMP (cGMP) synthesis in GABAergic neurons and fibres in the rat cervical spinal cord. In this study we investigated the effect of Baclofen on the cGMP synthesis in the spinal cord.

An immunocytochemical technique was used to visualize cGMP symthesis in the cervical spinal cord of 2.week old Lewis rats. Spinal cord slices were incubated in Krebs buffer with or without the presence of Baclofen. Slices were further incubated with the nitric oxide (NO) donor sodium nitroprusside (SNP) to activate soluble guanylyl cyclase (sGNC) or ANP to activate particulate guarylyl cyclase (pGNG).

We found an inthibitory effect of Baclofen on the ANF mediated CGMP synthesis in the superficial dorsal horn (laminae I.II) of the rat cervical spinal cord. This inhibitory effect of Baclofen could not be detected after incubation with the NO donor SNP. 
As a neurotransmitter, GABA has an important role in presynaptic inhibition of sensory motor input [2]. It is known that GABA depresses excitatory synaptic transmission in the spinal cord. mainly in the dorsal horn (laminae $|| 1 \mid$. ) and in lesser extend in laminae $\mathrm{V}$. $I$ and the vemtral hom. In addition, in the spinal cord. GABA is associated with interneurons in both the laminae $1-111$ and the vantral horn [10]. During development GABA is thought to have a controling action in the formation of spinal locomotor networks [2].

Recently we reponted that atrial natriurelic peptide (ANP) stimulates cGMP accumulation in GABAergic structures of laminae 1 . Hll in the rat cervical spinal cord $[17]$. Although the presence of natriuretic peptides (NP) and NP receptor has been described several years ago, there is no report on the functional significance of NP stimulated cGMP syrthesis in the spinal cord [19].

The $\mathrm{CABA}_{13}$ agonist Bacloten is a widely used drug in the treatment of spasticity [12]. Spasticity may be viewed as the autcome of a disorder of developing spinal networks [4]. In this study we investigated the effects of Baclofen on CGMP synthesis in the developing spinal cord

A total of 12 male Lewis rats aged 2 weeks were used. For biochemical measurements of cGMP five rats were used and for CGMP immunocytochemistry we used seven rats.

All experiments were approved by the committee on animal welfare according to Dutch governmental regulations. Rats were bred and housed at the University facility for experimental aninals.

Rats were decapitated without anaesthesia and the cervical spinal cord was taken out while cooled in ice-cold Krebs buffer, desheated and cut into $4004 m$ slices using a Mcllwain tissue chopper in the cold room at $4^{\circ} \mathrm{C}[14]$. Individual slices were immediately placed in aerated Krebs.Pinger bicarbonate buffer containing $1 \mathrm{mM}$ isobutymethylxarthine (IBMX) to inhibit phosphodiesterase (PDE) activity. Subsequently the temperature was raised till $35^{\circ} \mathrm{C}$ and the slices were incubated in the same buffer for 30 minutes under an atmosphere of $95 \% 0_{2}$ and $5 \% \mathrm{CO}_{2}$.

In each experiment the slices were further incubated for another 10 minutes 
with either 100nM ANP or $0.1 \mathrm{mM}$ of the NO donor sodium mitroprusside to achivate particulate (plasma membrane bound) guanyly cyclase (pGC) or soluble guanyly cyclase (SGC). respectively. Incubations were done in the presence or absence of $10 \mu \mathrm{M}$ Baclofen. The incubations were terminated by: (a) transferring slices into ice cold $5 \%$ TCA for biochemical measurement of cGMP levels using a radioimmunoasssy (RIA) as descibed in detail [16]; and (b) adding ice.cold fixative Solution (final concentration 4\% paraformaldehyde, $10 \%$ sucrose, $\mathrm{pH} 7.4$ ) for slices used for cGMP immunocytochemistry. Fixation was continued for $2 \mathrm{~h}$, followed by a $30 \mathrm{~min}$ wash in ice cold 0.1 M phosphate $(\mathrm{pH}$ 7.4) containing $10 \%$ sucrose. Cryostat sections $(10 \mu \mathrm{m})$ were cut and thawed on to chrome-alum/gelatim.coated slides and processed for immunochemistry. All antibodies dilutions were made in Tris buftered saline (TBS; pH 7.6) containing $0.3 \%$ (V/v) Triton X.100 (TBS-T). Sections were incubated overnight at $4^{\circ} \mathrm{C}$ with sheep anti-cGMP antiserum (1:4000). Primary antibody was visualized with a fluorescein Alexa 488-conjugated goat anti-sheep antiserum at a 1:100 difution (Molecular Probes).

Sections were analysed using an Olympus $A \times 70$ microscope equipped with an Olympus Digital Video-Camera F.View, a cooled CCD camera.. Fluorescence intensity was measured and converted into 265 gray value classes $(0.265$ high to low). Inages were recorded and subsequently analysed with analysis software Laminae 1.111 and laminae IV.X were selected as the region of interest and the mean gray value of the selected region was calculated. The effect of ANP with or without Baclofen on CGMP levels was calculated from the measurement of the immunofluorescence intensity, after subtracting the walwes obtaint from slices incubated without ANP, setting the effect of ANP alone as $100 \%$ effect. The validity of this approach in assessing cGMP levels in slices has been described in detail [16]. The data were statisticaly analysed using a paired sample T-test. A p value of $<0.05$ was considered to be statistically significant. Proteirn level was measured according to Lowry et all. [9].

Biochemical measurement of CGMP in the spinal cord slices showed no statistically significant difference between ANP stimulated and ANP/Baclofen stimulated slices (Table 1). Similarly, stimulation with SNP and SNP/Bacloten did 
not result in a significant difference in cGMP level. However regional differences within a segment of the spinal cord can not be detected using this approach. Therefore, in order to analyze the effects of Bacloten at the segmental level. we turned to CGMP immunocytochamistry.

\begin{tabular}{l|cccc} 
condition & $n$ & mean & SD & significance \\
\hline basal & 5 & 5.14 & 0.98 & \\
basal/Baciofen & 4 & 5.86 & 0.86 & $p=0.284$ \\
SNP & 5 & 98.69 & 26.85 & \\
SNP/Baclofen & 6 & 112.88 & 26.46 & $p=0.402$ \\
ANP & 6 & 15.39 & 1.85 & \\
ANP/Baciofen & 13 & 13.59 & 4.5 & $p=0.364$
\end{tabular}

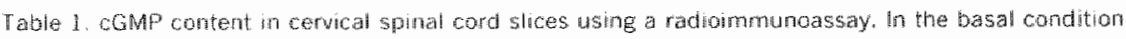

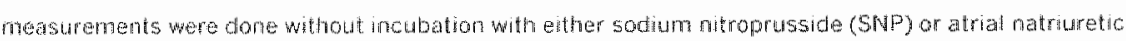

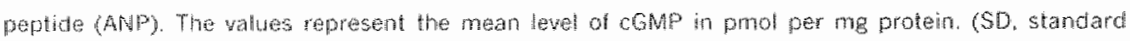
Gevialion: n, number of experiments?.

In cervical spinal cord slices of 2 weeks old rats, the CGMP immunostaining in the absence of stimulators of either pGNC or 5GNC (ANP respectively SNP) was low and anly present in laminae H.11. These findings on basal cGMP immunoreactivity are well in accordance with earlier findings [17]. Surprisingly. after timulation of CGMP synthesis by $100 \mu \mathrm{M}$ ANP in the presence of $10 \mathrm{fMM}$ Baclofen luorescence intensity in lamimae 1.111 decreased to $77+\gamma$. $4 \%$ (mean $+/$. SEM) of control values (Fig. la, b). This decrease was highly slignificant $(P<$ 0.0001). Under these conditions, the apparent decrease of CGMP immumo. fluorescence intensity in laminae $I V \cdot X$ proved to be non signficant $(87+1 \cdot 8, P=$ 0.01)

Stimulation of soluble GC with SNP resulted in strong CGMP immunoreactivity in all laminae of the cervical spinal cord. However, incubation of slices in the combined presence of SNP and Baciofen did not result in a statisticaliy significant decrease of CGMP immunoreactivity; $87+\% .9 \%(P=0.474)$ for laminae 1.111 and 
$94 \%+1.5 .5 \%(P=0.703)$ for laminae IV $x$ of the mean gray value obtained after stimulation with SNP alone (Fig. 1. d).
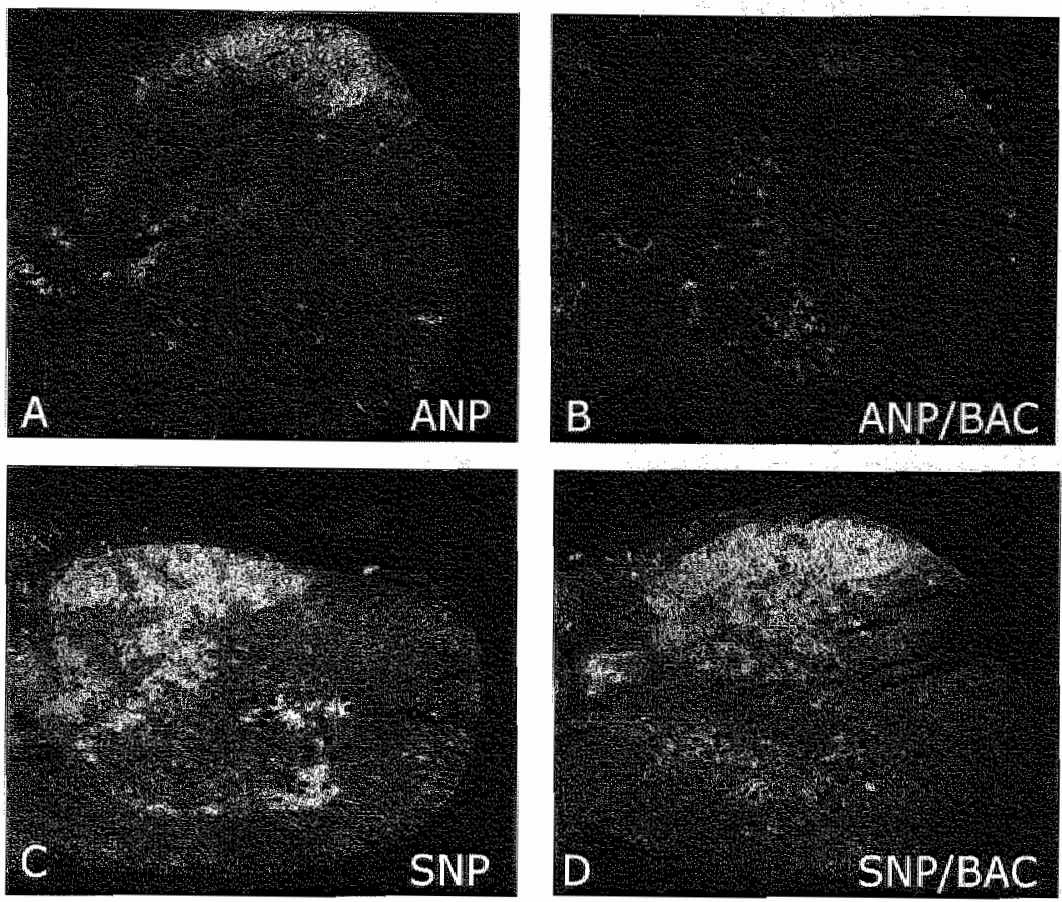

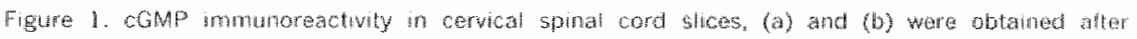

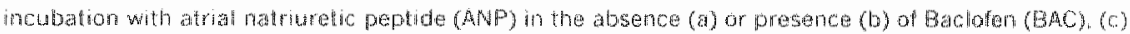

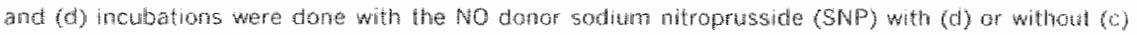
Bacholon. Bar fapresents 50 inm.

In our study we demonstrated the inhibitory action of Bacloten on ANP stimulated CGMP formation in laminae I.1I of the cervical spinal cord of rats, using semiquantitatiwe immunofluorecence analysis. Because of the lacalized effect of Bacloten on CGMP synthesis in the spinal cord slices we were unable to demonstrate a decrease of CGMP level using a radioimmunoassay. 
The functional significance of ANP stimulated CGMP synthesis in the spinal cord is not known. Nevertheless, low density ANP.binding sites have been desicribed in the dorsal horn and ventral hom [14, 19]. Specific ANP.binding sites in the rat spinal cord were detected on neurons and astrocytes [8]. Similarly, using autoradiographic analysis, a high density of $G A B A_{5}$ receptors in laminae I. H has been clescribed [3]. This localization of $\mathrm{GABA}_{\mathrm{e}}$ receptors corresponds with the location where in our study we abserwed that Baclofen decreased ANP stimulated CGMP immunoreactivity.

From a structural point of wiew the inhibitory effect of Baclofen on ANP induced activation of pGC is surprising. Nevertheless, isatin(indole 2,3 dione) which is also structurally unrelated to ANP has been described as an inhibitor of PGC [7]. Recently it has been demonstrated that isatin inhibits $p G C$ independent of the occupation of the ANP receptor [11]. It is known that phosphorylation of the ANP receptor is required for optimal catalytic activity [5] activationof GABAB receptors might result in activation of phopholipase $A$ and potentiation of CAMP formation [18]. Thus, the effect of Baclofen might involve triggering of a phosphorylating/dephosphorylating cycle of the intracellular part of the ANP receptor and subsequently downregulation of the PGC activity [13].

From a functional point of view, little is known about the role of cGMP in the spinal cord. NO-mediated CGMP is involved in naciception in the spinal cord, an increased level of CGMP in the dorsall horn of the spinal cord is associated with hyperalgesia through activation of CGMP dependent protein kinase lalphe $[1,6.15]$. Data on ANP mediated CGMP synthesis in the spinal cord is almost lacking completely [17].

Wo conclude that stimulation of the GABA receptor by Bacloten leads to inhibition of CGMP synthesis in laminae 1.111 in the rat cervical spinal cord at the age of wo weeks. The clinical effect of Bacloten on the reduction of pain and spasticily draws attention to apossible role of ANP.induced cGMP synthesis in these climical conditions. 


\section{References}

Aley K.O., McCarter G. and Levine J.D. Nitric oxide signaling in pain and nociceptor sensitization in the rat. I Neuroscl. 18 (1998) 7008 -7014.

Bertrand $S$, and Cazalets J.R. Presynaptic GABAergic control of the locomotor drive in the isolated spinal cord of neonatal rats. Eur $j$ Neurosci. 11 (1999) 583.592.

Bowery N.G., Price G.W. Hudson A.L. Hill D.R., Wikin G.P. and Turnbull M.J. GABA receptor multiplicity. Visualization of citierent receptor types in the mammalian CNS. Neuropharmacology. 23 (1984) 219231.

Filloux F.M. Neuropothophysiology of movement disorders in cerebral palsy. J Child Neurol. 11 Suppl 1 (1996) S5.S12.

Foster D.C. and Garbers D.L. Dual role for adenine nucleotides in the regulation of the atrial natriuretic peptide receptor, guanylyl cyclase-A. J Biol Chem. 273 (1998) $16311 \cdot 16318$.

Garry M.G. Richardson J.D. and Hargreaves K.M. Sodium nitropnusside evokes the release of immunoreactive calcitonin generelated peptide and substance p from dorsal hom slices via nitric oxidedependent and nitric oxide-independent mechanisms. J Neurosci. 14 (1994) 4329.4337.

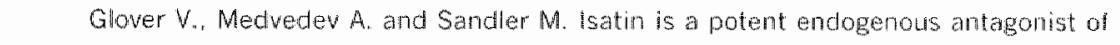
guanylate cyclase coupled atrial natriuretic peptide receptors. Life Sci. 57 (1995) 2073.2079

Hosl E. and Hosti L. Autoradiographic localization of binding sites for arginine vasopressin and atrial natruretic peptide on astrocytes and neurons of cultured rat centraf nerwous system. Neuroscience. 51 (1992) 159.166.

Lowny O. Rosenbrough N., Farr A and Randall F. Protein measument with the Folin reagent. J Biol Chem. 193 (1951) 453.457.

Malcangio M. and Bowery N.G. GABA
Pharmacol Sci. 17 (1996) 457.462 .

1 Medwedew A. Sandler $M$. and Glover $W$. The influence of isatin on guanylyl cyclase of rat hear membranes. Eur. J. Pinarm. 384 (1999) 239241.

Misgeid U. Bijak M. and Jarolimek Wh. A physiological role for GABAB receptors and the effects of baclofen in the mammatian central nerwous system. Prog Nebirobiol. 46 (1995) 423.462 . 
Pottar L.R. and Hunter T. Guanyly cyclase-finked natriuretic peptide receptors: structure and regulation. J Biol Chem. 276 (2001) 6057.6060 .

14. Shofitsch $G$ and Jacobowtz D.M. Atral natruretic peptide in the central nervours system of the rat. Cell Mol Heurobiol. 8 (1988) 339.391.

15 TaoYX. Hassan A. Haddad E. and Johns R.A. Expression and action of cyclic GMp. dependent protein kimase 1. alpha in inflammatory hyperalgesia in rat spinal cord. Neuroscience. 95 (2000) 525.533.

16 van Staveren W.C., Markerink van Ittersum M., Steinbusch H.W.M. and de Vente J. The effects of phosphodiesterase intibition on cyclic GMP and cyclic AMP accumulation in the hippocampus of the rat. Brain Res. 888 (2001) 275.286 .

17 Ves V.S.H., de Louw A.J.A., Stenbusch H., Markerink-van Ittersum M., Steinbusch H.W.M. Bianco C.E. Axer H. Troost J. and de Vente J. Localization and age related changes of nitric oxide. and ANP mediated cyclic GMP synthesis in rat cervical spinal cord: an immunocytochemical study. Brain Res. 857 (2000) 219.234.

18 Wojcik W.J and Holopaimen I. Role of central GABAB receptors in physiology and pathology. Neuropsychophamacology. 6 (1992) 201.204 .

19 Zamir N., Skoffesch G., Eskay F.L. and Jacobowitz D.M. Distribution of immunoreactiwe atrial natruretic peptides in the central nervous system of the rat. Brain Res. 365 (1986) 105. 111 . 




\section{Abstract}

Spasticity is a locomotor abnormality which can be observed after perinatal asphyxia. The $G_{A B A}$ agonist Baclofen is a widely used drug for the treatment of spasticity. In this study we inwestigated the effects of Bacloten on the ANP and SNP mediated CGMP synthesis in the rat cervical spinal cord after perinatal asphyxia.

Using a slice experiment and immunocytochemical techniques, we observed ANP mediated cGMP synthesis in astroglial cells after perinatal asphyxia. In normal rats, a decreasing effect of Baclofen on ANP mediated CGMP synthesis was observed, while an increasing effect on NO mediated cGMP synthesis was observed after perinatal asphyxia.

Our results suggest that the effects of Baclofen in the spinal cord are at least partially NO-cGMP mediated. 


\section{Introduction}

Perinatal asphyxia (PA) is the most common cause of mortality and morbidity in childhood, with a prevalence of 1.5 to 2.5 per 1000 live births [12]. PA can lead to mental retardation, epilepsy and motor abnormalities such as spasticity [7]. The pathophysiological mechanisms in spasticity atter PA are not completely understood. Yet, in spastic cerebral palsy, evidence for hyperexcitability of spinal alpha motor neurons due to abnormal supraspinal inhibition or abnormal spinal inhibitory control of spinal motor neuron output exists [4, 8, 18].

Recently, we reported that atrial natriuretic peptide (ANP) and sodium nitroprusside (SNP), a nitric oxide (NO) donor, stimulated CGMP accumulation in GABAergic structures of laminae 1.lll of the rat cervical spinal cord at the aige of 2 weeks [20]. Furthermore, we observed an inhibitory effect of the GABA agonist Baclofen, a well known and widely used drug in the treatment of spasticity, on ANP mediated CGMP synthesis in the 2 weeks old rat dorsal hom [2].

In the central nervous system (CNS), the second messenger CGMP is synthesized by guanylyl cyclases. Two classes of guanylyl cyclases can be distinguished, a soluble (SGC) and a membrane bound or particulate guanylyl cyclase ( $p G C$ ). Activation of $\mathrm{SGC}$ is $\mathrm{NO}$ mediated while activation of $p \mathrm{GC}$ is mediated by natriuretic peptides [21]. In the rat brain. ANP mediated CGMP immunoreactive (CGMP.IR) cells have been partly identified as being astroglial cells [3]. Moreover, specific ANP-binding sites were detected on cultured neurons and astrocytes from the rat spinal cord [9].

In the spinal cord, cyclic nucleotides like cGMP contribute to spinal hyperalgesia [6]. Recent studies provide evidence for a contribution of the NO. CGMP pathway in the development and maintenance of central semsitization of spinothalamic tract neurons by reducing the effectiveness of spinal inhibition [13]. Furthermore, cyclic nucleotides are thought to be involved in the guidance of neural growth cones during development [1]. As spasticity after PA may be viewed as a symptom of decreased spinal inhibitory control and CGMP is thought to influence the effectiveness of spinal inhibition [13], we studied the effects of PA on 
ANP and SNP mediated CGMP synthesis in the adult rat spinal cord, especially in relation to the effects of the spasmolytic drug Baclofen on the AMP and SNP mediated cGMP synthesis after PA.

\section{Materials and methods}

\section{Animal experiments}

Time pregnant Wistar rats at the last day of gestation were obtained from Charles.River company and housed at the University Maastricht facility for experimental animals. Water and food were given ad libitum. All experiments were approved by the committee on animal welfare acconding to Dutch governmental regulations and all efforts were made to minimize the number of rats used and their suffering. Severe PA was induced as described in detail by Loidl et al [14].

In short, the rats were decapitated and hysterectomized after their first pup had been allowed to be delivered vaginally (control, CVD). Both the uterus horns were placed in a water bath at $37^{\circ} \mathrm{C}$ for 20 minutes (severe perinatal asphyxia, SPA). After 20 minutes the uterus horns were opened, the pups removed, resuscitated and allowed to recover in an incubator at $37^{\circ} \mathrm{C}$. Male pups were than placed with a surrogate mother. The mortality after severe PA was approximately 40\% in our model and comparable with earlier studies using this modell [14].

\section{Tissue preparation}

Six males from the SPA group and six male CVD rats were used for the slice experiments at the age of 8 weeks. After decapitation without anaesthesia, the cervical spinal cord was taken out while cooled in ice cold Krebs buffer, desheated and cut into 400 mm slices using a Mclwain tissue chopper in a cold room at $4^{\text {:0 }} \mathrm{C}$ [.9]. Individual slices were immediately placed in aerated Krebs.Ringer bicarbonate buffer containing $1 \mathrm{mM}$ isobutylmethylxanthine (IBMX) to inhibit phosphodiesterase activity. Subsequently the temperature was raised till $35^{\circ} \mathrm{C}$ and the slices were incubated in the same buffer for 30 minutes under an atmosphere of $95 \% \mathrm{O}_{2}$ and $5 \% \mathrm{CO}_{2}$. 
In each experiment the slices were hurther incubated for another 10 minutes with either $100 \mathrm{nM}$ ANP or $0.1 \mathrm{mM}$ of the NO donor sodium nitroprusside to activate $\mathrm{pGC}$ or $5 \mathrm{GC}$ respectively. Incubations were done in the presence or absence of $10 \mu \mathrm{M}$ or $100 \mathrm{~m} \mathrm{M}$ Bacloten. The incubations were teminated by adding ice cold fixative solution (final concentration 4\% paraformaldehyde, $10 \%$ sucrose, $\mathrm{pH} 7.4$ ) and processed for immunocytochemistry as described in detaill [20].

\section{Immurocytochemistry}

All antbodies dilutions were made in Tris.buffered saline ( $\mathrm{pH} 7.6)$ containing $0.3 \%(\mathrm{~V} / \mathrm{v})$ Triton $X \cdot 100$. Sections were incubated overnight at $A^{\circ} \mathrm{C}$ with sheep anti. cGMP antiserum (1:4000). Primary antibody was visualized with a fluorescein Alexa 488-conjugated donkey anti-sheep antiserum at a 1:100 dilution (Molecular Probes). In order to identify cGMP immunoreactive (CGMP.IR) cells, we used antibody to monoclonal anti-glial fibrillary acidic protein (anti.GFAP) (1:1600, Signa) visualized with a fluorescein CY3 donkey antimouse antiserum (1:800. Jackson).

\section{Analysis}

Sections were analysed using an Olympus AX70 microscope equipped with an Olympus Digital Video-Camera F.View, a cooled CCD camera. Fluorescence intensity was measured and converted into 265 gray value classes 0.265 low to high fluorescence intensity). Images were recorded and subsequently analysed with analySIS software. Laminae 1.14 was selected as the region of interest and the mean gray value of the selected region was calculated. The effects of ANP and SNP with or without Baclofen on CGMP levels was calculated from the measurement of the immunoluorescence intensity, setting the effect of ANP or SNP alone as $100 \%$ effect. The data ware statistically analysed using an ANOVA. A p.walue of $<0,05$ was considered to be statistically significant. All clata are represented as means and standauld error of means (SEM). 


\section{Results}

The nomal rat spinal cord

In cervical spinal cord slices of 8 week old rats, the mean gray value intensity of CGMP.IR in the absence of stimulators of either PGC or SGC (basal conditions) was $57+/ .8$ for the control group and only present in laminae 1.11, although IBMX was present. In the contral group an increase could be detected from $57+/ .8$ to $90+/-11(\mathrm{p}=0.037)$ after stimulation with SNP and an increase from $57+1 / 11$ to $80+/ .9(p=0.032)$ after stimulation with ANP.

\section{Perinatal asphyxia}

The mean gray value intensity of CGMP.IR in the asphyxia group was $62 * / \cdot 10$. An increase in the mean gray value was seen from $62+/ 11$ to $79+/ \cdot 3(p=0.14)$ and from $62+\% \cdot 11$ to $73+/ .8(P=0.23)$ for SNP and ANP respectively. Without the presence of Baclofen, no statistically significant differences could be detected between the control and asphyxia groups, neither under basal conditions nor after stimulation with either SNP or ANP (Table 1).

\begin{tabular}{|c|c|c|c|c|}
\hline condition & & $n$ & mean & SEM \\
\hline \multirow[t]{2}{*}{ BASAL } & asphyxiä: & 6 & 62 & 11 \\
\hline & control & 5 & 57 & 8 \\
\hline \multirow[t]{2}{*}{ SNP } & aspifyxia & 6 & 79 & 3 \\
\hline & control & 5 & 90 & 11 \\
\hline \multirow[t]{2}{*}{ SNP/Baclofen10 } & asphyxia & 6 & 83 & 6 \\
\hline & control & 5 & 78 & 6 \\
\hline \multirow{2}{*}{ SNP/Baclofen 100} & asphyyxia & 6 & 94 & 6 \\
\hline & control & 6 & 72 & 6 \\
\hline \multirow[t]{2}{*}{ ANP } & asphyxia & 6 & 73 & 8 \\
\hline & control & 6 & 80 & 9 \\
\hline \multirow[t]{2}{*}{ ANP/Baclofen 10} & asphyxia & 6 & 67 & 9 \\
\hline & control & 6 & 68 & 6 \\
\hline \multirow[t]{2}{*}{ ANP/Baclofen 1.00} & asphyma & 6 & 74 & 4 \\
\hline & cantrol & 6 & 69 & 3 \\
\hline
\end{tabular}

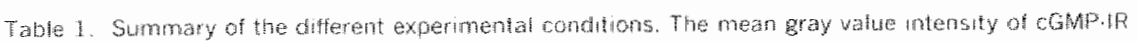
(mean) for both asphyctuc and control rats after stimulation whth aither athal natritate peptide (AvP)

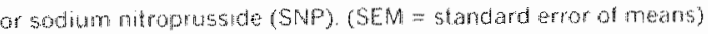




\section{Bacloten}

For assessing differences between cGMP levels in the asphyxia and control group with or without Baclofen. we subtracted the values obtained from slices incubated without Baclofen, setting the effect of ANP or SNP alone as 100 \% effect.

In the control group a statistically significant decrease to $85 \%+1.5$ of cGMP. IR was seen in laminae 1.11 when cGMP was stimulated with ANP in the presence of $10 \mu \mathrm{M}$ Baclofen $(p=0.04)$. This decrease could not be detected for ANP stimulated CGMP in the presence of $10 \mu \mathrm{M}$ Baclofen in the asphyxia group $(92 \%$ $+\%, p=0.36$ ), nor in after stimulation of COMP by SNP in the control group ( $88 \%$ $+1,15, \mathrm{p}=0.49)$

In the presence of $100 \mu M$ Baclofen the mean gray value intensity of CGMP-IR significantly increased in the perinatal asphyxia group $(94+1.6)$ compared to the control group $(72+/ .6, p=0.024)$. In laminae 1.11 of the perinatal asphyxia group SNP in the presence of $100 \mu \mathrm{M}$ Baclofen significantly increased the cGMP.1R to 1.18 percent $(p=0.004)$ compared to the $100 \%$ stimulation with SNP alone (Figure 1) in the control group a decrease to 81 percent was observed under these conditions $(p=0.013)$.
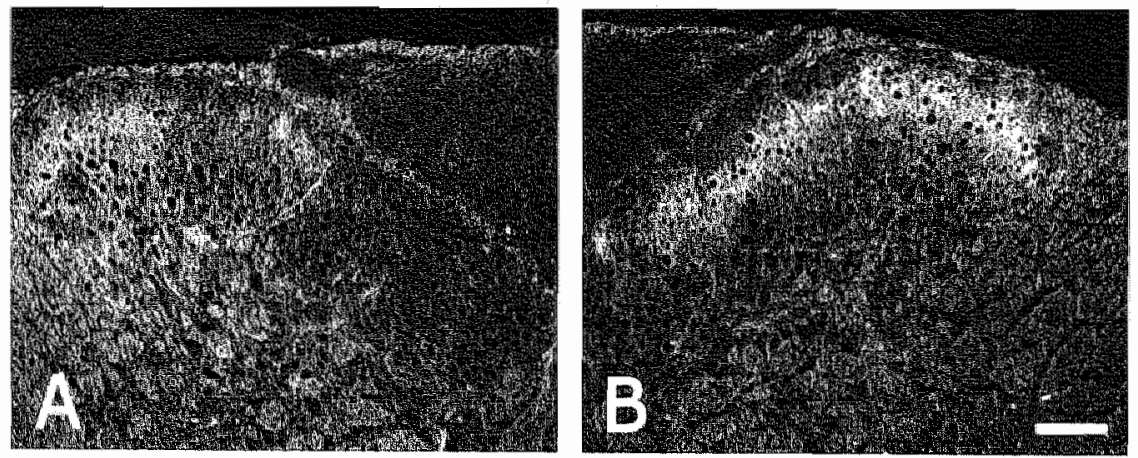

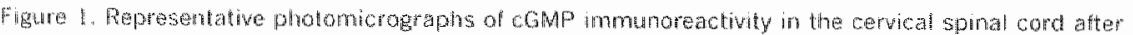

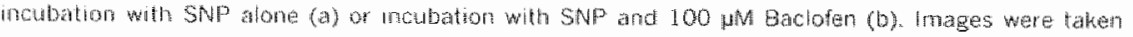

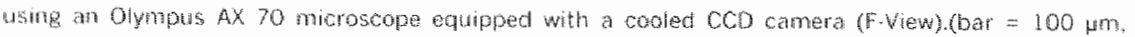
magn 
Double immunocytochemical staining

Using a double immunocytochemical staining techniques witi anti GFAP antiserum, a small number of the cGMP.IR cells could be identified as astroglial cells (Figure 2). Co-localization between CGMP and GFAP was most pronounced in the asphyxia group after stimulation with ANP alone and after stimulation with ANP and incubation with $100 \mu \mathrm{M}$ Baclofen.
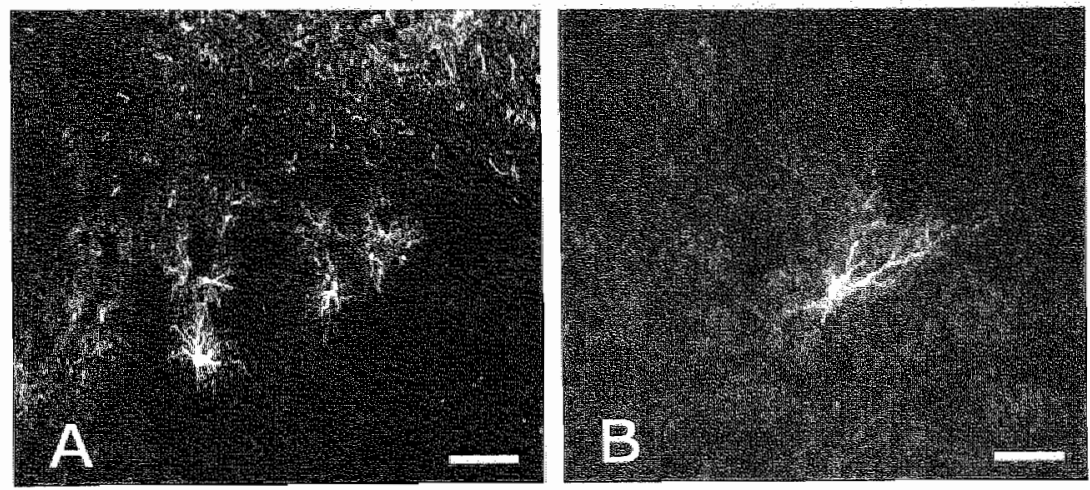

Figure 2. Photomicrograph showing CGMP IR astrocytes. Images were tatken nsing an Oympus AX70 microscope equipped with a cooled CCD camera (f.View). (bar $=20 \mathrm{~mm}$. magnification aOx an and 10 um, natganfification $100 \mathrm{x}$ in $\mathrm{b}$ ) 


\section{Discussion}

We investigated the effects of Bactofen on ANP and SNP stimulated CGMP.IR in laminea 1.111 of the cervical spinal cord of 8 week old rats after perinatal asphyxia. A decrease of the CGMP.IR after stimulation with ANP in the presence of Baclofen was detected in the contral group. This decrease was not seen in the perinatal asphyxia group, nor after stimulation with the NO donor SNP in the control group. Using semiquantitative immunofluorescence analysis, we found an increase in NO mediated CGMP in laminae 1.111 after stimulation with SNP in the presence of 100 $\mu$ M Baclofen after perinatal asphyxia.

The findings of the inhibitory effect of Baclofen on the ANP mediated CGMP synthesis in the adult rat are in accordance with our earlier findings in the 2 week old rat spinal cord [2]. From a structural point of wew the inhibitory effect of Baclofen on ANP.induced activation of $\mathrm{pGC}$ is surprising. It is known that phosphorylation of the ANP receptor is required for optimal catalytic activity [5]. Activation of $G A B A_{B B}$ receptors might result in activation of phospholipase $A$ and potentiation of CAMP formation [22]. Thus, the effect of Baclofen might involve triggering of a phosphorylating/ dephosphorylating cycle of the intracellular part of the ANP receptor and subsequently downregulation of the pGC activity [16].

Presently, the function of ANP mediated CGMP synthesis in the spinal cord remains unknown. Nevertheless, in an electrophysiological study the presence of ANP receptors on cultured spinal cord astrocytes was demonstrated [10]. Furthermore, in a recent study in humans an increase was observed in ANP immunoreactive astrocytes arter brain ischemia [15]. In our study a small part of the ANP mediated cGMP.IR cells could be identified as astroglial cells on the basis of their GFAP immunostaining. Double immunostained cells were mainly detected in the SPA group under 2 experimental conditions: after stimulation with ANP alone and after stimulation with ANP in the presence of $100 \mu \mathrm{M}$ Baclofen. No colocalization between ANP mediated CGMPIR and GFAP was observed in the contral group.

The effects of NO On CGMP in the adult rat spinal cord are region specific, in 
laminae 1.111 an inhibitory effect on spontaneous neural electric activity has been described [17]. We earlier reported an extensive colocalization between No stimulated CGMP synthesis and parvabumin-positwe (GABAergic) neurons and fibres [20]. Activation of the GABA receptor in the dorsal horn is known to inhibit the rellease of both glutamate (excitalory) and GABA (inhibitory) in the spinal dorsal horn [11]. Using a whole cell voltage clamp recording technique, Vang et al showed a slow outward intibitory current in dorsal horn neurons after bath application of Baclofen [23]. The findings in our present study suggest that the known inhibitory effects of the GABA agonist Baclofen in the spinal cord dorsal horn are at least partly NO-CGMP mediated. However. the exact mechanism by which Baclofen interacts with the NO.cGMP pathway remains unknown.

\section{Conclusion}

In spasticity after perinatal asphyxia the equilibrium between excitation and inhibition of spinal motor neurons is disturbed in favour of the excitatory activity. Inhibition of excitatory afferent input, both phamaco-therapeutically and surgically, is one of the comerstones in the treatment of spasticity [24].

In our study we have demonstrated that the known inhibitory effects of the $\mathrm{GABA}_{\mathrm{B}}$ agonist Baclofen could at least partially be NO-GGMP mediated.

Baclofen seems to have a variable effect on CGMP synthesis in the spinal cord dorsal horn under different conditions. In nomal rats, a decreasing effect on ANP mediated CGMP synthesis was observed, whille an increasing effect on NO mediated cGMP synthesis was observed after perinatall asphyxia.

Further studies on the effects of perinatal asphyxia on the GABA, receptor in the dorsal horn could provide further insights in the pathophysiological mechanisms of spasticity after perinatal asphyxia. 


\section{References}

Caron P. Oriving the growth cone. Science. 281 (1998) 14651466.

de Louw A.J.A. de Vente J., Steinbusch H.P.J., Steinbusch H.W.M., Troost J. and Ves J.S.H. Bacloten inhibits the ANP.mediated cyclic GMP synthesis in the rat cervical spinal cord. Neuroso Lett. 321 (2002) 120.122.

de Vente 1. Manshanden C.G. Sikking R.A. Ramaekers F.C.S. and Steinbusch H.W.M. A functional parameter to study heterogeneity of glial cells in rat brain slices: cyclic guanosine monophosphate production in atrial natriuretic sactor (ANF). responsive calls. Glia. $3(1990) 4354$

Filloux F.M. Neuropathophysiology of movement disorders in cerebral palsy. J Child Mearol. 11 Suppl 1 (1996) 55.512 .

Foster D.C. and Garbers D.L. Dual role for adenime nucleotides in the regulation of the atrial natriuretic peptide receptor, guanylyl cyclase. $A_{\mathrm{A}}$. J Biol Chem. 273 (1998) 16311.16318.

Garry M.G. Abraham E., Hargreawes K.M. and Aanonsen L.M. Intrathecal injection of cell permeable analogs of cyclic $3^{2}, 5^{\prime}$. guanosine monophosphate produces hyperalgesia in mice. Eur J Pharmacol. $260(1994)$ 129.131.

Hack M. and Fanarof A.A. Outcomes of children of extremely low birthweight and gestational age in the 1.990s. Semin Neonattol. 5 (2000) 89.106.

Harrison A. Spastic cerebral palsy: Possible spinal intemeural contributions. Dev Med Child Neurol. 30 (1989) $769 \cdot 780$.

Hosli E. and Hosli L. Autoradiographic localization of binding sitas for arginime vasopressin and atrial natruretic peptide on astrocytes and neurons of cultured rat central nerwous system. Neuroscience. 51 (1992) 159.166.

Hosli L., Hosll E., Kaeser $H$. and Lefkowits M. Colocalization of receptors for vasoactive peptides on astrocytes of cultured rat spinal cord and brain stem: electrophysiological effects of atrial and bram natriuretic peptice. neuropeptide $Y$ and bradykinin. Neurosci Lett. 148(1992) 114.116 .

11 Yyadomi M. Iyadomi 1., Kumamoto E., Tomokuni K. and Yoshimura M. Presynaptic intibition by bacloten of miniature EPSCs and IPSCs in substantia gelatinosa neurons of the adult rat spinat dorsal horn. Pain. 85 (2000) 385393.

Kuban K.C. and Levito, A. Cerebral palsy. N Engl J Med. 330(1994) 183.195. 

tract neurons by spinal glycine and GABA is modulated by guanosine $3.5^{2}$-cyclic monophosphate. J Neurophysiol. 81 (1999) 10951103.

14 Loid C.F., De Vente J., wan Ittersum M.M. wan Digk E.H., Vles, J.S.H., Steinbusch H.W.M. and Bianco C.E. Hypothermia during or after severe permatall asphyxia prevents increase in cyclic GMP.related nitric oxide levels in the newborn rat striatum. Brain Res. 791 (1998) 303.307.

15 Nogami M., Sniga J., Takatsu A. Endo N. and Itabastriku K. immunohistochemistry of atrial natriuretic peptide in brain infarction. Histochem J. 33 (2001) 87.90.

16 Potter L.R. and Hunter T. Guanyly cyclaselinked natruretic peptide receptors: structure and regulation. J Bial Chem. 276 (2001) 6057.6060.

17 Schmid H.A. and Peht U. Regional specific effects of nitric oxide donors and cGMP on the electrical actiwity of neurons in the rat spinal cond. 1 Chem Neuroanat. 10 (1996) 197201.

18 Sheean G. Pathophysiology of spasticity. In G. Sheean (Ed.) Spasticity relhabilitation. Churchill Communications Europe Lta. London. 1998 , pp. $17 \cdot 38$.

19 Skofitsch G. and Jacobowitz D.M. Atrial natriuretic peptide in the central nerwous system of the rat. Cell Mol Neurobiol. 8 (1988) 339391 .

20 Vles J.S.H., de Louw A.J.A., Steinbusch H.P.J., Markerink-wan Ittersum M. Steinbusch H.W.M., Blanco C.E., Axer H. Troost J. and de Vente J. Localization and age related changes of nitric oxide and ANP mediated cyclic.GMP synthesis in rat cerwical spinal cord: an immunocytochennical study. Brain Res. 857 (2000) 219.234.

21 Wedel B.J. and Garbers D.L. New insights on the functions of the guanyly! cyclase receptors. FEBS Lett. 410 (1997) 29.33

22 Wojick W.J. and Holopanen I. Rote of cental GABAB receptors in physiology and pathology. Netsopsychopharmacology. $6(1992) 201.204$.

23 Yang $K$. Wang $D$. and Li Y. Distribution and depression of the GABA(B) receptor in the spinal dorsal horn of adutt rat. Brain Res. Bull. 55 (2001) 47985 . Young R.R. Spasticity: a review. Neurology. $44(1994) 512.20$. 





\section{Abstract}

Radiofrequency lesions of the dorsal root ganglion can be used in the treatment of pain and spasticity. To date the effects of a radiofrequency lesion has been studied in peripheral nerves and in the spinal cord dorsal horm shortly atter the treatment. In our study we investigated the long. term effects of a RF.DRG treatment on the spinal cord using c.Fos immunoreactiwity. Furthermore, we used different immunocytochemical markers to identify c. Fos immunoreactive (c-Fos IR) cells.

In 6 Wistar rats RF.DRG treatments were performed adjacent to 6 dorsal root ganglions, and 6 ganglions were used as sham operated controls. Tissue was investigated al postoperative day 7 .

In the RF.DRG treated rats a highly significant increase in C.Fos IR cells was observed as compared to the sham operated controls. C. Fos IR cells were detected both ipsi. and contratateral of the treatment side. Furthermare, c. Fos IR cells could be identified as activated micraglia, astrocytes and motor neurons but not as oligodendrocyles.

We conclude that the long- term effects of a RF.DRG treatment cam be detected in all Rexed's laminae both ipsi and contra-lateral after an unilateral treatment. We furthermore suggest that the clinical effects of a RF.DRG treatment in spasticity and pain are possibly due to interference with both afferent input into the spinal cord and efferent output from the spinal cord. 


\section{Introduction}

Radiofrequency lesions of the dorsal root ganglion (RF.DRG) are widely used for the treatment of chronic cervical pain [16]. Besides the USe of RF.DRG in the treatment of pain, a beneficial eftect of RF.DRG has been described in the treatment of spasticity $[5,17]$.

In RF.DRG treatment, as in all neurosurgical treatments for spasticity, a reduction of spasticity is thought to be established through interruption of the afferent part of the stretch reflex in order to decrease excitation. The clinical effects of a RF-DRG lesion on spasticity and pain are not immediate but can only be detected after several weeks. An initial motor reaction of the muscles corresponding to the treated spinal level can be observed during RF-DRG treatment for spasticity.

The effects of a radiofrequency lesion have been studied on peripheral nerve fibres. An early effect of radiofrequancy lesions on small A-delta and $C$ fibres. followed by a delayed effect on fibres in the A-alpha and beta group has been described [9]. In contrast, other studies report an indiscriminating effect on all peripheral fibre types $[13,15]$. We recently reported an increase of proliferation insicte the dorsal root ganglion after a RF.DRG lesion adjacent to the ganglion without signs of neural tissue damage (e.g necrosis) inside the ganglion [1].

Recently, an increase of c.Fas immunoreactive cells in laminae 1 and 11 was noted 3 hours after a RF. DRG lesion [2]. The proto oncogene c.fos is knowr as a cellular immediate early gene, used as a functional anatomical mapping toal to identify cells that become activated in response to various stimuli [8]. Under basal conditions c-fos expression is low [3]. The maximal level of c. Fos protein is detectable between 1 and 3 hours after a stimulus and gradually disappears from the cell nucleus by 4 to 6 hours after stimulus [8]. However, a biphasic $c$-fos response has been described after excitotoxic insults [18]. Fos immunoreactivity was detectable in rat dorsal horn neurons for 30 days after chronic constrictive injury to the sciatic nerve [20]. 
To our knowiedge, no studies have been done on the long term effects of a RF. DRG lesion on the spinal cord. Taken into account the delayed clinical effects of a RF.DRG lesion in the treatment of spasticity, we investigated the long tem c.Fos protein immunoreactivity in the adult rat spinal cord after a radiofrequency lesion adjacent to the dorsal root ganglion.

\section{Materials and methods}

Radiofrequency lesions

A total of 7 male and female Wistar rats (250.270 grams) were used for the experiments. In 3 rats (experimental group) a radiofrequency lesion was made adjacent to 2 dorsal root ganglia on the right side (the left side being used as controly. Another 3 rats were used as sham operated controls. One rat was used as a double control, all pre- and postoperative measures were taken without performing the actuall operation. Rats were bred by Charles-River company and housed at the University Maastricht facility for experimental animals. Water and food were given ad libitum. All experiments were approved by the committee on animal welfare according to Dutch governmental regulations.

Rats were anaesthetised with an i.p. injection of sodium pentobarbital (Sanofi, $60 \mathrm{mg} / \mathrm{kg}$ ), the abdomen and cervical region was sheaved and the rat was placed on an inductionpad connected to a radiofrequency generator (Radionics). After identifying the cervical vertebra prominence as a landmark, a cervical hemi. laminectomy was performed on the lewels $\mathrm{C5}$ and $\mathrm{CG}$. The corresponding dorsal root ganglia on the right side were identified and a $100 \mathrm{~mm} 30 \mathrm{G}$ Levin chordotomy electrode (Radionics) with a $2 \mathrm{~mm}$ exposed tip was introduced adjacent to the dorsal root ganglion C5 and C6 using a micromanipulator (Leitz welalar, Germany)

The impedance (an indicator for the type of tissue next to the cannula tip) was tested, and if high (above $1000 \mathrm{Ohm}$ ) the tip of the cannulla was manipulated in order to obtain an impedance below 700 Ohm, indicating that the tip of the cannula was mear to soft tissue (e.g. the dorsal root ganglion). After checking the 
impedance, electrical stimulation was started at a rate of $2 \mathrm{~Hz}$ and $50 \mathrm{~Hz}$ and the rat was observed for muscle contractions in the corresponding muscles of the stimulated level (C5 or $\mathrm{C} 6$ ). If muscle contractions were observed the stimulation threshold was noted

A. radiofrequency current was then led through the electrode in order to increase the temperature to $67^{8} \mathrm{C}_{n}$ in lime with the procedure in the clinical practice. A $60 \mathrm{sec} 67^{\circ} \mathrm{C}$ unilateral lesion was made adjacent to the dorsal root gangtion at level $\mathrm{C} 5$ and $\mathrm{C} 6$ on the right side. After the lesion the muscles were approximated and the skin was closed. In 3 rats the procedure was identical with omission of the radiofrequency current (sham operated contrals).

\section{Tissue preparation}

At post-operative day 7 , the rats were anaesthetised by an i.p. irmection of sodium pentobarbital (Sanofi, $60 \mathrm{mg} / \mathrm{kg}$ ) and transcardially perfused with a flush of Tyrode solution $(\mathrm{pH} \mathrm{7.4)}$ ) followed by phosphate buffered $4 \%$ paratormaldehyde (pH 7.4). The cervical spinal cord with the attached dorsal root ganglions was dissected and post fixed in phosphate buffered $4 \%$ paraformaldehyde overnght. Then, the spinal cord was dissected into parts of one segment, and embedded in 10\% porcine gelatin. The gelatin cups were allowed to harden on ice for 1 hour, and post fixed in phosphate buffered $4 \%$ paratarmaldehyde for 2 hours. The tissue was cryoprotected in $15 \%$ sucrose in Tris buffered saline (TBS) overnight at $4^{0} \mathrm{C}$. and frozen in a liquid nitrogen colled bath with 2 methylbutane. Subsequently cryostat sections (10 Hm) were cut (Leica CM3050. cryostat) and thawed on to chrome-alum/gelatine coated slides and processed for immunocytochemistry.

\section{Inmmunocytochemisty and histochemistry}

For morphological detemination and verification of the actual lesion site, (e.g. next to the dorsal root ganglion and not insidey a hematoxylin and eosin (HE) staining was used. For the identification of c. Fos immunoreactive (c.Fos.IR) cells. we used an immunocytochemical fluorescent staining technique. A polyclonal rabbit antic Fos (4) antibody (1:4000. Santa Cruz biotechnology Inc) was used as a 
primary antibody. After application of the primary antibody, slides were kept overnight at $4^{\circ} \mathrm{C}$. Slides were further incubated with donkey anti rabbit Cy3 1.800 ; Jackson ImmunoResearch Laboratoties Inc) in TBS containing $0.3 \%$ Triton X.100 (TBS.T) and thereafter washed with TBS for $2 \times 5$ min, after which slides were incubated with Hoechst (1:500, Sigma) in TBS.T. The procedure was finished by washing with TBS for 10 min and enclosure with TBSiglyceroll (1:3).

\section{Double staining}

In order to characterize the C.Fas.IR cells a number of double(immuno) stainings were performed. To identify astrocytes we used an antibody to monoclonal antiglial fibrillary acidic proteir (anti-GFAP) (1:1600, Sigma). Oligodendrocytes were detected with an ant 04 antiserum (1:50, Chemicon International, Temacula). For identification of activated microglia we used an anti ED1 antibody (1:5, gift from J. Damoiseaux, University Maastricht, The Netherlands). As secondary antibody we used goat anti-mouse Alexa (1:100. Molecular Probes. USA). Negative controls were performed by omitting the primary antibody.

For the detection of (pro)apoptotic cells an activated caspase-3/c. Fos double staining was performed using a goat monoclonal antibody against actiwated caspase-3 (BD Biosciences, Europe).

After counting c-fos-IR cells, glass covers of the slides were removed and the slides were washed with TBS $3 \times 5$ min. After application of the primary antibodies as clescribed above, slides were kept overnight at $4^{\circ} \mathrm{C}$. After repeated washes with TBS and TBS.T, the appropriated secondary antibodies were added and the slides were enclosed with TBS:glycerol $(1: 3)$.

\section{Analysis}

The counting of C.FOS IR cells was done in 4 consecutive sections for each ganglion on the levels $C 5$ and $C 6$, both ipsi and controlateral. Cells were counted in 4 different spinal cord gray matter regions; the dorsal horn (Rexed's laminae I. (II). the intermediate zone (Rexed's Iaminae W.VII), the ventral horn (Rexed's 
laminae $V I I I+(X)$ and the area surrounding the central canal (Rexed's laminae $X$ ) [1].

Mears and the standard error of mean (SEM) were calculated and statistically analysed using a one way ANOVAand a non parametric test when appropriate. A $p$ value $<0.001$ was taken as a significant difference.

Microphotographs were taken using an Olympus AX70 microscope. Details on the photography are supplied in the legends of the figures.

\section{Results}

\section{Experimental procedure}

Both the experimental and the sham operated rats showed no clinical signs of paralysis or sensory deficits (e.g. pain) of the limbs on post operative examination. The rinean stimulation threshold was $0.65+/ .0 .24 \mathrm{~V}$ for the sham oparated rats and $0.52 \%=0.12 \vee(P=0.64)$ for the $R F \cdot D R G$ treated rats respectively. In accordance with the clinical observation in patients, an initial motor reaction of the muscles corresponding to the treated spinal level could be observed during the first few seconds of RF-DRG treatment

Examination of the HE stained sections showed infiltration with leucocytes and macrophages in the tissue adjacent to the lesioned dorsal root ganglion in the experimental group (Figure 1). On the untreated controlateral side only mild signs of infitration could be detected. Using HE staining, no morphological changes like degenerating cells displaying light micrascopic features af apoptosis (condensation, shrinkage and nuclear fragmentation) could be detected in both the dorsal root ganglion nor the spinal cord after the radiofrequency treatment. Furthermore, using the marker for activated caspase-3, no evidence for apoptosis was observed. 

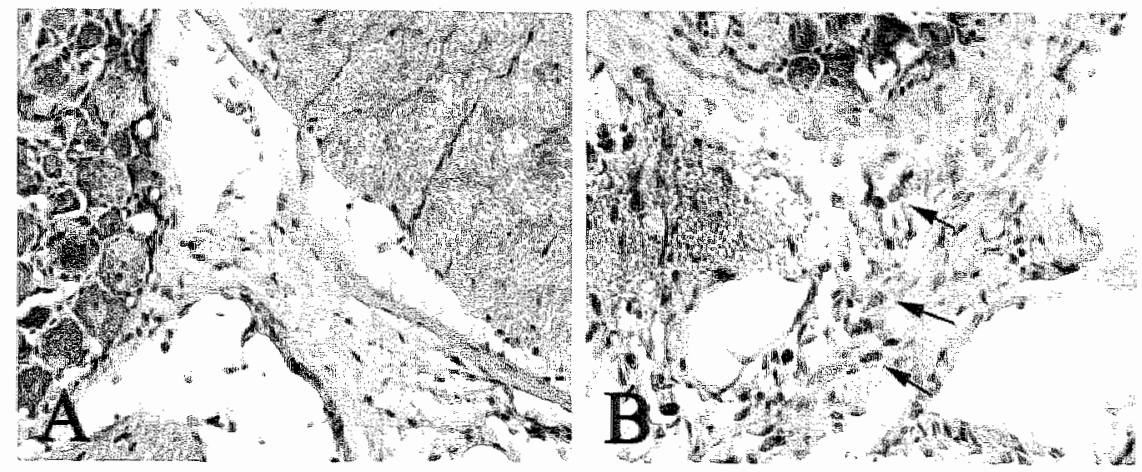

Figure 1. Photomicrograph showng the tissue adjacent to the dorsal root gangion in: a) a shan operated tall and b) a RF.ORG treated rat. Atter RF. ORG treatment, machophages (andews) were detected. (HE staining. magnification 20x).

Localisation of c.Fos IR celis

The localization and numbers of C.Fos $\mathbb{R}$ cells in the spinal cond are summarized in Table 1 . In both the sham operated controls and the double control rat, only few C. Fos IR cells could be detected without an obvious preference for a circumscribed region. In contrast, in the control group, abumdant c.Fos IR cells could be detected in all Rexed's laminae 7 days after RF-DRG treatment, both ipsiand contra-laterall of the lesion side (Figure 2). In the dorsal horn an increase from $0.5+/ .0 .2$ to $94+/ \cdot 13(\mathrm{p}<0.0001)$, in the intermediate zone an increase from 3.5 * 1.2 to $188+/ .24(p<0.0001)$ and in the ventral hom an increase from $0.3 \%$ 0.2 to $14+1.3(p<0.0001)$ in c.Fos $\mathbb{R}$ cells was observed.

No significant difference in the number of c.Fos IR cells could be detected between the treated and the contra-lateral side, although in all amimals the higher numbers were observed in the treatment side: in the dorsal horn $94+/ 13 \mathrm{C}$. Fos IR celis, in the treatment side versus $62+13(\mathrm{p}=0.107)$ in the contrallateral side, for the intermediate zone $188+/ .24$ cells ws $1.35+/ .20$ cells $(p=0.1 .19)$ and for the ventral horn $69+\% \cdot 10$ cells ws $57+/ 10$ cells $(p=0.423)$. 


\begin{tabular}{lccccc} 
group & $n$ & dorsal & intermediate & ventral & central \\
\hline RF.DRG & 6 & $94(13)^{*}$ & $188(24)^{*}$ & $69(10)^{*}$ & $1.4(3)^{*}$ \\
sham & 6 & $0.5(0.2)$ & $3.5(1.2)$ & $1.7(0.3)$ & $0.3(0.2)$ \\
control & 2 & $0.5(0.5)$ & $1.5(0.5)$ & $0(0)$ & $0(0)$
\end{tabular}

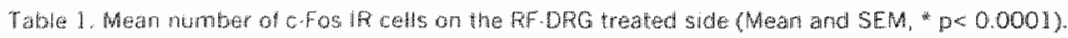

Identification of c Fos IR cells

In contrast to the immediate c-Fos expression in the nucleus, c.Fos IR was observed within the cytoplasm of ventral horn motor neurons (identification of cells based on mor phology and localization within the spinal cord) 7 days atter a RF-DRG treatment (Figure 3).

Using double immuno-fluorescent techniques, c.Fos IR cells could partially be identified as activated microglial cells (EDI positive) and astroglial cells (GFAP positive) (Figure 4). No co.tocalization was observed between the oligodendrocytal marker $\mathrm{O} 4$ and $\mathrm{C}$-Fos IR.
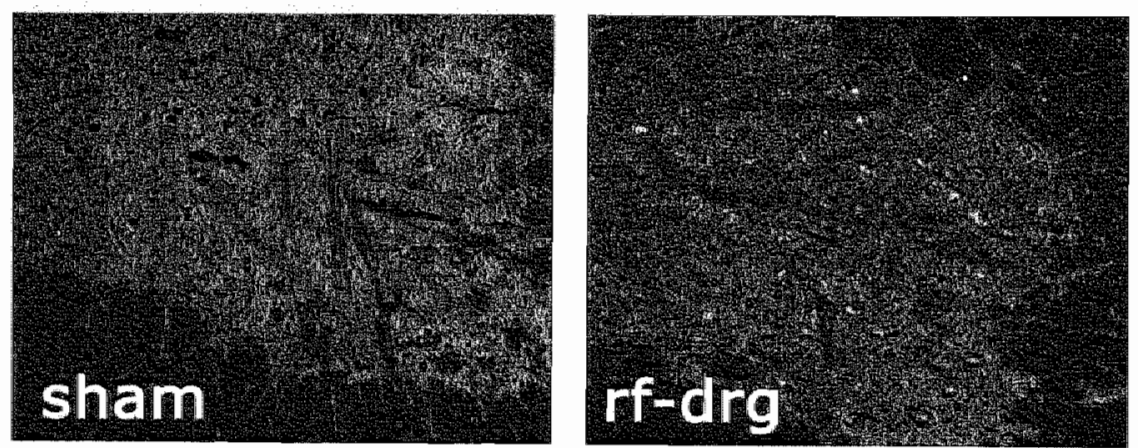

Figure 2. Reproswhatwe photomicrograph showng o Fos immunoreactwe cells (white) in the spinat cord

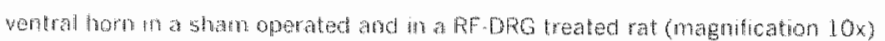




\section{Discussion}

In our study we investigated the long term effect of a RF.DRG lesion on C.Fos expression in the rat cervical spinal cord. Using double immunocytoctremical flurescent staining techniques, we observed an increased expression of c. Fos IR in motor neurons, astrocytes and activated microglia in the spinal cord gray matter, both ipsi. and contro- lateral, atter a unilateral RF.DRG lesion. At post operative day 7 the expression of c.Fos protein was found to be cytoplasmic and not nuclear.

The expression of the c. fos protein is generally known to be an indicator of celluar activation in an early stage [4]. The peak of nuclear c.fos expression is reached within 3 hours after stimulation, after which a gradual decrease to total nuclear elimination is reached at 24 hours [8]. Howewer, at day 7 , a second peak in fos expression has been described [12]. The localization of $\mathrm{c}$. fos during this second peak was found to be cytoplasmic instead of nuclear. Moreaver, cytoplasmic expression of c.fos was evident exclusively in vunerable regions after a NMDA agonist induced excitotoxic cascade [6].

In the CNS, c.Fos immunoreactivity has been suggested to be related to apoptotic cell death $[7,12]$. After a lesion of the developing sciatic nerwe apoptosis of spinal motor neurons, and dorsal hom intemeurons has been observed [10]. Using the sciatic injury model in transgenic nice, c.Fos expression was observed in the dorsal root ganglia and ventral motor neurons [12]. However, in our study. no morphological features of apoptosis or induction of caspase-3 could be observed.

Induction of c.Fos in the rat spinal dorsal horn has been described within severai hours after dorsal rhizotomy and after a RF. DRG lesion [2, 14]. In our study, the long term effects of a radiofrequency lesion adjacent to the dorsal root ganglion in the adult rat were not only found to be within the dorsal horn, but also on relatively remote spinal motor neurons. The observation of c. Fos expression in neurons remote from the lesion site has been described before. 

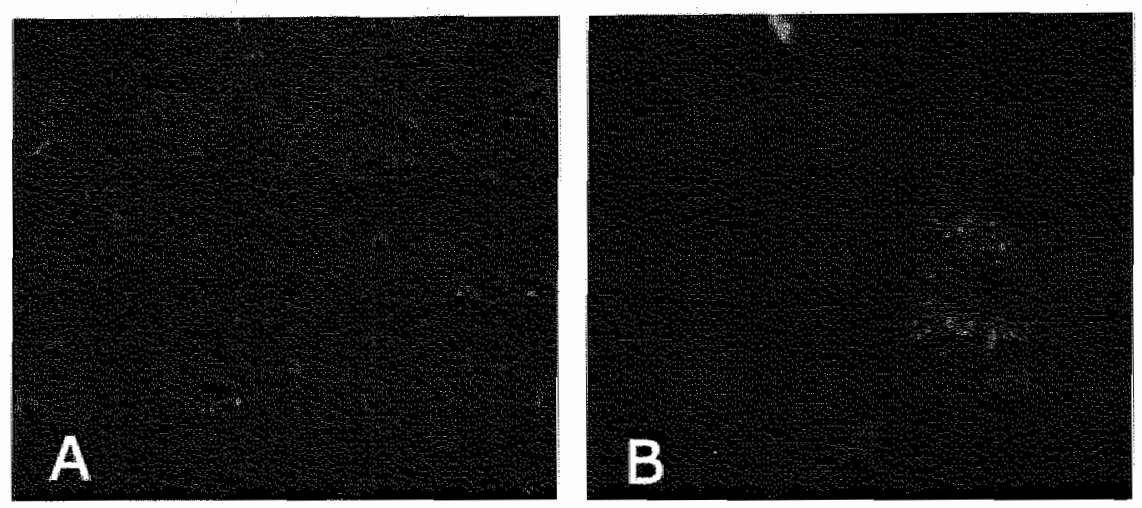

Figure 3. Photomicrograph showing cytoplasmatic o. Fos expression (green) in motor neurons after a RF. ORG treatment. Nuclei are staned bue (Hoechst) and astrocyles are stained red (GFAPh. Images were

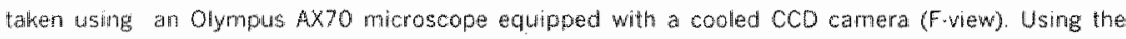
Image Ainalysis system (SIS), gray scaled images were directly conwerted into artificial colors. (magnification in $40 x$ and in b $100 x$ )
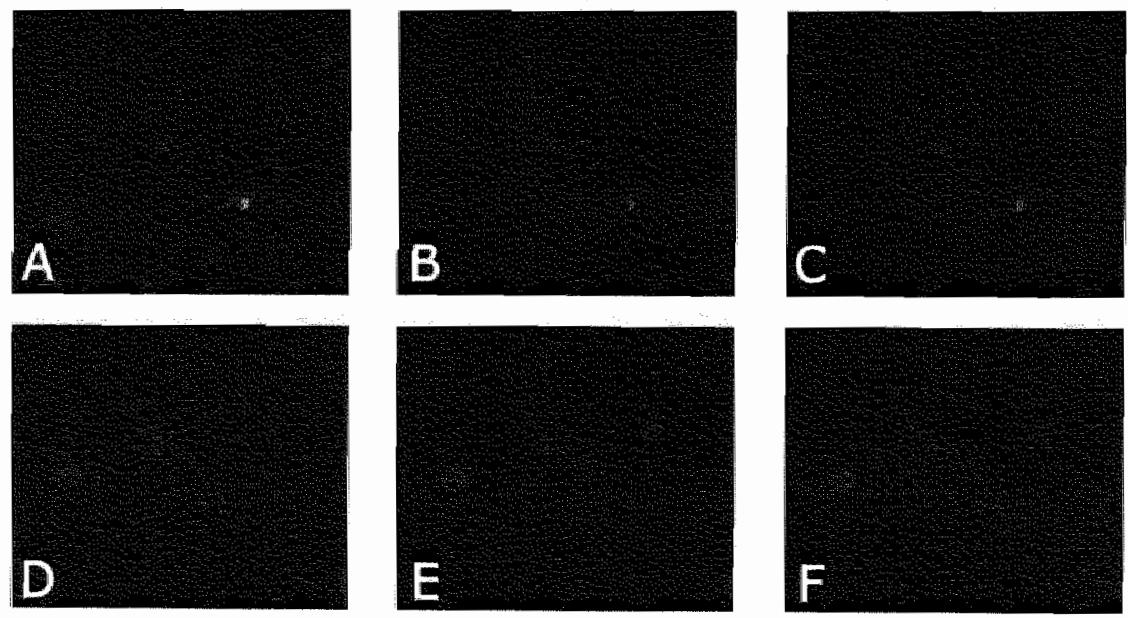

Figure 4. Photomicrograph illustrating double immunostaining for: (a) c. Fos and the activated microgliall marker EDI and (d) c Fos and GFAP Images of o. Fos (red, b and e) were taken using a Cr3 (U) 41007a) filker, Green staning iin figures (c) and (f) represent EOI immunoreactiwity and GFAP immothoreacrivity respectivaby. Nucle are stained blue (Hoechst). (magnification $100 x$ for all indages). 
Cytoplasmic expression of Fos immunoreactivity in cervical spinal cord motor neurons (bilaterally) has been reported after focal (unilateral) cerebral ischemia [19]. In this study it was suggested that the remote c. Fos expression was due to "transneural degeneration "as a result of deprivation of afferent inputs following the death of corticospinal neurons.

We observed c.Fos IR cells both ipsi. and contralateral of the lesioned side. These findings are in accordance with the findings of bilateral c. Fos expression in dorsal hom neurons after a unilateral sciatic nerve injury [20]. Minor skir damage is known to evoke c.Fos explession. The observed bilateral c.Fos expression after a unilateral lesion could have been the result of the surgical procedure (midline incision). However, wirtually no c. Fos IR cells were observed in the sham operated controls in our study, thus rulling out an operation artifact. The exact mechanism of contralateral c.Fos expression remains unknown. Nevertheless, the above described mechanism of transneural degeneration after a CNS lesion could at least partially play a role.

\section{Conclusion}

In our study we demonstrated delayed c. Fos expression in several cell types in the rat spinal cord after a radiofrequency treatment of the dorsal root ganglion. $\mathrm{A}$ striking outcome was the bilateral effect on c. Fos expression after an unilateral RF. DRG treatment, even on the more remote motor neurons. Therefore, our results suggest that the clinical effects of a RF.DRG treatment in spasticity and pain is two folded: firstly, by reducing afferent input and secondly by a delayed and remole effect on motor neurons possibly resulting in a reduction of efferent output. 


\section{references}

de Low A.J.A. Wes J.S.H., Freling G., Herpers M.J.H.M. Arends J.W. and van Kuleef M. The morphological effects of a radiofrequency lesion adjacent to the dorsal root ganglion (RF.DRG) . An experimental study in the goat. Eur J Pain. 5 (2001) 169. 174 .

Higuchi 'w. Mashold B.S., Sluifter M., Cosman E. and Pearlstein R.D. Exposure of the dorsal rool ganglion in rats to pulsed radiofrequency current activates dorsal horn laminal and ll neurons. Newrosurgery. 50 (2002) 850.856 .

Hughes P. Lawlor P. and Dragunow M. Basal expression of Fos. Fos.related, Jun, and Krox 24 protens in rat hippocampus. Brain Res Mol Brain Res. 13 (1992) 355 . 357.

Hughes P.E., Alexi T., Walton M., Willams C.E., Dragunow M., Clark R.G. and Gluckman P.D. Activity and injury-dependent expression of inducible transcription factors, growth factors and apoptosis-related genes within the central nerwous system. Prog Newrobiol. 57 (1999) 421.450.

Kasdon D.L. and Lathi E.S. A prospective study of radiofrequency thizotomy in the treatment of postraumatic spasticity. Neurosurgery. 15 (1984) 526.529.

Kasoff G.M., Mandelzys A., Maika S.D., Hammer R.E., Curran T. and Morgan U.I. Kainc acidinduced neuronal death is associated with DNA damage and a unique immediate early gene response in c-fos.lacz transgenic rats. I Neurosci. 15 (1995) $4238 \cdot 4249$.

Kim J.M., Lee K.W., Chung Y.H., Shin C.M., Baik S.H, and Cha C.I. C.Fos basa! immunoreactivity decreases in rat spinal cord during normal ageing. Neuroreport. $10(1999) 585.588$.

Kovacs K.J. c.Fos as a transcription factor: a stressful (re)view from a functional map. Neurochem int. 33 (1998) 287.297. Letcher F.S. and Goldring S. The effect of radiofrequency current and theat on peripherat nerve action potential in the cat. J Neurosurg. 29 (1968) 42.47.

Olveira A.L., Risling M., Deckner M., Lindholm T., Langone F. and Cullheim S. Neonatal siciatic nerve transection induces TUNEL labeling of neurons in the rat spinal cord and DRG. Neuroreport. 8 (1997) 2837.2840.

11 Rexed B. The cytoarchitectonic organizationof the spinat cord in the cal. J Comp Neurol. 96 (1952) 415.494. 

L.M. Curran T. and Morgan J.1. Continuous c.tos expression precedes programmed cell death in wivo. Nature. 363 (1993) $] 66.169$.

13. Smith H.P., Mchorter J.M. and Challa V.R. Radiofrquency netrolysis in a clinical model neuropatholgical correlation. J Neurosurg. 55 (1981) 246.253.

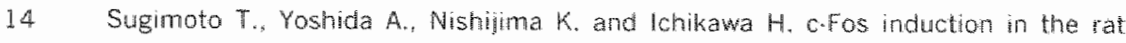
spinal dorsal hom partially deafferented by dorsal mizotomy. Neurosci Lett. 178 (1994) 239.242 .

15 Uematsu S., Udwarhelyi G.B., Benson D.W. and Siebens A.A. Percutaneous radiofrequency mizotomy. Surg Neurol. 2 (1.974) 319.325 .

16 wan Kleet M. Radiofrequency iesions of the dorsal root ganglion in the theatment of spinal pain. Thesis. Maastricht University, Maastricht. 1996

17 Vles J.S.H. van Kleef M., Sleypen F., Bulstra S. Szpak K. Luickx G.J., Beuls E. Sluyter M.E. and Troost J. Radiofrequency lesions of the dorsal root ganglion in the treatment of hip flexor spasm: a report of two cases. Eur J Paed Neurol. 4 (1997) $123 \cdot 126$.

18 Walker P.D. and Corlock L.R. Immediate early gene actiwation during the initial phases of the excitotokic cascade. I Neurosci Res. 36 (1993) 588.595.

19 Wu Y.P., Tan C.K. and Ling E.A. Expression of Fos-like immunoreactivity in the brain and spinal cord of rats following middle cerebral artery occlusion. Exp Brain Res. 115 (1997) $129 \cdot 136$.

Yamazaki Y. Maeda T., Someya G. and Wakissaka S. Temporal and spatial distribution of Fos protein in the lumbar spinal dorsal horn neurons in the rat with chronic constriction injury to the sciatic nerve. Brain Res. 914 (2001) 106.114. 




\section{Abstract}

The use of percutaneous radiofrequency lesion adjacent to the dorsal root ganglion (RF-DRG) in the treatment of pain has been established for years. A relatively novel indication for RF.DRG treatment is spasticity in children with cerebral palsy. In this article the pathophysiology and management of spasticity is discussed with an emphasis on the role of RF.DRG. In the management of spasticity, RF.DRG could prove to be a little invasive treatment option with little adverse effects. 


\section{introduction}

Cerebral palsy is the most common motor disorder in childhood. The term cerebral palsy hatbors different pathological conditions of the central nervous system, all resulting in locomotor abnormalities. The pathophysialogical mechanisms involved in cerebral palsy are intrauterine ischemia, intrauterine infection, perinatal asphyxia and prematurity $[13,18]$. The incidence and prevalence of cerebral palsy is estimated to increase in the near future because of still changing perinatal care resulting in a lower mortility $[1,22]$. Cerebral palsy can lead to mental retardation, epilepsy and motor abnormalities such as spasticity [9]. Cerebral palsy is the result of a multiple motor disorders known as the Upper Motor Neuron syndrome (UMN). The UMN syndrome is divided in positive and negative symptoms. Negative symptoms are; paresis, fatigability and loss of dexterity. The positive components of the UMN syndrome, characterized by excessive motor activity, are spasticity, hyperreflexia, dystonia and contractures [20].

\section{Spasticity}

Spasticity is defined as a sensorimotor disorder with a velocity dependent increase in tonic stretch reflexes and exaggerated tendon reflexes as a result of hyperexcitability of the stretch reflex [14]. In cerebral palsy, spasticity can be a very disabling feature: timited locomotor ablities, contractures (lasting stiffness of muscles, tendons, ligaments and joints), pain and limitations for self-care and care givers, amount to considerable healthcare costs.

The exact pathophysiological mechanisms of spasticity in cerebral palsy remain unclear: Nevertheless, it is generally accepted that the balance between excitation and inhibition is disturbed in favour of the excitatory forces.

The lat afferent stretch reflex arc is the most basic neural circuit within the pathophysiology of spasticity [12]. Fast conducting semsory fibres (la afferents) relay excitatory impulses originated in muscle spindles after muscle stretch. After excitation of the primary afferent la fibres an excitatory action on the alpha. 
motoneuron of the agonistic muscle is established. Besides monosynaptic connections on motor neurons by primary afferents, oligosynaptic and polysymaptic conmections with excitatory interneurons are established [27]. The la afferents also connects with inhibitory interneurons that project directly to the antagonist motoneuron, known as reciprocal inhibition. In spasticity, the reflex circuit is impaired in favour of the excitatory action by an enhanced processing of afferent information within the spinal cord $[15,20]$. Reducing the positive symptoms of the UMN syndrome associated with the hyperactive spinal reflex arcs form the basis of the management of spasticity [?].

\section{Management of spasticity}

The management of spasticity in children with cerebrall palsy remains to be complex, although several new treatments have been developed in recent years. The management is focussed on the improvement and/or prevention of complications like contractures. Because spasticity goes beyond the scope of one specific discipline, careful evaluation of the patient in a multidisciplinary team is required. An emphasis on functional improvement and/or facilitating rehabilitation after treatment should be made.

The management of spasticity with the aid of physical therapy in order to improve functionality and awoid painful contractures has beer the only treatment option for years. Besides physical therapy, roughly three treatment options are available nowadays; oral pharmacotherapeutic, chemical denervation and surgery $[7]$

Drugs mostly used for orall administration are; Baclofen, Diazepam, Dantrolene and Tizanidine. All these drug enhance inhibition by inhibiting excitatory neurotransmitters or augmenting inhibitory neurotransmitters at the spinal cond level, in order to reduce spasticity. An impartant side effect of oral drug is sedation due to an effect on brain neurotransmitters. These side effects are a limiting factor in the use of oral pharmacotherapy.

The second therapeutical option is chemical denervation. Before the 
introduction of Botulinum toxin type A (BTX.A), local injections with Phenol or alcohol were pertormed.

Nowadays, intramuscular injections with BTX.A made the use of Phenol as a local denerwation agent almost obsolete. The beneficial effect of BTX.A on function and muscie tone has been extensively proven in randomized double blinded clinical trails [2.8]. The major drawback of $B T X$ is the recurrence of spasticity, the mean curation of the effect is approximately 3 months. Moreower, adverse ewents of repeated $B T X$ therapy have been reported [17].

Besides orthopaedic interventions for the relief of contractures, the surgical management of spasticity is mainly focussed on selective dorsal rhizotomies (SDR) and intrathecal baclofen pumps. In all neurosurgical interventions, reduction of spasticity is established through interruption of the stretch reflex in order to decrease excitation [21].

\section{Rhizotomy}

Selective dorsal rhizotomy (SDR) for the treatment of spasticity in children with cerebral palsy has recently regained considerable interest. The first dorsal rhizotomy for the treatment of spasticity was described by Foerster in 1913 [5]. Because of complications like excessive sensory loss due to extensive sectioning of the dorsal root, the procedure fell into disgrace. The treatment has been modified since by several authors, resulting in the SRD technique used nowadays. The observation of an abnomal contraction of spastic muscles after stimulation of rootlet sections while non spastic muscles responded with a normal contraction. made it possible to selectively sectioning of the rootlets responsible for spasticity $[5]$

In SDR major surgery is involved. After extensive laminectomy of the levels $L 2$ to $S 1$, the rootlets are identified using electronyography and partially resected. The used techniques relieve spasticity without interferimg with sensation. The reported results of selective dorsal thizatomy on the relief of spasticity in a sellected population of children with cerebral paisy are promising [4, 16]. The reduction in muscle tone can be detected almost immediately post operative. 
Some controversy an the degree of functional improvement after SDR exists. However, functional improvement of functional abilities, especially sitting, is seen in the majority of children.

The invasive techniques used in the SQR are complicated and time consuming pracedures only to be performed by highly specialized neurosurgeons. Moreover. considerable cooperation of the patient is required in order to successfully complete the post operative rehabilitation program during one year. Indications for SDR are improvement of walking in ambulatory diplegic children and improvement of care in the quadriplegic non-ambulatory child [24]. Patients must preferably have the mental capabilities of a toddler. Many children with severe cerebra! palsy are to severely retarded for treatment with SDR. An alternative for the SDR is the percutaneous radiofrequency lesion adjacent to the dorsal root ganglion (RF.DRG).

\section{Radiotrequency lesion adjacent to the dorsal root gangion}

In the 1980's several authors reported on the beneficial effects of RF.DRG on adult patients with intractable spasticity $[10,11]$. In these studies recurrent spasticity was seen after 6 to 9 months, although the pre-operative level of spasticity was not reached. More recently Vles et al reported the use of RF.DRG in the treatment of flexor spasms of the hip of spinal and cerebral origin in children [25]. Accumulated clinical experience with RF.DRG has shown that it is possible to alleviate pain without chinical signs of nerve damage [23]. Furthermore, RF DRG is a simple and safe treatment with little side effects [19].

The assumed mechanism of action of RF.DRG in the treatment of spasticity is the same as in SDR; a reduction of spasticity is established through intermption of the stretch reflex in order to decrease excitation. The exact mechanism of action of a RF-DRG lesion itself remains unknown. Nevertheless, an increase in nitric oxide synthetase (the key enzyme, regulating NO concentration) and motor neuron death was obserwed after root avulision in the postnatal rat [26]. Moreover, we recently reported an increase of proliferation inside the dorsal root ganglion after a RF.DRG lesion adjacent to the ganglion without signs of neural tissue damage re.g 
mecrosis) inside the gangtion [3]. At the moment a study is conducted to inwestigate the effects of a RF.DRG lesion on the dorsal root ganglion and the spinal cord.

Recently, in a pilot study, we investigated the effects of RF.DRG on spasticity and pain of the lower extremities in children with cerebral palsy cunpublished data). In this study we treated children with RF.DRG on muitiple lumbar levels after $\mathrm{BTX}$ had failed to give improvement. Although the studied group was small, we found a bereficial effect on both muscle tone and care. giving. Furthermore, RF-DRG improved pain associated with the spasticity, a feature not treated with BTX. No adverse effects or treatment complications were reported. All treatments were performed on am outpatient basis under general anaesthesia.

In our pllot study the follow up was 4 weeks. We did not inwestigate the long term outcome of RF-DRG treatment in spasticity. A randomized blinded chinical trial comparing BTX, RF.DRG and physical therapy alone in the treatment of spasticity has been started, with an emphasis on both short and long term outcome.

\section{Conclusion}

The treatment of spasticity in children with cerebral palsy remains to be a problem, despite several new treatment options. RF. DRG could prove to be a little inwasive treatment option with little adwerse effects. Further studies should focus on the long term effects. 


\section{References}

1. Colver A.F., Gitson M. Hey E.N. Jarvis S.N. Mackie P.C. and Richmond S. Increasing rates of cerebral pasy across the severity spectrum in inorth east England 1964.1993. The North of England Coltaborative Cerebral Palsy Survey. Arch Dis Child Fetal Neonatal Ed 83 (2000) F7.F.2.

2 Corry 1., Cosgrove A. Walsh E. McClean D. and Graham H. Botulinum toxin A in the hemiplegic upper limb; a double blinded trial. Dev Med Child Neurol, 39 (1997) 185. 193.

3 de Louw A.J.A. Vles J.S.H. Frellng G. Herpers M.J.H.M., Arends J.W, and wan Kiaef M. The morphological effects of a radiofrequency lesion adjacent to the donsal root ganglion (RF.DRG) - An experimental study in the goat. Eur J Pain. 5 (2001) 169. 174

4 Engsberg J.R., Olree K.S. Ross S.A. and Park T.S. Spasticity and strength changes as a function of selective dorsall rhizotomy. J Neurosurg. 88 (1998) 10201026.

5 Fasano W.A., Broggi G. Zeme S. Lo Russo G. and Sguazzỉ A. Long term liesults of posterior functional thizotomy. Acta Neurochir Suppl wien. 30 (1980) 435.439.

6 Foerster D. On the indications and results ot the excision of posterior spinal roots in men. Surg Gymecol Obstet, $16(1913) 463474$.

7 Goldstein E.M. Spasticity management: an overwew. J Child Newrol. 16 (2001) 16 32 .

8 Graham H.K., Aoki K.R. Autt.Ramo I. Boyd R.N., Delgado M.R. Gaebler.Spira D.J., Gormey M.E. Guyer B.M., Heinen F., Holton A.F., Mathews D., Molenaers G., Motta F. Garcia Rutz P.J. and Wissel J. Recommendations for the use of bolutinum toxin type A in the management of cerabral palsy. Galt Postura. 11 (2000) 67.79.

9 Hack M. and Fanarof A.A. Outcomes of chidren of extremely llow bithweingt and gestational ase in the 1990s. Semin Neonatol. 5 (2000) 89.106.

10 Her D.M. Parsons K.C. and Pearl L. Percutaneous radiofrequency foramena! rhizotomies. Spme. $8(1983) 729732$.

11 Kasdion D.L. and Lath E.S. A prospective stwdy of radiofrequency ritzotomy the treatment of postraumatic spasticity. Neurosurgery. 15 (1984) 526.529.

12 Katz R.T. and Rymer W.Z. Spastic hypertonia: mechanisns and masurement. Aroh Plys Mad Rehabil. 70 (1989) 144.155.

I3 Kuban K.C. and Leviton A. Cerebral palsy. N Engl I Med. 330 (1994) 188.95 

Lecture. Neurology. $30(1980) 1303 \cdot 1313$.

Mayer M. Chn Chophysologic concepts of spasticity and motor dystunction in aduts whth apper motoneuron tesion. Muscle Nerve Suppt. 6 (1997) S1-13.

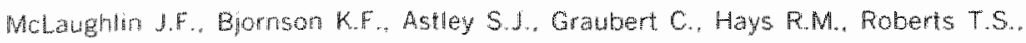

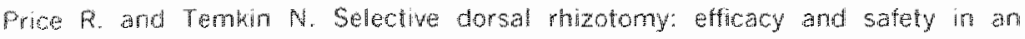

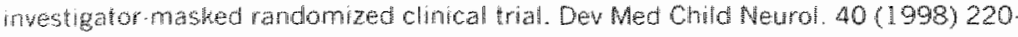
232.

17 Mohamed K.A. Moore A.P. and Rosenbloom L. Aclverse events followirg repeated injerions with botuhum toxin A in children with spasticity. Dev Med Child Neurol. $43(2001) 791.792$

18 Nelson K.E. and Willoughby R.E. Infection, iriflammation and the risk of cerebral palsy. Curr Opin Meurol. $13(2000) 133.139$.

19 Segnarbieux F. and Frerebeau P. The difterent copen surgical, percutameous themal. and irtrathecal chemicaly rhizotomiss for the treatment of spasticity. In M. Sindou, R. Abbati and K. Y. (Eds.) Meurosurgery for spasticity: a multidiciplinan approach. Springer Verlag. New York. 1991, pp. $133 \cdot 139$.

20 Sheean G. Pathophysiology of spasticity. In G. Sheean (Ed.) Spasticity rehabihation. Churchill Communications Europe Ltd. London. 1998. pp. 17.38.

21 Smyth M.D. and Peacock W.J. The surgical treatment of spasticity. Muscle nerwe. 23 (2000) $153-163$

22 Stanley F.J. Survival and cerebral palsy in 10 wirhweight infants: implications for perinatal care. Paediatr Perinat Epidemiol. 6 (1992) 298-310. van Ka $\mathrm{m}$. Radiofrequency lesions of the dorsal root ganglion in the treatment of sphat pain. Thesis, Maasthicht University. Maastricht, 1996.

24 Vabghan C.L. Subramanan N. and Busse M.E. Selective dorsal rhizotomy as a treatment option tor children wh spastic cerebral palsy. Gall Posture. 8 (1998) 43 9

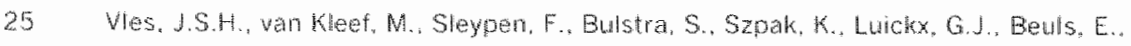
Slatyer, M. and Trowst, J., Radiofrequency lestons of the dorsal root gangtion the treatment of hip flexor spasm: a report of two cases. Eur J Paed Meurol, 4 (1997) $123 \cdot 126$. 
26. WL Y. Li Y., Liu H. and Wu W. Induction of nitric oxide synthase and motoneuron death in newborn and early postnatal tats following spinal root awulsion. Neurosci Lett. 194 (1995) $109 \cdot 112$.

27 Young R.R. Spasticity: a rewiew. Neurology. 44 (1.994) $\$ 12.20$ 





\section{Abstract}

The treatment of spasticity in children with cerebral paisy remains to be a problem. The selective dorsal rhizotomy as a treatment was shown to be effective, although major surgery is involved and adverse events have been reported. Percutaneous radiofrequency lesion of the dorsal root ganglion (RF.DRG) could be a simple and safe alternative treatment. We investigated the effects of RF.DRG on muscle tone and daily activities of life and found a beneficial effect. 


\section{Introduction}

Selective dorsal rhizotomy (SDR) for the treatment of spasticity in children with cerebral palsy (CP) has recently regained considerable interest. The reported resuits of SDR on the relief of Spasticity in a selected populaticn of children with CP are promising [5]. Nevertheless, the invasive techniques used in the SDR are complicated and time consuming procedures. Moreover, considerable cooperation of the patient is required in order to successfully complete the post operative rehabilitation program.

An atternatiwe for the SDR is the percutaneous raciofrequency lesion of the dorsal root ganglion (RF-DRG), a treatment for pain since 30 years [9]. In the 1980 's several authors reported on the beneficial effects of this method on adult patients with intractable spasticity $[2,3]$. More recently, in a case report, the use of RF. DRG in the treatment of flexor/adductor spasms of the hip in children was reported [12]. The aim of this pilot-study was to investigate the effects of RF.DRG on spasticity in children with CP.

\section{Materials and methods.}

Inciusion

Children $(n=6)$ included in this study were seen in a multidisciplinary spasticity manalgement team. Individwal treatment goals were determent after a careful assessment of the etiology, functional ability and assaciated impairments as a result of the spasticity. During the last 3 years 137 patients were seen. Inclusion criteria for RF.DRG consisted of CP with spasticity of the lower extremities, with severe hip flexor/adductor spasms accompanied by pain or care giving difficulties. Children were not eligible for the RF.DRG treatment if no functional improvement was to be expected due to severe contractures. Patients characteristics are summarized in Table $\mathbb{1}$, all children suffered from mental retardation and failed to respond on oral medication and intramuscular Botulinum toxin type A treatment. 


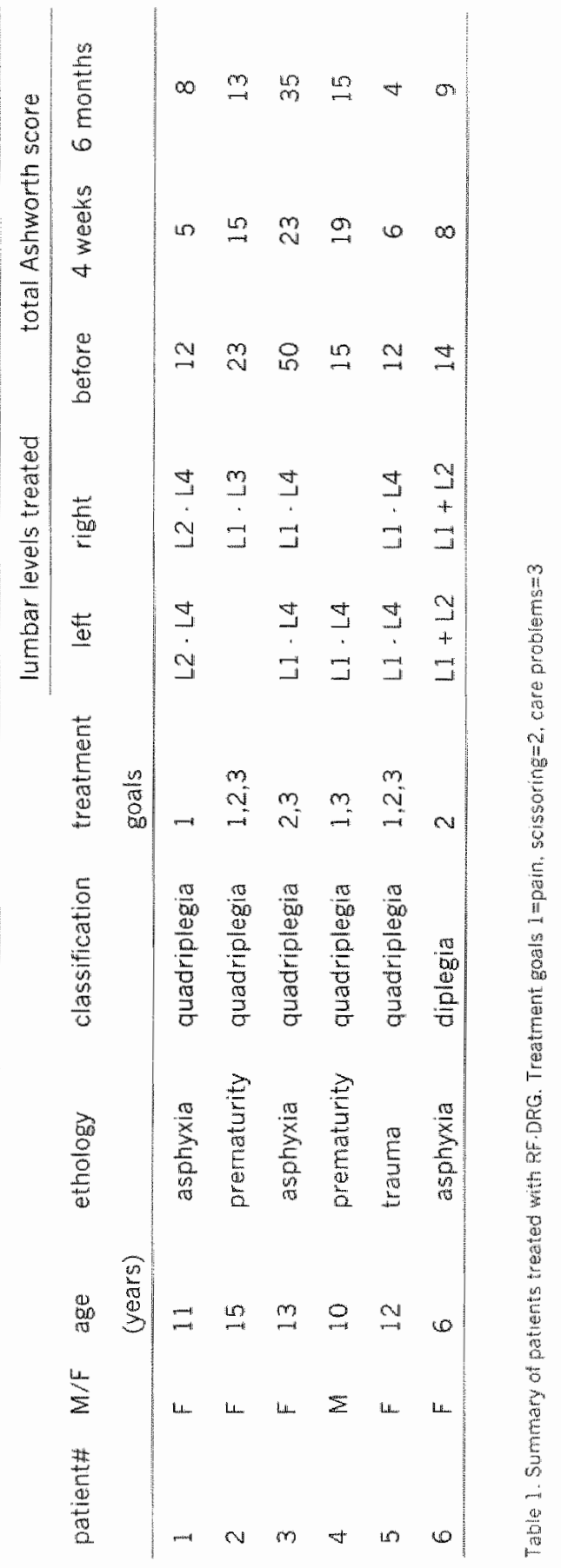


The study was approved by the ethical committee of the academic hospital Maasuricht, according to Dutch governmental regulations. Children were included in this study atter a written informed consent by the parents.

\section{RF DRG procedure}

All patients were treated in our outpatient clinic. After general anaesthesia, the patients were placed in a prone position on a operating table. The procedure was performed in tunnel vision technique, this term is assigned to a technique for entering the electrode in the direct vision of the $X$-rays. Therefore a mobile C.arm of a fluoroscopic apparatus (Philips bv 25) was positioned in such a way that the entry point on the skin was found just under the transverse proces and slightly wentral of the inferior articular proces of the relevant level. A $100 \mathrm{~mm} 22 \mathrm{G}$ SMK cannula (Radionics) with a $5 \mathrm{~mm}$ exposed tip was introduced at this entry point. Through slight manipulation, the tip of this electrode was placed in the craniodorsal part of the foramen. This position was contirmed with the C-arm in a lateral wiew (Figure la).

Then the C-arm was changed in an Anterior. Posterior position and the needle was advanced until the tip projected over the middle of the facetal column. The location of the cannula was tested using radio-opaque contrast (Omnipaque 0.5 ml) (Figure 1b). Then a radiofrequency probe (Radionics) was introduced. After checking the impedance (an indicator for the type of tissue next to the cannula tip), electrical stimulation was started at a rate of $2 \mathrm{~Hz}$ and the corresponding muscles were observed for contractions. Radiofrequency current was then led thirough the electrode in onder to increase the temperature to $67^{\circ} \mathrm{c}$ for 60 seconds. After full recovery from the anaesthesia, the patients were discharged at the same day.

\section{Study outher}

After inclusion, a baseline assessment was performed by a physical therapist (LP). The modified Ashworth scale was used for the assessment of changes in muscle tone [7]. In the Ashworth scale the muscle tone is scored on a 5 point 
scale, in which " 0 " represents no hypertonia or increase of muscle tone and " 4 " represents severe hypertonia and severe stiffiness of the extremities. In each patient hip flexion and adduction, knee flexion and extension and dorsal and plantar flexion in the ankle were tested in both legs.

Functional improvement was assessed using the Gross Motor Function Measure (GMFM), a widely used scale for evaluating treatment of spasticity in children with cerebral palsy consisting of 5 different locomotor domains [4, 8]. Furthermore, we developed a questionnaire for care-givers based on a visual analog scale (VAS). Besides items on pain, several items of daily activities of life. like dressing, undressing, and bathing, were investigated. Parents were asked to mark the items on a 11 point scale in which " 0 " represents a poor performance and "10" represents a good performance.

Short term (4 weeks) and long term ( 6 months) evaluation of the treatment was done by the same physical therapist using the instruments described above. Data were statistically analysed using a students $T$. test and a Wilcoxon signed rank test. A p value of $<0.05$ was considered to be statistically significant. All data are represented as means and standard error of means (SEM).
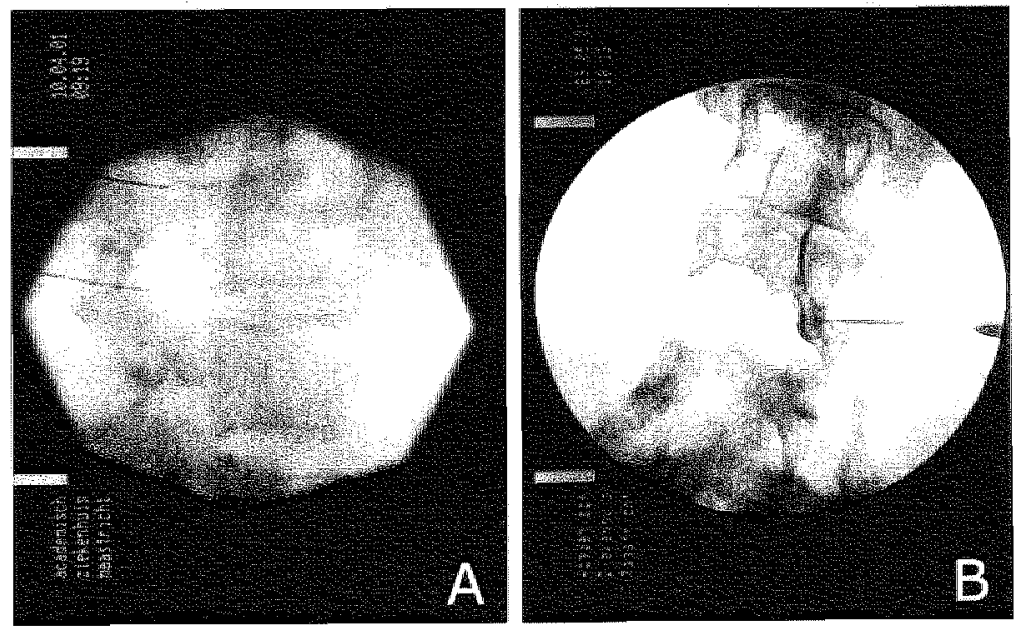

Figure 1. Photomichograph showng the posthon of a Rf electrode at lateral view and b: Anterior Posterior wisw, after injection of Omnipager. 


\section{Resuls}

AlI RF DRG procedures were performed without complications. No side effects like dysaesthesia or excessive weakness in the treated limbs were reported. An initial motor reaction, on the unilateral side, corresponding with the treated level could be observed during the first few seconds of the RF.DRG reatment in all patients. No significant differences were obserwed between the different lumbar levels for both the impedance and the stimulation threshold.

A significant improvement of muscle tone after RF. DRG could be detected on both the short (4 weeks) and long (6 months) term using the Ashworth scale. The mean overall Ashworth score (all evaluated joints included) before treatment was $21+/-6$, at 4 weeks after treatment the mean total score was $13+1-3(p=0.046)$ and after 6 months the mean totall score was $14 \mathrm{H} / .4(\mathrm{p}=0.043)$. Especially the right hip adductors showed improvement on the Ashworth score from $22+/ .0 .5$ before RF.DRG to $0.5+/ \cdot 0.2(p=0.031) 4$ weeks after RF.DRG and $1.0+1 / 0.4(p=$ 0.02) 6 months after RF.DRG.

The GMFM showed no improvement after RF.DRG treatment. At baseline a mean total score including all 5 domains of $17.2 \%+\%$ was observed. After 4 weeks the score was $17.3 \%+\% .7$ (not significant) and after 6 months the score was $16.2 \%+\%$ (not significant).

Using the care giwers questionnaire, an improvement in dally activities of life was detected. Although statisticaly not significant, in four patients an improvement of pain in the lower extremities was cletected, both at 4 . weeks and at 6 months. In one patient there was no change in pain and in another patient pain increased at 4 weeks but improved at 6 months as compared to the baseline. The mean total score of 5 ittems concerning dressing improved from $33+2.7$ to 39 $\$ 2.7$ on a total score of $50(p=0.024)$. Especially putting on trousers was more easy after a RF.DRG treatment, on a 10 point scale improvement was detected from $5.5+1.107 .5+\% \cdot 0.7(p=0.042)$ 


\section{Discussion}

The management of spasticity in chitdren with cereoral palsy remains complex. In the past decade BTX and SDR have been shown to be effective therapies in the treatment of spasticity. The major drawback of BTX is the recurrence of spasticity, the mean duration of the effect is approximately 3 months. Moreover, adverse ewerts of repeated BTX therapy have been reported [6].

One model of spasticity is the hypothesis that locomotor abnombalities are the result of hyperexcitability of spinal intermeurons involved in the spinal stretch reflex [13]. The reduction of spinal input through deafferentation is the basis of SDR. Although the results of SDR are promising in a selected population of children with CP, major surgery is involved and several adverse events have been described [11]. Modulating the spinal stretch reflex through partial deafferentation by RF.DRG could be a less invasive alternative for SDR.

We observed improvemert in muscle tone and care giving 4 weeks and 6 months after the RF.DRG treatment. The main treatment goal in all patients was reduction of scissoring due to aductor spasm of the hip. At 6 months we could still observe a reduction in hip adductor tone. No functional improvement could be detected using the GMFM. This most probably is due to the severity of cerebral palsy in our treatment group and the small number of treated children.

In a study by McLaughlin et al improvement in function using the GMFM could be detected in a randomized clinical trial investigating the efficacy and safety of SDR, however no difterences with the control group were detected [5]. Beneficial effects of RF. DRG in the treatment of spasticity in adults have been reported [2. 31. In these studies recurrent spasticity was seen atter 6 to 9 months, although the pre-operative level of spasticity was not reached. The results obtained in children in our study point in the same direction.

The mechanisms of action of RF.DRG remain largely unknown. In a recent study in the goat we demonstrated that RF.DRG increased proliferation inside the dorsal ganglion without causing damage (i.e. necrosis) of the neurons inside the ganglion [1]. Moreover, accumulated clinical experience with RF. DRG has shown 
that it is possible to alleviate pain without clinical signs of nerve damage or signs of motor denerwation [10].

We found that RF.DRG is an effective treatment for spasticity in children. The advantages are the less invasive and safe character of RF.DRG compared to the SDR. Furthermore, FR-DRG is an outstanding treatment for pain, a feature not treated with BTX. A relative disadwantage of RF.DRG could be the recurrence of spasticity. although the treatment can easily be repeated. In order to investigate the long term outcome and efficacy of RF.DRG, a randomized clinical trail comparing BTX and RF.DRG as a treatment for spasticity in children with CP has been started. 


\section{References}

1 de Louw A.J.A. Wes J.S.H., Freling G. Herpers M.J.H.M., Arends J.W. and van Kleef M. The morphological effects of a radiofrequency lesion adiacent to the dorsal root ganglion (RF.DRG) - An experimental study in the goat. Eur J Pain. 5 (2001) 169-174.

2 Herz D.A., Parsons K.C. and Pearl L. Percutaneous radiofrequency foramenal rhizotomies. Spine 8 (1983) 729.732.

3 Kasdon D.L. and Lathi E.S. A prospective study of radiotrequency rhizotomy in the treatment of postraumatic spasticity. Neurosurgery. 15 (1984) 526.529.

4 Kirschner J. Heinen F., Mall F., Linder M. Stein S. Michaels $U$. and Korinthenberg R. Gross Motor Function Measure for therapy evaluation in children treated with botulinum toxin A. Dev Med Child Neurol. 78 Suppil (1998) 11.

5. Mclaughlin J.F., Bjornson K.F., Astley S.J., Graubert C., Hays R.M., Roberts T.S. Price R. and Temkin N. Selectiva dorsal mizotomy" efficacy and salety in an investigatar-masked randonized clinical trial. Dew Med Child Neurol. 40 (1998) 220-232.

6 Mohamed K.A. Moore A.P. and Rosenbloom L. Adverse events following repeated injections with botulinum toxin $A$ in children with spasticity. Dev Med Child Neurol. 43 (2001) 791.792 .

7 Richardson D. Climical rating of spasticity. I edn. Churchill Communications Europe Ltd. London. 1998, 39.50.

8 Russell D., Rosenbaum P.. Gowland C. Hardy S., Lane M., Plews N., McGavin H., Cadman D. and Jarvis S. Manual for the Gross Motor Funtion Measure. Hamilton ON, Mc Master Universily. 1993.

9 Uematsu S., Udvarhelyi G.B., Benson D.W. and Siebens A.A. Percutanedus radiofrequency hizizotomy Surg Neurot. 2 (1974) 319.25.

10 van Kleef M.. Spaans F., Dingemans W.A.A.M., Barendse G.A.M.. Foor E. and Sluijter M.E. Effects and side effects of a percutaneous themal lesion of the dorsal root gangion in patients wilh cervical pain syndrome. Pain. 52 (1993) 49.53.

11 Vaughan C.L., Subramanian N. and Busse M. E. Selective dorsal mizotomy as a treatment option for children with spastic cerebral palsy. Gat Posture. 8, 1998$) 43.59$.

12 Vles J.S.H. wan Kleef M. Sleypen F., Bulstra S., Szpath K. Luickx G.J. Beuls E., Sluyter M.E. and Troost A. Radiofrequency lesions of the dorsal root ganglion in the treatment of thip flexor spasm: a report of two cases. Eur J Paed Neurol. 4 (1997) 123.126.

13 Young R.R. Spasticity: a review. Neurology. 44 (1994) 512.20. 



Although the origin of the locomator impairment in children with cerebral palsy is embedded in the term cerebral palsy itself, the spinal cord is at least partially responsible for some of it's clinical features. It is commonly accepted that cerebral palsy is the result of different pathological conditions during pre. and postnatal development [21]. Among these pathological conditions, perinatal asphyxia is responsible for approximately 10 to 20 percent of the cases of cerebral palsy [24]. There are numerous animall studies on the effects of perinatal asplyxia on the developing brain, using different models (see introduction) Surprisingly, virtually no studies have been done on the effects of perinatal asphyxia on the (developing) spinall cord. whereas the spinal cord is indispensable in controlling locomotion.

The results of our animal studies show abnormal development of the spinat cord after perinatal asphyxia and support a role for the spinal cord in the pathophysiological mechanisms of spasticity.

\section{Apoptosis}

Besides normal developmental apoptosis, we observed an increase in apoptotic cell cleath in the intermediate zone of the lumbar spinall cord after perinatal asphyxia. The observed increase in apoptotic cells in the lumbar spinal cond after perinatal asphyxia, most probably will have an effect on the normal development of local spinall cord networks at this level.

Besides an increase in apoptatic cells in the spinal cord, apoptotic neuronal 
loss in the neGnatal rat stratum after perinatal asphyxia has been detected [32] In the human nenatal brain, perinatal asphyxia is known to cause brain lesions in several regions. The location of the lesions is dependent on the severity of the asphyxia and the developmental stage of the neonate (e.g. full-term or pre-term) $[7]$.

Cerebral lesions, as all CNS lesions, are known to inflict damage on remote cells within the CNS through a process called transneuronal degeneration. In transneuronal degeneration, the target cells atrophy and/or die after distuption of the major inputs from the afferent cell [14]. The observed increase of apoptotic cell deatl" in the lumbar spinal cord after asphyxia in our study, could to our opinion not be the result of transmeuronal degeneration, because corticospinal axons originating from sensorimotor cortex neurons only reach their target at the mid lumbar level at the fifth postnatal day [13]. The lumbar gray matter targets are not yet reached at postnatal day two, thus the observed increase in apoptotic cell death most probably is not secondary to cerebral lesions.

We demonstrate apoptosis in the white matter of the developing spinal cord of nomal postmatal rats. Apoptotic cells could be identified as oligodendrocytes and activated microglia. This observation was made serendipitously while studying the effects of perinatal asphyxia on the developing spinal cord in rats. To our knowledge no studies have previously reported developmental apoptosis in the rat spinal cord white matter. These findings imply a role for apoptosis in the spinal cord white matter in the development of normal locomotor behavior.

The increase in apoptosis after perinatal asphyxia was mainly observed in the lumbar intermediate zone (Rexed's lamimae IV-VII) at postnatal day 2 . In the spinal cord intermediate zone abundant numbers of interneurons thave been described [4]. Therefore, we speculated that part of the apoptotic cells observed in our study could be interneurons. There are some other studies on apoptosis of spinal interneurons during normal dewelopment which supported apoptosis of interneurons $[16.19]$. In these studies, as well as in our study, no direct ewidence was found for interneuron apoptosis by means of double immunostaining techniques. To date no reliable marker for interneurons has been developed. 
The functions of spinal interneurons are to mediate an inhibitory effect upon motor neurons [30]. In spasticity. it has been suggested that these interneurons do not function normally, probably by making false connections [8, 37].

The concept of spinal interneuron involvement in the pathophysiological mechanisms of spasticity has mainly been studied by measuring changes in reflex excitabilty using neurophysiological techniques [31]. Our studies in an animal model for perinatal asphyxia provide additional direct evidence for spinal cord involvement. In the studies described in this thesis, no functional outcome parameters were assessed after perinatal asphyxia. Future studies on the effect of perinatal asphyxia on the spinal cord should involve meurophysiological techniques like sensory evoked potentials and EMG in order to clarify the functional implication of the observed increase in interneuron apoptosis.

\section{Cyclic GMP}

When starting the studies on the effects of perinatal asphyxia on the spinal cord, Hitle was known about the localization and dewelopmental changes of No or ANP mediated cGMP synthesis in the rat spinal cord. We abserved abundant NO. mediated cGMP synthesis in all laminae of the rat cervical spinal cord. Moreover, NO cGMP synthesis was observed in laminea 1 .lll in 14 day-old rats, which activity was nearly absent at the age of 3 manths. Using double immunostaining techniques, NO.mediated and ANP mediated cGMP immunoreactive (cGMP.IR) cells in both the gray and white matter could partially be identified as astrocytes and GABAergic (parvalbumin positive) neurons.

The observation of NO mediated cGMP synthesis in GABAergic cells in laminae 1.1II of the rat cenvical spinal cord raised the question wether GABA could activate nNOS to synthesize NO, which, as a retrograde messenger molecule, would activate CGMP symthesis in GABAergic terminals. Therefore we investigated the effects of Baclofen on CGMP synthesis. The GABA agonist Baclofen is a widely used drug in the treatment of spasticity [38].

In normal rats we found an inhibitory effect of Baclofen on the ANP.mediated CGMP synthesis in laminea 1.lll of the cervical spinal cord at the age of two weeks 
and two months. This inhibitory effect of Baclofen could not be detected after the incubation with the NO donor SNP. From a structural point of view the inhibitory effect of Baclofen on ANP induced activation of particulate guanylyl cyclases is surprising. Nevertheless, isatin (indole 2,3 dione) which is also structurally unrelated to ANP has been described as an inhibitor of PGC [5]. Recently it was shown that isatin inhibits $P G C$ independent of the occupation of the ANP receptor [20]. Activation of GABA, receptors might result in activation of phospholipase $A$ and potentiation of CAMP formation [6]. Thus, the effect of Baclofen might irvolve triggering of a phosphorylating/dephosphorylating cycle of the intracellular part of the ANP receptor and subsequently downregulation of the pGC activity [23].

In the study describing the effects of perinatal asphyxia on the ANP and NO mediated CGMP synthesis, a small part of the ANP mediated CGMP.IR cells could be identified as astroglial cells on the basis of their GFAP immunostaining. Double immunostained cells were mainly detected in the SPA group under 2 experimental conditions: after stimulation with ANP allone and after stimulation with ANP in the presence of $100 \mu \mathrm{M}$ Baclofen. No colocalization between ANP mediated CGMP.IR and GFAP was observed in the control group.

To date, the rolle of natriuretic peptides in CNS physiology and pathology is still rather unclear. In a recent study in humans an increase was observed in ANP immunareactive astrocytes after brain ischemia [22]. Furthermone, in an electrophysiological study the presence of AlvP receptors on cultured spinal cord astrocytes was demonstrated [11]. Nevertheless, the findings of both the decreasing effects of Bacloten on ANP mediated cGMP synthesis in the normal rat spinal cord and the observed ANP mediated CGMP synthesis in astroglial cells after perinatal asphyxia, remain difficult to explain.

In addition. we found an increase in NO mediated CGMP in laminae 1 -11 after stimulation with SNP in the presence of $100 \mu \mathrm{M}$ Baclofen after perinatal asphyxia. Activation of the GABA receptor in the dorsal horn is known to inhibit the release of both glutamate (excitatory) and GABA (inhibitory) in the spinal dorsall horn [12]. Using a whole cell voltage clamp recording technique, Yang et al showed a slow outward inhibitory current in dorsal horn neurons after bath application of 
Baclofen [36]. Our results suggest that the inhibitory effects of Baclofen are at least partly NO-CGMP and/or ANP-cGMP mediated. A possible future study to elucidate the effects of Baclofen on the NO and ANP mediated CGMP symthesis should involve cell cultures of spinal astrocytes.

\section{Rat model for perinatal asphyxia}

We used an animal model for perinatal asphyxia described by Loid el al, a representative model for the clinical situation of perinatal asphyxia [18]. Regarding our studies, the major drawback of this model is the lack of clinical features of spasticity in the rat after perinatal asphyxia. In rats, spasticity has only been described in the so called mutant Han-Wistar rats [34].

A parallel between perinatal asphyxia in rats and the human situation during birth is difficult to make. A substantial difference between CNS maturation at birth exists between the two species [1]. Studies describing the effects of perinatal asphyxia on the spinal cord of human neonates are rare. In the few published studies on the effects of perinatal asphyxia on the human spinal cord. signs of ischemia and necrosis have been described [2.25].

Knowing the results obtained in animal experiments and their limitations, it seems inevitable to further investigate the effects of perinatal asphyxia on the brain and spinal cord using pastmortem tissue of human neonates.

Radiofrequency lesion adjacent to the dorsal root ganglion

In the last three chapters of this thesis the use of a radiofrequency lesion adjacent to the dorsal root ganglion (RF.DRG) for the treatment of spasticity in children with cerebral palsy is described. In RF.DRG treatment, as in all neurosurgical interventions for spasticity, reduction of spasticity is established through interruption of the stretch reflex in onder to decrease excitation of spinal neural networks [28]. The beneficial effects of a RF.DRG in the treatment of spasticity in adults has been demonstrated in the 1980's [9. 15]. Whereas the clinical effects of a RF.DRG lesion in the treatment of pain have been well described, the exact mechanism of action of the RF. DRG lesion itself remains 
unknown [33].

In order to investigate the effects of a RF.DRG on the dorsal root ganglion and the spinal cord, we deweloped a rat model. We firstly intended to perform a percutaneous RF.DRG in the rat model, parallel to the technique used in the patient. Due to the small diameter of the ganglion in the rat and the relative lairge diameter of the radiofrequency probe, we did not succeed in producing a reproducible lesion. In a larger animal this would not have been a problem [3].

Nevertheless, for logistic reasons, we choose to perform a laminectomy in the rat in order to have a direct wiew on the dorsal root ganglion. Based on the lack of c. Fos IR immunoreactivity (C.Fos IR) in the sham operated rats and the morphological localization of the treatment site (outside the ganglion) in both the sham and the RF.DRG treated rats, we believe that the open surgical model is a good alternative for the percutaneous modell.

Seven days after radiofrequency treatment of the dorsal root ganglion we observed an increased expression of c. Fos $\mathbb{R}$ in motor neurons, astrocytes and activated microglia in the spinal cord, both ipsi. and contra lateral, after a unilateral RF.DRG treatment. At post operative day 7 the expression of c.Fos protein was found to be cytoplasmic and not nuclear.

Induction of c.Fos in the rat spinal dorsal horn has been described within several hours after dorsal rhizotomy and after a RF.DRG lesion [10. 29]. In our study, the long term effects of a radiofrequency lesion adjacent to the dorsal root ganglion in the adult rat were not only found to be within the dorsal horn, but also on relatively remote spinal motor neuroms. The observation of c.Fos expression in neurons remote from the lesion site has been described before. Cytoplasmic expression of Fos immunoreactivity in cervical spinal cord motor neurons (bilaterally) has been reported after focal (unilateral) cerebral ischemia [35]. in this study it was suggested that the remote c. Fos expression was due to "transneural degeneration "as a result of deprivation of afferent inputs following the death of corticospinal neurons.

To date, the effects of a radiofrequency treatment of the dorsal ganglion were thought to be merely by reducing afferent input on spinal cord neurons. In our 
study we demonstrated that the clinical effects of a RF.DRG treatment in spasticity seems to be two folded. Firstly, by reducing afferent input and secondly by a remote effect on motor neurons possibly resulting in a reduction of efferent output.

A future direction of the studies on the effect of RF.DRG lesions in the rat, both in mormal rats and after perinatal asphyxia, should involve neurophysiological parameters like electromyography, in order to investigate the functional implications of the lesion, especially related to the effects on efferent output.

A second future direction on the effects of RF.DRG on the rat spinal cord and dorsal root ganglion will focus on different techniques to perform a RF. DRG lesion. In our study we used a continues radiofrequency current at $67^{\circ} \mathrm{C}$. In a recent study no difference could be observed in the outcome of pain treatment between a $67^{\circ} \mathrm{C}$ and a $40^{\circ} \mathrm{C}$ lesion [26]. Pulsed radiofrequency (PRF), a non destructive method of exposing tissue to RF electric frelds at $42^{\circ} \mathrm{C}$ with potentially lesser side effects. was recently proposed by Sluijter [27]. A study comparing the effects of a RF and a PRF lesion on the spinal cord and the dorsal root ganglion is conducted at the moment.

The preliminary results obtained in our study on the effects of a RF.DRG lesion in the treatment of spasticity, are promining. However only a small group of children was included in this pilat study. Moreower, no data was awailable on the long term outcome after treatment. In earlier studies on RF.DRG treatment of spasticity in adults, recurrent spasticity was seen after 6 to 9 months, although the pre-operative level of spasticity was not reached [9. 15$]$. Momentarily, a randomized clinical trial comparing Botulinum toxin A, RF-DRG and physical therapy allone in the treatment of spasticity has been started, with an emphasis on both short and long term outcome. 
Final remarks

In 1861. Little presented his magnum opus on the locomotor changes after difficult birth [17]. With the statement that the features of spasticity are (partially) related to lesions of the spinal cord, he proved to be a visionary. Little by little we have started to investigate the effects of perinatal asphyxia on the developing spinal cord. 


\section{References}

1 Clancy B., Darlington R.B. and Fintay B.L. Translating developmental time across mammalian species. Neuroscience. 105 (2001) $71 \%$.

2 Clancy R.R., Sladky J.T. and Rorke L.B. Hypoxic ischemic spinal cord injury following pernatal asphyxia. Ann Neurol. 25 (1989) 185. 189.

3 de Louw A.J.A., Vles J.S.H., Freling G., Herpers M.J.H. M., Arends J.W. and wan Kleef M. The morphological effects of a radiofrequency lesion adjacent to the dorsal noot ganglion (RF.QRG). An experimental study in the goat. Eur J Pan. 5 (2001) 169.174.

4 Eide A.L., Glover J., Kjaerulff 0 , and Kiehn 0 . Characterization of commissural interneurons, in the lumbar region of the neonatal rat spinal cord. $J$ Comp Neurol, 403 (1999) 332345 .

5 Foster D.C. and Garbers D.L. Dual role for adenine nucleotides in the reguation of the atrial natriuretic peptide receptor, guanylyl cyclase.A. J Biol Chem. 273 (1998) 1631 1. 16318.

6 Glover $V_{.}$, Medvedev A. and Sandler M. Isatin is a potent endogenous antagonist of guanylate cyclase coupled atrial natriuretic peptide receptors. Life Sci. 57 (1995) 2073. 2079.

7 Goddard. Finegold J. Perinatal aspects of cerebral palsy. in G. Miller and G.D. Clark (Eds.) The cerebral palsies. Butterworth-Heinemann. Boston. 1998. pp. 151172.

8 Harrison A. Spastic cerebral palsy: Possible spinal intemeurat contributions. Dev Med Child Neurol. 30 (1989) 769.780.

9 Herz D.A. Parsons K. and Pean L. Percutaneous radorrequency foramenal mizotomies. Spine. $8(1983) 729732$

10 Higuchi Y., Nashold B.S. Sluigter M. Cosmen E. and Peartsten R.D. Pused radiofrequency stimulation of the dorsal root ganglion in rats selectively activates dorsat horn lamina I and II neurons. Neurosurgery, 50 (2002) 850856

11. Hosli E, and Hosh L. Autoradiographic localization of binding sites for argmane vasopressin and atral natriuretic peptide on astrocytes and neurons of culturad rat central newous system. Neuroscience. 51 (1992) 159 -166.

12 lyadomi M. Yyadomi I. Kumamoto E., Tomakuni K. and Yoshimura M. Presynaptic inhibition by baclofen of miniature EPSCS and PSCS in substantia gelatinosin neurons of the adult rat spinal dorsal horm. Pain. 85(2000) 385.393 . 
13 Joosten E.A. Bar P.F. and Gspen W.H. Corlicospinal axons and mechanism of target innervation th ra lumbar spinal cord. Brain Res Dev Brain Res. 79 (1994) 122.127.

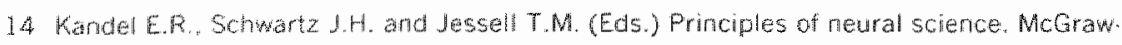
Hith New York 2000,1414 pp.

15 Kasdon D.L. and Lath E.S. A prospective study of radiofrequency rhatomy in the Ireatment of postraumatic spasticity. Neurosurgery. 15 (1984) 526.529.

16 Lawson S.J., Daves W.J., Bennet J.P. and Lowrie M.B. Evdence that spinal interneurons undergo programmed cell death postnatally in the rat. Eur I Neurosci. 9 (1997) 794 . 799.

17 Lithe W.J. On the influence of abnormal parturation, difficult labors premature birth. and asphyxia reonatorum, on the mental and physical condition of the child especially in relation to deformities. Trans Obstef Soc. 3 (1861) 293344.

18 Loid C.F. Gavilanes A.W., Van Dikk E.H., Vreuls W. Blokland A. Vtes J.S.FH, Steinbusch H.W.M. and Blanc C.E. Effects of hypothermia and gender on survial and behavior atter perinatal asphyxia in rats. Physiol Behav. 68 (2000) $263-269$.

19 Lowrie M.Q. and Lawson S.J. Cell death of spinal interneurones. Prog Neurobiol. 61 (2000) $543 \cdot 555$

20 Medvedev A. Sandler M. and Glower $V$. The inthence of isatin on guanylyn cyclase of rat heart mentbranes. Eur J Pharm. 384 (1999) 239.241.

21 Melson K. B. and Willougmby R.E. Infection, inflammation and the risk of cerebral palsy. Curr Opin Neurol. 13(2000) 133.139.

22 Nogami W. Shiga J. Takatsu $A_{\text {. }}$ Endo N. and Itabashiku K. Immunohistochemistry of atrial natriuretic peptide in brain infarction. Histochem J. 33 (2001) 87.90 .

23 Potter L.R. and Hunter T. Guanyly cyclase hinked natriuratic peptide receptors: structure and regulation. J Biol Chem. 276 (2001) $6057-6060$.

24 Pschirer E. R. and Yeomans E. R. Does asphyxia cause cerebral palsy? Semin Perinatol. $24(2000) 215 \cdot 220$.

25 Sladky J.T and Rorke L.B. Perinatal hypoxic/ischemic spinal cord injury. Pediatr Pathol. $6(1986) 8 \% \cdot 101$

26 Slappendet R. Grit B.J.P. Baak G.J.J., Geurs J.W.M., Bonj L.H.D.J., Voeman W.F. and de Bon T. The efficacy of radiofequency lesioning of the cermical spinal dorsal root ganglion in a double binded randomized stwdy: no difference between $40 \mathrm{C}$ and $67 \mathrm{C}$ treatments. Pain. 73(199\%) 159.163.

27 Stuliter M.E. The role of radiofrequency in falled back surgery patients. Curr Rev Pain. 4 (2000) $49 \cdot 53$ 
28 Smyth M.D. and Peacock W.J. The surgical treatment of spasticity. Muscle nerve. 23 (2000) $153 \cdot 163$

29 Sugmoto T., Yoshida A., Nishimak Kand Ichikawa H. C. Fos induction in the rat spinal dorsal hom partialy deafferented by dorsal rhizotomy. Neurosci Lett. 178 (1994) 239. 242.

30 Takakusaki K., Konyam J., Matsuyama K. and Mori S. Medullary reticulospinal tract medlating the generalized motor inhibition in cats: parallel inhibitory mechanisms acting on motoneurons and on interneuronal transmission in reftex pathways. Neuroscience. $103(2001) 511.527$.

31 Thompson F.J. Pamer R., Reier P.J., Wang D.C. and Bose P. Scientific basis of spasticity: insights from a laboratory model. J Child Nesrol. 16 (2001) 29.

32 van de Berg W.D.J. Schmitz C., Steinbusch H.W.M. and Blanco C.E. Perinatat asphyxia induced neuronall loss by apoptosis in the neonatal rat striatum. A combined TUMEL and stereological study. Exp Neurol. 174 (2002) 29-36

33 van Kleet M., Spaans F., Dingemans W.A.A.M. Barendse G.A.M. Floor E. and Stuiter M.E. Effects and side effects of a percutaneous thermal lesion of the dorsal root ganglion in patient's with ceirvical pain syndrome. Pain. 52 (1993) 49.53

34 Wagemann E., Schmidt Kastmer R. Block F. and Sontag K.H. Neuronal degeneration in hippocampus and cerebellum of mutant spastic Han Wistar rats. Neurosci Lett. 121 (1991) $102 \cdot 106$.

35 Wu Y.P. Tan C.K. and Ling E.A. Expression of Fos.like immunoreactivity in the brain and spinat cord of rats following middle cerebrall artery occlusion. Exp Brain Res. 115 (1997) $129 \cdot 136$

36 Yang K. Wang D. and Li Y. Distribution and depression of the GABA(B) receptor in the soinal dorsal hom of adult rat. Brain Res Bull. 55 (2001) 479.485 .

37 Young R.R. Spasticity: a review. Neurology. 44 (1994) S12.20.

38 Zamir N. Shofisch G. Eskay R.L. and Jacobowitz D.M. Distribution of immunoreactive atrial natriuretic peptides in the central newous system of the rat. Brain Res. 365 (1986) $105 \cdot 111$ 





\section{Summary}

The present thesis was designed to investigate the effects of perinatal asphyxim on the spinal cord in order to better understand the pathophysiological mechanisms of spasticity in children with cerebral palsy. Moreover, based on the findings in an animal model, an attempt is made to introduce a treatment option for spasticity.

\section{Chapter 1}

In Chapter 1, am introduction is given on the present knowledge of the pathophysiology of perinatal asphyxia, cerebral palsy and spasticity in relation to the current treatment options and the morphological and biochemical concepts. used in this thesis. Furthermore, the general aims of the studies in this thesis are introduced.

\section{Chapter 2}

In Chapter 2 an immunocytochemical technique was used to study the localization and developmental aspects of GMP.synthesizing structures in the cervical spinal cord of 2 weeks and 3 months old Lewis rats in response to the nitric oxide (NO) donor sadium nitroprusside (SNP) and/or atrial natriuretic peptide (ANP). By using cell-specific markers, the cell structures involved were investigated. Nos. mediated cGMP synthesis was observed in the cervical spinal cord in laminae I, II and 11 in 14 days old rats, which activity was mainly absent at the age of 3 months. Using confocal laser microscopy, Na-mediated CGMP synthesis was observed in large cholinergic terminals nearby motor neurons in the ventrall horn. An extensive co-localization between NO-stmulated cGMP synthesis and parvalbumin positive (GABAergic) neurons and fibres was observed in all laminae. In the ANP.stimulated condition a colocalization with parvalbumin structures was found in laminae ll and 내.

In conclusion, our data show the presence of an abundant NO-cGMP signaling 
system in all layers of the spinal cord. The NO mediated cGMP synthesis takes place in parvalbumin (GABAergic) neurons and in the ventral horm in axon terminals probably connecting to the motor neurons. In addition CGMP synthesis can be found in a subpopulation of glial cells either through activation of pGNC and/or SGNC.

\section{Chapter 3}

In Chapter 3 we investigated developmental apoptosis in the white matter of the neonatal rat cervical spinal cord at postnatal day 2, 5, and 8. Apoptotic cells were labelled using TUNEL and caspase-3 immunostaining. Apoptotic cells were diffusely distributed throughout the white matter of the spinal cord. The total amount of apoptotic cells in the cervical spinal cord white matter was related to postinatal age, being the lowest at P2 (mean 7.9, SD 5.6) and the highest at P\& (mean 109, SD 21.4). Using double immunostaining for EDI and 04 , apoptotic cells. could be identified as microglia and oligodendrocytes.

\section{Chapter 4}

In Chapter 4, we investigated the effect of perimatal asphyxia on developmental apoptosis in the cervical and lumbar spinal cord in the neonatal rat.

Perinatal asphyxia was induced by keeping pups at term in utero in a water bath at $37^{\circ} \mathrm{C}$ for $20 \mathrm{~min}$. followed by resuscitation. Effects of this treatment on developmental apoptosis were studied at postnatal day 2,5 and 8 using TUNEL and caspase-3 staining. TUNEL positiwe cels were characterized using double Ummunostaining.

On postnatall day 2 an increase of $215 \%$ in TUNEL positive cells was detected (p $=0.005$ ) in laminae IV.VII of the lumbar spinal cord of rats that underwent perinatal asphyxia compared to controls. TUNEL positive cells could be partly characterized as microglial cells (EDI positive) and oligodendrocytes (OA pasitive).

As the effect of perinatal asphyxia on programmed cell death in the neonatal rat spinal cord was mainly observed in the intermediate zone and dorsal horn of the lumbar spinal cord, it is concluded that this may have a profound effect on the 
development of motor networks.

\section{Chapter 5}

In Chapter 5 we report an inhibitory effect of Baclofen on the ANP. mediated CGMP synthesis in the superficial dorsal horn (laminae 1.111) of the rat cervical spinal cord. This inhibitory effect of Baclofen could not be detected after incubation with the NO donor SNP. Baclofen is the drug of choice in treating spasticity, therefore these results point to a possible role of ANP in controlling spinal locomotor networks.

\section{Chapter 6}

In Chapter 6 we investigated the effects of permatal asphyxia and the infuence of Baclofen on the ANP and/or SNP mediated CGMP synthesis in the adult rat cervical spinal cord. In normal rats, a decreasing effect of Baclofen on ANP mediated cGMP synthesis was observed, while an increasing effect on No mediated CGMP synthesis was observed after perinatal asphyxia. Our results suggest that the effects of Baclofen in the spinal cord are at least partially No. cGMP mediated.

\section{Chapter 7}

In Chapter 7 we investigated the long-term effects of a RF.DRG treatment on the spinal cord using c.Fos immunoreactivity. Furthemore, we used different immuno. cytochemical markers to identify C.Fos immunoreactive (C. Fos IR) cells.

In 6 Wistar rats a laminectomy was performed. RF.DRG treatments were performed adjacent to 6 dorsal ront ganglions, and 6 ganglions were used as sham operated controls. Moreover, one rat was used as double control. Tissue was investigated at postoperative day 7 .

C.Fos IR cells were detected both ipsi. and contralateral of the treatment side. Furthermore, c.Fos IR cells could be identified as activated microglia, astrocytes and motor neurons but not as aligodendrocytes.

We conclude that the long.term effects of a RF.DRG treatment can be detected 
in all Rexed's laminae both ipsi-and contra-lateral after an unilateral treatment. We turhermore suggest that the clinical effects of a RF.DRG treatment in spasticity are possibly due to interference with both afferent input into the spinal cord and efferent output from the spinal cord.

\section{Chapter 8}

In Chapter 8 , in a review, the present pathophysiological mechanisms of spasticity and its treatment options are reviewed. Furthermore, the use of radiofrequency lesions of the dorsal root ganglion in the treatment of spasticity in children with cerebiral palsy is reviewed.

\section{Chaster 9}

In Chapter 9 we investigated the effects of a radiofrequency lesion of the dorsal root ganglion in the treatment of spasticity in children with cerebral palsy on muscle tone and daily activities of life. We found a beneficial effect 4 weeks and 6 months after treatment without signs of side effects.

\section{Chapter 10}

In Chapter 10, the morphological and biochermical findings in the spinal cord after perinatal asphyxia in the rat are discussed. Furthermore, an attempt is made to put the findings in the rat model in a clinical perspective. Especially for the use of the radiofrequency treatment of the dorsal root ganglion as a treatment for spasticity in children with cerebral pallsy. Moreover in this chapter, future studies on the role of the spinal cord in the pathophysiological mechanism of spasticity are described

With the studies that form this thesis we "little by Little" have started to investigate the effects of perinatal asphyxia on the developing spinal cord. 


\section{Samenvatting}

Het leven van een kind met cerebral palsy kan ernstig beperkt zijn. Deze beperkingen worden ondemeer veroorzaakt door de gevolgen van spasticiteit. zoals verminderde mobiliteit, pinklachten en verzorgingsproblemen. Het excacte pathofysiologische mechanisme van spasticiteit bij cerebral palsy is nog niet geheel bekend. Tot op heden wordt de oorzaak van cerebral palsy vooral gezocht in de hersenen, zoals het woord cerebral in cerebral palsy al aangeeft. De invloed van de hersenen op het klinisch beeld van cerebral paisy is ongetwijfeld groot, alhoewel niet alle klinische verschijnselen zijn te verkliaren door heirsenschade. Met name de beperkingen in motoriek zouden ook een oorsprong kumnen hebber op een lager niveau van het centrale zenuwstelsel namelijk het ruggenmerg. Deze klinische constatering vormt de basis van de studies waaruit dit proefschift bestaat.

Op dit moment bestaat er nog geen behandeling waarmee we spasticiteit kumnen voorkomen. De huidige behandeling richt zich dan ook wooral op het verminderen vam bovengenoemde problemen. Een beter inzicht in de pathofysiologie van spasticiteit kan mogelijk leiden tot meer rationele behandelmethoden.

Het klinisch beeld vam cerebral palsy wordt veroorzaakt door uiteenlopende aandoeningen welke voor een deel onbekend zijn. Bij een deel van de kinderen is perinatale asphyxie de oorzaak van cerebral palsy. In dit proefschrift worden de effecten van perinatale asphyxie op het ruggenmerg van de rat onderzocht, om aen beter inzicht te krijgen in het pathophysiologische mechanisme van spasticiteit bij kinderen met cerebral palsy. Daarnaast wordt de radiofrequente laesie naast het dorsale ganglion als mogeilike behandeling voor spasticiteit bij kinderen gentroduceerd.

\section{Honfolstuk 1}

Hoofdstuk 1 bestaat uit een algemene introductie van de onderwerpen die in de verschillende hoofdstukken aan de orde komen. De huidige inzichten in cle pathophysiologische mechanisme van perinatale asphyxie, cerebral palsy en 
spasticiteit worden besproken in relatie tot de morphologische (geprogrammerde celdood) en biochemische (NO.CGMP signaal transductie) concepten die voor de verschillende studies worden gebruikt. Daarnaast worden de doelen van de verschillende studies beschreven.

\section{Hoofdstuk 2}

In hoofdstuk 2 hebben we de expressie wan cGMP in reactie op stimulatie met de NO donor sodium mitropursside (SNP) en /of atrial natriuretic peptide (ANP) in het ruggenmerg gedurende de normale ontwikkeling van de rat bestudeerd. Met behulp van immunocytochemische technieken en celspecifieke markers hebben we de betrokken celstructuren onderzacht. Op de $14^{3}$ postnatale dag wordt NoS gemedieerde CGMP synthese waargenomen in laminae I-lll van het cervicale ruggenmerg, deze activiteit is vrijwel geheel verdwenen op de leeftijd van 3 maanden. Met behulp van confocale laser microscopie wordt NO gemedieerde cGMP synthese gezien in grote cholinerge axon-uiteinden op motor neuronen in de ventrale hoom. In alle laminae hebben we een overvloedige co fokalisatie waargenomen tussen NO gemedieerde cGMP synthese en parwalbumine (GABAerg) positieve neuronen en vezels. Na stimulatie met ANP wordt deze co-lokalisatie tussen cGMP en parvalbumine waargenomen in lamimae I en II.

Concluderend laten onze resultaten een overvloedige aanwezigheid van het NOCGMP signaal transductie systeem in alle laminae van het cervicale ruggenmerg zien. Bovendien vindt de NO gemedieerde CGMP synthese plats in parvalbumine positieve (GABAerge) neuronen en in axon-uiteinden die mogelijk uitkomen op motor neuronen in de ventrale hoorn. Daarnaast wordt cGMP synthese waargenomen in een subpopulatie van gliale cellen na stimulatie van zowel particulated guanylaat cyclase (ANP) of soluble guanylaat cyclase (SNP).

\section{Hooidstuk 3}

In hoofdstuk 3 wordt de aanwezigheid wan apoptose in de witte stof wan het ruggenmerg van neonatale ratten gedurende de normale ontwikkeling beschreven. Door middel wan TUNEL en caspase.3 immumocytochemische kleuringen worden 
apoptotische cellen gezien in de gehele witte stof wan het ruggenmergvan de rat. Het totale aantal apoptotische cellen in de witte stof is het laagste op de tweede dag post nataal en het hoogste op de achtste dag postnatal. Mel behulp van dubbelkleuringen hebben we een deel van de apoptotische cellen geidentificeerd als microgliale cellen (EDI positief) en oligadendrocyten ( 04 positief).

\section{Hoofdstuk 4}

In thoofdstuk 4 wordt het effect van perinatale asphyxie op apoptose gedurende de ontwikkeling in het cervicale en lumbale ruggenmerg van de rat beschreven. Pierinatale asphyxie wordt geinduceerd door à terme rattenpups in utero bloot te stellen aan onderdompeling in water van $37^{\circ} \mathrm{C}$ gedurende 20 minuten, gevolgd door resuscitatie. De effecten van deze behandeling zijn bestudeerd door middel van TUNEL en caspase-3 immunowtochemische kleuringen op dag 2,5 en 8 postnataall. We hebben de TUNEL positieve cellen geidentificeerd met behulp van dubbelkleuringen.

Na perinatale asphyxie zagen we op dag 2 postrataal een toename in TUNEL positieve cellen in laminae IV VII van het lumbale ruggenmerg wan $215 \%$ ( $\mathrm{p}=$ 0,005). De TUNEL positieve cellen hebben we gedeeltelijk kunnen identificeren als microgliale cellen (EDI positief) en oligodendrocyten ( 04 positief).

In de pathofysiologie van spasticiteit spelen spinale interneuronen een belangrijke rol. Aangezien in deze studie de meeste toename vam apoptotische celdood na asphyxie is wargenomen in gebieden war zich veel interneurohen bevinden, vermoeden wij dat deze toename een effect kan hebben op de ontwikkeling van spinale locomotor netwerken.

\section{Hooldstuk 5}

In hoofdstuk 5 rapporteren wij een remmend effect van bacloten op de ANP. gemedieerde CGMP synthese in de dorsale hoom (laminae 1.111) van het cervicale ruggermerg van de rat. Het remmende effect wan bacloten kan niet worden geobserveerd na incubatie met de NO donor SNP. Aangezien Bacloten een weel gebruikt medicin woor de bellandeling van spasticiteit is, wijzen onze resultaten 
naar een mogelijke rol van ANP in de controle van spinale locomotor netwerken.

\section{Hootostuk 6}

In hoofdstuk 6 hebben we het effect van perinatale asphyxie in combinatie met bacloten op de ANP. en SNP. gemedieerde oGMP synthese in het ruggenmerg van volwassen ratten onderzocht. In normale ratten zagen we een remmend effect van bacloten op de AMP.gemedieende cGMP synthese, terwijl na asphyxie een stimulerend effect van baclofen op de NO gemedieerde cGMP synthese is gezien. Onze resultaten suggereren dat de effecten van baclofen op thet ruggenmerg na perinatale asphyxie ten minste gedeeltelijk via het NO.CGMP signaaltransductie systeem verlopen.

\section{Hooldstuk 7}

In hoofdstuk 7 hebben we de lange terminn effecten wan een RF.DRG behandeling op het ruggenmerg bestudeerd met behulp van c-Fos immunoreactiviteit. Daamaast zijn verschillende immunocytochemische markers gebruikt om de C.Fos immunoreactieve (c.Fos IR) cellen te identificeren.

We hebben bij 6 Wistar ratten een cervicalle llaminectomie verricht. De RF.DRG behandeling is toegepast naast 6 dorsalle ganglions, 6 ganglions zijn behandeld met een sham operatie en 1. rat is gebruikt als dubbele controle. De weefsels zijn zeven dagen na de ingreep onderzocht. We zagen een hoog significante toename in c.Fos positieve cellen na RF.ORG behandeling in vergelijking met de sham geopereerde ratten. We hebben na een unilaterale ingreep zowel contra. als ipsi. lateraal c.Fos positieve cellen wargenomen. Bovendien hebben we de c.Fos positieve cellen kunnen identificeren als geactiveerde microglia en astrocyten, maar niet als olligodendrocyten.

We concluderen dat de lange termijn effecten van een RF.DRG behandeling in alle Rexed"s laminae waarneembaar ziin. zowel ipsi. als contra lateraal, Daamaast zijn de klinische effecten van een RF.DRG behandeling voor spasticiteit mogelijk thet gevolg van een effect op zowel de afferente input als de efferente output van het ruggenmerg. 


\section{Hooidstuk 8}

In hoofdstuk 8 worden de pathofysiologische mechanismen van spasticiteit en de huidige behandelopties besproken. Daamaast wardt het gebruik van de RF. DRG voor de behandelling van spasticiteit bij kinderen met cerebral palsy besproken.

\section{Hoofdstuk9}

In hoofdstuk 9 hebben we de kinische effecten van de RF.DRG op spasticiteit bij kinderen met cerebral palsy onderzocht. Met behulp van de Ashworth schaal vinden we een verbetering van de spasticiteit op zowel 4 weken als 6 maanden na behandeling zonder dat er bijwerkingen zijn gezien. Daarnaast zien we een werbetering van de verzorging na RF.DRG behandeling.

\section{Hoordstuk 10}

In hoofdstuk 10 worden de morfolagische en biochemische bevindingen in het ruggenmerg na perinatale asphyxie bediscussieerd. Daamaast worden deze bevindingen in het rattenmodel in een klinisch perspectief geplatst, met name voor de RF.DRG behandeling. Tevens worden de toekomstige studies over de rol van het ruggenmerg voor de pathofysiologische mechanismen van spasticiteit beschreven.

We zijn stukje bij beetje (little by Little) begonnen met het bestuderen van de effecten vam perinatalle asplyxie op het ruggenmerg. 


\section{Dankwoord}

Dit proefschrift is tot stand gekomen vanult een gezamelijke inspanning van een aantal mensen wan een zeer divers pluimage. De initiator en naar mijn inzlens geestelijk wader van het onderzoek naar de effecten van perinatale asphyxie op het ruggenmerg en spasticiteit bij kinderen met cerebral palsy is professor doctor Ves. Zonder zijn gave om relatief laat in zijn levensloop vanuit een klinische vraagstelling terug te gaan naar het basale onderzoek, zou er in Maastricht geen onderzok over het effect van perinatale asphywie op het ruggenmerg zijn geweest. Ondermeer daarom. Hans, beschoww ik je als mijn mentor (en getuige) in de breedste zin van het woord. Hierwoor mijn dank en respect.

Professor doctor Troost, Jaap, ik ben je veel dank verschuldigd voor het gestelde vertrouwen. Jij hebt er uiteindellijk voor gezorgd dat ik in stat ben gesteld om dit onderzoek vit te woerem.

Professor doctor Steinbusch, Harry, bedankt voor je begeleiding bij het perfectioneren van de manuscripten

Doctor de Vente, Jan, ik bewonder je beschouwellike, bescheiden, altijd ter zake doende inbreng in ons project. Het maakt je tot een groots wetenschapper en min "basale" leermeester.

De techmische waardigheden die nodig zijn om cellen te "verven"zijn bij mij maar summier ontwikkeld. Hellen, ik dank je voor de prettige samenwerking en je waardevolle fechnische inbreng. Het was goed om te zien dat je steeds enthousiaster werd over ons onderzoek. Daarnaast wil ik Marianne bedanken woor de ondersteuning en de samenwerking.

De aspliyxie groep vormt de broedkamer van ons laboratorium onderzoek, beste Wilma, Arjan. Danillo, Tom en Carlos, bedankt voor de samenwerking en discussie.

Professor doctor van Kleef en "collega" wan Zundert, beste Maarten en Jan, zonder jullie inzet zow het onderzoek naar de effecten van de RF.DRG behandeling, zowel in de kliniek als in de rat, miet op dit peil zijn gekomen. Ik zie wit naar de toekomstige samenwerking. 
Zonder onderwijs geen onderzoek, ik dank Judith en Haike woor hun formidabele inbreng als student(assistent). Ik heb veel van jullie geleerd.

Speciale dank gaat wit naar Theo van de Nagel "je vakgroep owerstigende hulp was van onschatbare warde.

Zoals de asphyxie groep de broedkamer van het basale onderzoek vormt, is de werkgroep spasticiteit de spil waar de behandeling van kinderen met spasticiteit om draait. Ik heb grote bewondering voor de specifieke kundigheid en inzet van alle leden. Wat betreft het kinisch onderzoek gaat min dank met name uit naar Liesbeth en Margriet voor hum niet aflatende organisatie. Co-pro-io Kessels (Kroes, 2002) en Lisette van Raak will ik danken voor de statistiek en hulp bij het protocol.

De vakgroep waarbinnen ik werkaam mag zijn heb ik altijd als zeer plezierig ervaren. In een hechte (assistenten) groep komt iedereen tot bloei. Er liggen nog vele jaren in het verschiet. De betrokkenheid van Desiree bij de studies is niet aflatend, waarvoor dank.

Het bestuur van de Dr. W.M. Phellps stichting wil ik speciaal bedanken. Het getuigt wan grote visie on als stichting voor spastici het blikveld te vermuimen en zowel ons klinisch onderzoek als het basale onderzoek te financièren. Daarbij past ook een woord van dank voor Dr. J. Carpay, voor het inzicht dat een promovendus geen serie publicaties hoeft te hebben voordat hij aan zijn onderzoek mag beginnen.

Peter an Wibert, niet voor niets paranimfen

Tenslotte, een warm gezin is een wortreffielik geschenk en het begin wan alles.

Dank dat liefde liefde is. 


\section{Publications}

1. De Louw AJA, Twinstra A. Leffers P. Weinig uniformiteit en slechte therapietrouw bij het wekadvies na trauma capitis. Ned Tijdsch Geneeskd $1994: 138: 219799$

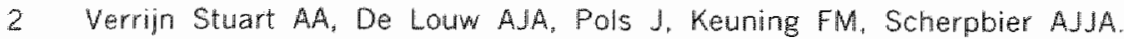
Raamplan 1994 versus de praktijk, vaardigheden tijdens de co-schappen in Maastricht en Groningen. Bulletin Medisch Onderwijs. 1996:15(2):6066.

3 Vles JS, De Louw AJA, Steinbusch H, Markerink wan Ittersum M. Steinbusch HW, Blanco CE, Axer H, Troost J, De Vente J. Localization and age-related changes of nitric oxide. and ANP.mediated cyclic.GMP synthesis in rat cervical spinal cond: an immunocytochemical study. Brain Res. 2000;857[1. 2).219.234.

4 De Louw AJA, Van Nieuwenthoven CA, De Krom MCFTM, Troost J. Local hyperhydrosis of the leff forearm. Neurology. 2000;55:5,26.

5 De Louw A.A, Vles JSH, Freling G, Herpers MJHM, Arends JW, van Kleef M. The morphological effects of a radiofrequency lesion adjacent to the dorsal root ganglion (RF,DRG) - An experimental study in the goat. Eur. J. Pain. $2001: 5(2): 169 \cdot 74$

6 De Louw AJA, Wan de Berg WDJ, De Vente J, Blanco CE. Gavilanes AWD, Steinbusch HPJ, Stembusch HWM, Troost J, Whes JSH. Developmental apoptosis in the spinal cord white matter in neonatal rat. Glia. 2002;37 (1):39. 91.

7 De Louw AJA, De Vente J. Steinbusch HPJ, Steinbusch HWM, Troost J, Whes $\downarrow S H$. Baclofen inhibits ANP. mediated cyclic GMP synthesis in the rat cervical spinal cord. Neurosci Lett. $2002: 321: 120 \cdot 122$ 
8 De Louw AJA, Van Kleef $M$. Vles JSH. Percutaneous radiofrequency lesion of the dorsal root ganglion in the treatment of spasticity in children with cerebral palsy. Pain Practice, accepted.

9 De Louw AJA, De vente J. Steinbusch HPJ. Gavilanes AWD. Steinbusch HWM, Blanco CE. Troost J. Vles JSH. Apoptosis in the rat spinal cord during postnatal development; the effect of perinatal asphyxia on programmed cell death. Neuroscience. 2002:112(4):751.758.

\section{Submitted}

10 De Louw AJA, van Zundert J, de Vente J. Paimans L, Steinbusch HPJ, Beuls EAM, Troost J, Vles IS. Dorsal root ganglion radiofrequency treatment for spasticity: clinical and cellular effect. Ann. Neurol. submitted

11 Van de Berg WDJ, Kwaaijtaal M. De Louw A.JA, Lissone NPA, Schmitz C. Faull RLM, Blanco CE, Steinbusch HWM. Compensatory mechanisms in the rat brain after perinatal asphyxia: relation between locomotor behaviour and the GABAergic system. Neuroscience, submitted.

12 Van Zundert J, Lamee I, De Louw A, Janssen, Kessels F, Patijn J, Van Kleef M. Pulsed radiofrequency of the cervical dorsal root ganglion in the treatment of chronic cervical pain syndromes: a clinical audit. Neuromadulation. submitted. 


\section{Abstracts and proceedings}

1 De Louw $A$, Twinstra A, Leffers $P$. What is the utility of a waking advice in patients with a mild brain injury. J. Neurology. 1994:241. Suppl. 1: 5123.

2 De Lou A, Weg Nan de, Webers J Scherpbier AJJA, Schaper N. Wat vinden co-assistenten van de voorbereiding in het Skillslab op de co assistentschappen. In: Houtkoop E. Pols J, Pollemans MC. Scherpbier AJJA, Verwijnen GM (eds). Gezond onderwijs.3. "s Gravenhage: Haagse Hogeschool, 1994:214.19.

3 Visser K, De Louw A. Luijk SJ wan, Scherpbier AJJA. De observator geobserveerd. In: Houtkoop E. Pols J. Pollemans MC. Scherpbier AJJA. Verwijnen GM (eds). Gezond Onderwijs-3. "s Gravenhage: Haagse Hogeschool, 1994: 119.24.

4 Luijk SJ van, de Louw $A$, Visser $K$, Scherpbier AJJA, Vleuten CPM van der. Opvattingen van observatoren bij de vaardigheidstoets over hun rol als observator en wat de interbeoordelaars betrouwbaarheid niet meet. in: Houtkoop E. Pols J, Pollemans MC. Scherpbier AJJA, Verwijnen GM (eds). Gezond Onderwijs.3. 's Gravenhage: Haagse Hogeschool, 1994: 125-30.

5 De Louw A. Verrim Stuart AA Keuning FM. Scherpbier AJJA, Pols J. Hoe goed ben ik voorbereicl? Vaardigheidsonderwijs in Maastricint en Groningen getoetst aan Raamplan 1994 en de praktijk. In: Pols J, Cate Th ten. Houtkoop E, Pollemans MC. Smal JA (eds). Gezond Onderwijs.4. Houten: Bohn Stafleu en Loghtum, 1995: 131.36.

6 Scherpbier AJJA, de Louw A, Verrijn Stuart AA, Keuning FM, Pols J. Vaardigheden in de praktijk; een wergelijking tussen Groningen en Maastricht. In: Cate Th ten, Dikkers JH. Houtkoop E, Pollemans MC, Pols J, Smal JA (eds). Houten: Bohn Stafleu van Loghum, 1996: 359.66. 


\section{Poster presentations}

1 De Louw AJA, Blanco CE, Van de Berg WDJ, Steinbusch HPJ, De Vente J, Vles JSH. Apotosis in the spinal cord during postmatal development: the effect of perinatal asphyxia on programmed cell death. 28 th Meeting of the fetal and neonatal physiological society. Auckland, New Zealand. 2001.

2 Van de Berg WDJ, De louw AJA. Gavilanes AD. Steinbusch HPJ, Vles JSH, Steinbusch HWM, Blanco CE. Perinatal asphyxia neurochemical and behavioural analysis. PhD day EURON. Maastricht. The Netherlands. 2001

3 Van de Berg WDJ, Kwaijtaal M, De Louw AJA, Lissone N, Schmitz C. Faull RLM, Blokland A, Blanco CE, Steinbusch HWM. Compensatory mechanisms in the rat brain after perinatal asphyxia: relation between lacomotor behaviour and the GABAergic system. FENS forum Paris, France. 2002. 


\section{Curriculum Vitae}

Anton de Loww werd geboren op 14 riovember 1968 te Schayk. In 1987 voltooide hij zijn HAVO opleiding. Na een kort intermezzo op de HBO Verpleegkunde te Breda. begon hij in 1990 aan de studie Geneeskunde aan de Universiteit Maastricht. In mei 1997 behalde hij het artsexamen en werkte aansluitend als AGiNIO bij de wakgroep neurologie van het academisch ziekenhuis Maastricht. Vanaf november 1999 werd deze aanstelling omgezet in een AGIKO aanstelling, welke werd gestart met een periode van 2 jaar onderzoek in het laboratorium van Prof. dr. H.W.M. Steinbusch onder de leiding van Prof. dr. J.S.H. Vles. In januari 2002 is hij gestart met de opleiding tot Neuroloog in het academisch ziekemhuis Maastricht. 